FABIANO ROGÉRIO CORRÊA

\title{
MAPEAMENTO SEMÂNTICO COM APRENDIZADO ESTATÍSTICO RELACIONAL PARA REPRESENTAÇÃO DE CONHECIMENTO EM ROBÓTICA MÓVEL
}

Tese de doutorado apresentada à Escola

Politécnica da Universidade de São

Paulo para obtenção do Título de Doutor em Engenharia.

SÃO PAULO 
FABIANO ROGÉRIO CORRÊA

\title{
MAPEAMENTO SEMÂNTICO COM APRENDIZADO ESTATÍSTICO RELACIONAL PARA REPRESENTAÇÃO DE CONHECIMENTO EM ROBÓTICA MÓVEL
}

\author{
Tese de doutorado apresentada à Escola \\ Politécnica da Universidade de São \\ Paulo para obtenção do Título de Doutor \\ em Engenharia. \\ Área de Concentração: \\ Engenharia de Controle e Automação \\ Mecânica \\ Orientador: \\ Prof. Livre-docente \\ Jun Okamoto Junior
}

SÃO PAULO 
Este exemplar foi revisado e alterado em relação à versão original, sob responsabilidade única do autor e com a anuência de seu orientador.

São Paulo, de abril de 2009.

Assinatura do autor

Assinatura do orientador

\section{FICHA CATALOGRÁFICA}

Corrêa, Fabiano Rogério

Mapeamento semântico com aprendizado estatístico rela cional para representação de conhecimento em robótica móvel / F.R. Corrêa. -- ed.rev. -- São Paulo, 2009. 135 p.

Tese (Doutorado) - Escola Politécnica da Universidade de São Paulo. Departamento de Engenharia Mecatrônica e de Sistemas Mecânicos.

1. Robôs 2. Modelos para processos estocásticos 3. Processamento de imagens I. Universidade de São Paulo. Escola Politécnica. Departamento de Engenharia Mecatrônica e de Sistemas Mecânicos II. t. 


\section{DEDICATÓRIA}

À Lauana, minha improvável e perfeita metade. 


\section{AGRADECIMENTOS}

Foram mais de quatro anos de dedicação nesse doutorado para entrar numa área (modelos probabilísticos e combinações com modelos lógicos) na qual eu não tive uma formação vinda da graduação. Pude ampliar meus conhecimentos ao participar, concomitantemente com parte do doutorado, de um projeto de classificação automática de textos. O resultado de tudo isso: um tempo muito grande para obtenção de resultados e o prazo final de conclusão batendo à porta. Foi uma época difícil, e tenho muito a agradecer para algumas pessoas.

Gostaria de agradecer imensamente à minha esposa, por ter suportado todo esse período de tumulto que vivemos para que fosse possível concluir a minha tese. Você foi e sempre será muito importante e especial pra mim.

Aos meus pais, que mesmo não convivendo diariamente comigo, partilharam das alegrias e frustrações de todo esse processo.

Aos professores Anna Helena, Fabio Cozman e Marcelo Finger cujas críticas ajudar a concretizar essa tese.

Ao meu orientador Jun Okamoto Junior, por todo o suporte financeiro, toda a infra-estrutura disponível, e toda liberdade que tive para perseguir os meus interesses acadêmicos. Não há nada melhor do que terminar um doutorado com a satisfação de ter acertado no tema. Espero continuar a me aprofundar nesses problemas por muitos anos ainda. 


\section{L'INFINITO}

Sempre caro mi fu quest'ermo colle, e questa siepe, che da tanta parte dell'ultimo orizzonte il guardo esclude. Ma sedendo e mirando, interinat spazi di là da quella, e sovrumani silenzi, e profondissima quiete io nel pensier mi fingo; ove per poco il cor non si spaura. E come il vento odo stormir tra queste piante, io quello infinito silenzio a questa voce vo comparando: e mi sovvien l'eterno, e le morte stagioni, e la presente e viva, e il suon di lei. Così tra questa immensità s'annega il pensier mio: e il naufragar m'è dolce in questo mare.

- Giacomo Leopardi 


\section{RESUMO}

A maior parte dos mapas empregados em tarefas de navegação por robôs móveis representam apenas informações espaciais do ambiente. Outros tipos de informações, que poderiam ser obtidos dos sensores do robô e incorporados à representação, são desprezados. Hoje em dia é comum um robô móvel conter sensores de distância e um sistema de visão, o que permitiria a princípio usá-lo na realização de tarefas complexas e gerais de maneira autônoma, dada uma representação adequada e um meio de extrair diretamente dos sensores o conhecimento necessário. Uma representação possível nesse contexto consiste no acréscimo de informação semântica aos mapas métricos, como por exemplo a segmentação do ambiente seguida da rotulação de cada uma de suas partes. O presente trabalho propõe uma maneira de estruturar a informação espacial criando um mapa semântico do ambiente que representa, além de obstáculos, um vínculo entre estes e as imagens segmentadas correspondentes obtidas por um sistema de visão omnidirecional. A representação é implementada por uma descrição relacional do domínio, que quando instanciada gera um campo aleatório condicionado, onde são realizadas as inferências. Modelos que combinam probabilidade e lógica de primeira ordem são mais expressivos e adequados para estruturar informações espaciais em semânticas. 


\begin{abstract}
Most maps used in navigational tasks by mobile robots represent only environmental spatial information. Other kinds of information, that might be obtained from the sensors of the robot and incorporated in the representation, are negleted. Nowadays it is common for mobile robots to have distance sensors and a vision system, which could in principle be used to accomplish complex and general tasks in an autonomously manner, given an adequate representation and a way to extract directly from the sensors the necessary knowledge. A possible representation in this context consists of the addition of semantic information to metric maps, as for example the environment segmentation followed by an attribution of labels to them. This work proposes a way to structure the spatial information in order to create a semantic map representing, beyond obstacles, an anchoring between them and the correspondent segmented images obtained by an omnidirectional vision system. The representation is implemented by a domain's relational description that, when instantiated, produces a conditional random field, which supports the inferences. Models that combine probability and firstorder logic are more expressive and adequate to structure spatial in semantic information.
\end{abstract}




\section{LISTA DE ILUSTRAÇÕES}

Figura 1. Sistematização proposta para classificar os trabalhos na área de mapeamento semântico.

Figura 2. Mapa topológico de um ambiente interno (extraído de Tapus e Siegwart, 2006).

Figura 3. Exemplos de cenas obtidas durante navegação em ambientes externos (extraído de Posner et al., 2006).

Figura 4. Segmentação topológica de ambiente interno (extraído de Zivkovic et al., 2007).

Figura 5. Mapa de atividades onde as setas indicam a direção de movimento associado à região e a espessura delas está relacionada à intensidade do fluxo (extraído de Lookingbill et al., 2005).

Figura 6. Anotação semântica apresentada na última coluna da figura ( extraído de Wolf e Sukhatme, 2006).

Figura 7. Mapa topológico construído com base na informação semântica (extraído de Mozos et al., 2007).

Figura 8. Classificação das células da grade (extraído de Triebel et al. 2007).

Figura 9. Mapa 3D do ambiente com as distinções de teto (vermelho), objetos (amarelo) e chão (azul) (extraído de Nüchter et al., 2005).

Figura 10. Resultados comparativos usando vários classificadores (extraído de Anguelov et al. 2005).

Figura 11. Objetos segmentados (extraído de Triebel et al. 2007). 
Figura 12. Esquema do mapa semântico multi-hierárquico (extraído de Galindo et al., 2005).

Figura 13. Exemplo do EKF-SLAM com os modelos de aparência de árvores (extraído de Ramos et al., 2006).

Figura 14. Grafo representando um mapa semântico de objetos (extraído de Vasudevan el al., 2007).

Figura 15. Exemplo do mapa proposto (Anguelov et al., 2004).

Figura 16. Exemplo de um RO-map (Limketkai et al., 2005).

Figura 17. Representação das medidas de cobertura e precisão.

Figura 18. Vizinhança: a) primeira ordem ou vizinhança-4; b) segunda ordem ou vizinhança-8; c) terceira ordem ou vizinhança-12 (extraído de Won e Gray, 2004).

Figura 19. Conjunto de cliques possíveis para sistema de vizinhança de segunda ordem (traduzido de Won e Gray, 2004).

Figura 20. MRFs no contexto de processamento de imagens.

Figura 21. MRF hierárquico.

Figura 22. CRFs no contexto de processamento de imagens.

Figura 23. Um fragmento de um grafo de fatores para ilustrar o cálculo da distribuição marginal $P\left(Y_{i}\right)$ (reproduzido de Bishop, 2007).

Figura 24. llustração da fatoração de um subgrafo associado com o nó - fator $f_{s}$ (reproduzido de Bishop, 2007).

Figura 25. Ilustração do vínculo.

Figura 26. Vínculo entre a grade e a imagem.

Figura 27. Modelo simplificado do vínculo.

Figura 28. Grafo completo referente à grade de ocupação. 
Figura 29. Sistema de projeção geométrica (extraído de Svoboda et al., 1998).

Figura 30. Construção do plano da perspectiva (extraído de Grassi Jr, 2002).

Figura 31. Cálculo da direção do plano de projeção perspectiva.

Figura 32. Os quatro intervalos na dimensão da distância a partir do centro do conjunto de pixels.

Figura 33. Robô Pioneer P3-AT.

Figura 34. Mapa local construído com dados do sensor laser.

Figura 35. Grade de ocupação obtida com o laser do Pioneer.

Figura 36. Padrão de calibração do sistema de visão omnidirecional.

Figura 37. Uma leitura do sensor laser projetada sobre a imagem omnidirecional.

Figura 38. Grade de ocupação de $250 \times 250$ células projetas sobre a imagem omnidirecional.

Figura 39. Imagem perspectiva de treinamento e respectivos rótulos.

Figura 40. Projeção das leituras do laser na imagens perspectivas.

Figura 41. Imagem perspectiva com o laser projetado e a respectiva característica associada.

Figura 42. Imagens perspectivas segmentadas.

Figura 43. Alguns resultados da segmentação.

Figura 44. Gráfico da comparação entre o tempo de treinamento do CRF com o SVM.

Figura 45. Grade de ocupação construída com os dados do laser e a estimação da posição do robô. 
Figura 46. Agrupamento das leituras do laser.

Figura 47. Região da imagem referentes a diversos tipos de obstáculos.

Figura 48. Mapa semântico (parte 1).

Figura 49. Mapa semântico (parte 2).

Figura 50. Mapa semântico (parte 3).

Figura 51. Mapa semântico (parte 4).

Figura 52. Mapa semântico (parte 5). 


\section{LISTA DE TABELAS}

Tabela 1. Vantagens e desvantagens das abordagens topológicas e baseadas em grades para a construção de mapas (traduzido de Thrun, 1998).

Tabela 2. Mapas de objetos.

Tabela 3. Modelo proposicional para classificação de pixels de uma imagem.

Tabela 4. Modelo relacional para um imagem considerando quatro pixels na vizinhança.

Tabela 5. Entidade célula da grade.

Tabela 6. Vínculo.

Tabela 7. Diferenças relativas ao número de escalas empregadas.

Tabela 8. Comparação entre descritores expandidos.

Tabela 9. Comparação entre descritores diferentes.

Tabela 10. Comparação do resultado considerando o valor do lambda na regulação.

Tabela 11. Comparação entre SVM e CRF.

Tabela 12. Comparação dos resultados do K-means para diferentes valores de K.

Tabela 13. Continuação dos resultados dos testes com o algoritmo K-means. 


\section{LISTA DE SÍMBOLOS}

K quantidade de classes no problema da classificação ou grupos no problema do agrupamento

$k$ uma das possíveis classes no problema da classificação

$y_{k} \quad$ rótulo de uma variável aleatória que pertence à classe $k$

$x \quad$ valor de uma variável aleatória observável

X conjunto dos valores das variáveis aleatórias observáveis do problema

y conjunto dos valores das variáveis aleatórias não-observáveis do problema

D valor da dimensionalidade de um espaço vetorial

Y conjunto das variáveis aleatórias não-observáveis do problema

X conjunto das variáveis aleatórias observáveis do problema

$\mathrm{P}_{k}(\mathbf{Y} \mid \mathbf{X})$ distribuição a posteriori referente à classe $k$

$\mathrm{P}_{k}(\mathbf{X} \mid \mathbf{Y})$ verossimilhança referente à classe $k$

$\mathrm{P}_{k}(\mathbf{Y})$ distribuição a priori referente à classe $k$

$\mathrm{P}(\mathbf{X}) \quad$ distribuição a priori de $\mathbf{X}$

$\mathrm{P}_{k}(\mathbf{X}, \mathbf{Y})$ distribuição conjunta de $\mathbf{X}$ e $\mathbf{Y}$ referente à classe $k$

A conjunto dos pontos que são obstáculos

$B \quad$ conjunto dos pontos que não são obstáculos

C conjunto dos pontos que recebem o rótulo obstáculo pelo classificador 
$|C \cap A|$ quantidade de elementos pertencente à união dos conjuntos $C$ e $A$

$|A| \quad$ quantidade de elementos do conjunto $A$

$|C| \quad$ quantidade de elementos do conjunto $C$

n quantidade de variáveis aleatórias não-observáveis no problema da classificação

$\delta_{n} \quad$ função delta

$\mu_{k} \quad$ vetor correspondente ao centro do agrupamento $k$

$x_{n} \quad$ valor da variável aleatória observável de número $n$.

$r_{n k}$ variável indicador relacionada à variável aleatória $n$ e ao agrupamento $k$

$J \quad$ medida de distorção no algoritmo $K$-means

pixel $n$ variável aleatória não-observada $n$ relacionada à imagem

$x_{i, j} \quad$ componente do vetor que representa uma variável aleatória observável

$s \quad$ índice do reticulado formado pelo campo aleatório

V conjunto de variáveis aleatórias observáveis e não-observáveis

$\mathbf{V}$ atribuição de valores às variáveis do conjunto $\mathbf{V}$

$V_{n} \quad$ variável aleatória $n$ do conjunto $\mathbf{V}$

$S \quad$ conjunto dos índices do reticulado

$N$ conjunto das vizinhanças das variáveis aleatórios num campo aleatório

$N_{1} \quad$ vizinhança da variável ido reticulado

$\mathbf{V}_{\mathbf{c}} \quad$ conjunto de variáveis aleatórios associadas ao clique $\mathrm{c}$ 
G um dado grafo não-direcionado

$E_{i} \quad$ entidade $i$ do modelo relacional

$\mathrm{C}(\mathrm{G})$ conjunto de cliques associados ao grafo $\mathrm{G}$

C um clique

$\phi_{c} \quad$ função potencial associada ao clique c

$\Phi \quad$ conjunto das funções potenciais

Z função de partição de uma rede de Markov

$v_{c} \quad$ valores das variáveis aleatórias associadas ao clique c

$w_{i} \quad$ peso ou parâmetro do modelo de CRF

$f_{i} \quad$ característica $i$ do vetor descritor num modelo de CRF

$X_{i} \quad$ variável observável $i$

$Y_{i} \quad$ variável não-observável $i$

$\boldsymbol{x}_{\boldsymbol{c}} \quad$ conjunto de valores das variáveis observáveis associadas ao clique C

$y_{c} \quad$ conjunto de valores das variáveis não-observáveis associadas ao clique c

$\varepsilon \quad$ esquema do domínio relacional

E.X conjunto de atributos de conteúdo da entidade $E$

E.Y conjunto de atributos de rótulo da entidade $E$

E.R conjunto de atributos de referência da entidade $E$

I(E) instanciação da entidade $E$

I.X instanciação dos atributos de conteúdo

I. $Y$ instanciação dos atributos de rótulo 
I.R instanciação dos atributos de rótulo

I.x instanciação dos valores dos atributos de conteúdo

I.y instanciação dos valores dos atributos de rótulo

I.r esqueleto da instanciação

$T \quad$ um template de clique

F um conjunto de entidades

W uma fórmula booleana

$\mathbf{S} \quad$ uma seleção de atributos

M uma configuração espacial do ambiente

OCC valor de ocupado da célula da grade

$S_{t+1} \quad$ leitura do sensor no instante $t+1$

EMP valor de vazio da célula da grade

$\mathrm{s}(\mathrm{Ci})$ variável aleatória binária relacionada à célula $\mathrm{C}_{\mathrm{i}}$

$\mathrm{C}_{\mathrm{i}} \quad$ célula $i$ da grade

q coordenadas de um pixel na imagem

K matriz de parâmetros intrínsecos da câmera

$Z_{c} \quad$ fator de escala

$R_{c} \quad$ matriz de rotação do sistema do espelho para o sistema da câmera

$\mathrm{R}_{\mathrm{m}} \quad$ matriz de rotação do sistema da câmera para o sistema global

$t_{m}$ vetor de translação do sistema da câmera para o sistema global

$t_{c} \quad$ vetor de translação do sistema do espelho para o sistema da câmera

F foco real da hipérbole 


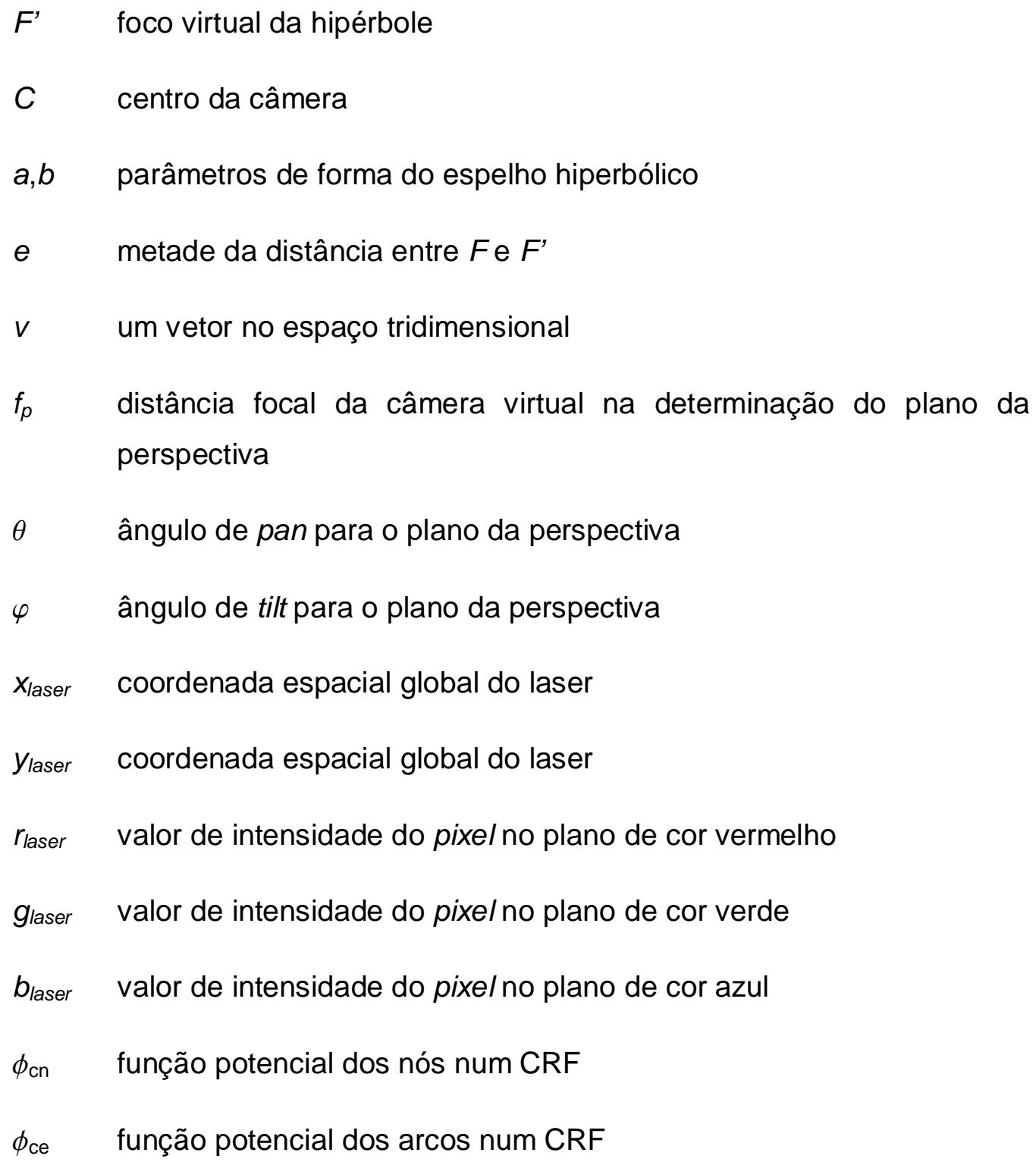




\section{SUMÁRIO}

1 INTRODUÇÃO

1.1 Um breve histórico do mapeamento por robôs móveis ......................3

1.2 A limitação das soluções empregadas .............................................4

$1.3 \mathrm{O}$ destaque dos modelos probabilísticos .......................................5

1.4 Aprendizado estatístico relacional ...............................................

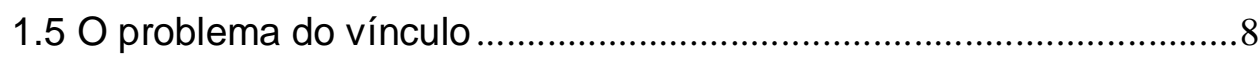

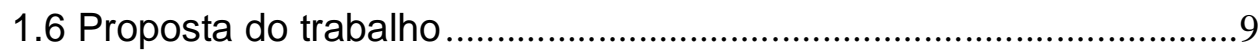

2 MAPEAMENTO EM ROBÓTICA MÓVEL ................................................. 11

2.1 Mapeamento com informação espacial.......................................12

2.2 Mapeamento com informação semântica ......................................16

2.2.1 Mapas cognitivos ............................................................... 19

2.2.2 Mapas anotados........................................................... 24

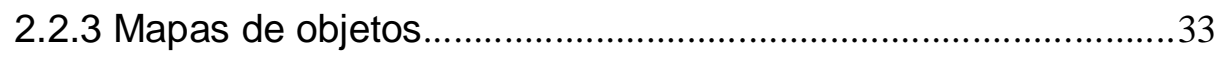

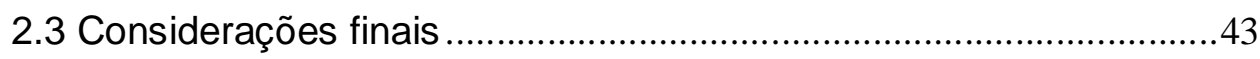

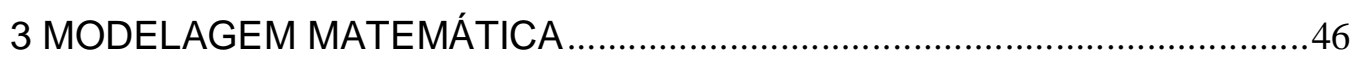

3.1 Aprendizado de máquina .......................................................48

3.1.1 O problema da classificação................................................49

3.1.2 Critérios de avaliação do resultado da classificação.................51

3.1.3 O problema do agrupamento ............................................52 
3.2 Aprendizado estatístico relacional 54

3.2.1 Exemplo da descrição relacional no domínio de imagens.........56

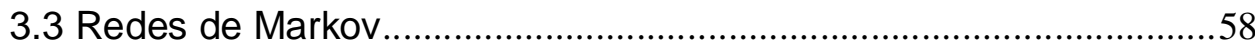

3.3.1 Campos aleatórios de Markov (MRF) .........................................5

3.3.2 Campos aleatórios condicionados (CRF)...................................64

3.3.3 Redes de Markov relacionais $(\mathrm{RMN})$.........................................66

3.3.4 Aprendizado dos parâmetros do modelo de CRF .......................68

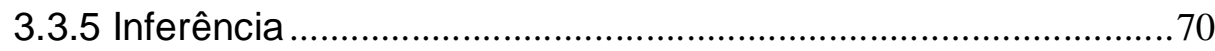

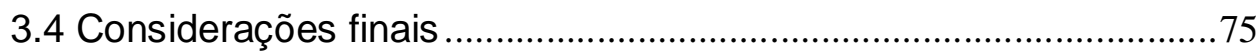

4 MAPEAMENTO SEMÂNTICO COM SEGMENTAÇÃO DE IMAGENS........76

4.1 SRL no problema do mapeamento semântico …………………….....76

4.1.1 Descrição relacional do domínio ................................................78

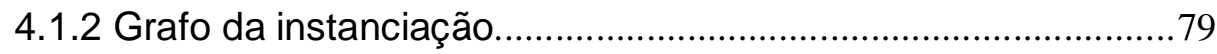

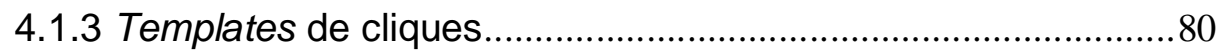

4.2 Algoritmo para o mapeamento semântico ………………………….....80

4.2.1 Construção da grade de ocupação ...............................................

4.2.2 Projeção dos pontos do laser na imagem ...................................84

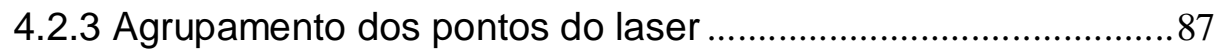

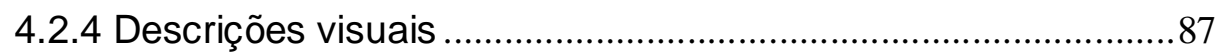

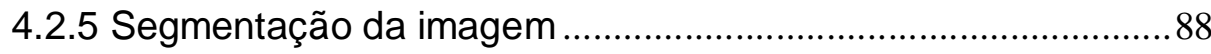

4.3 Aplicações para o mapa semântico .......................................................91 


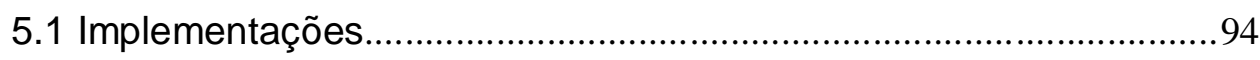

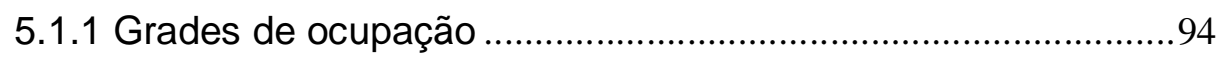

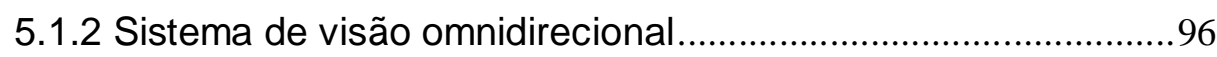

5.1.3 Calibração do sistema de visão.................................................97

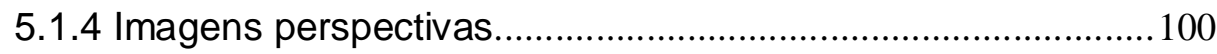

5.1.5 Agrupamento dos pontos do laser ............................................ 100

5.1.6 Segmentação de imagens com CRF .......................................101

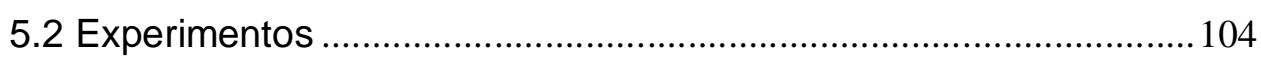

5.2.1 Testes com a segmentação de imagens...................................105

5.2.2 Mapeamento semântico ............................................................111

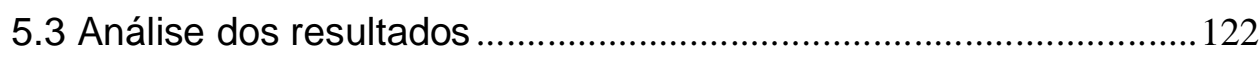

6 CONCLUSÃO

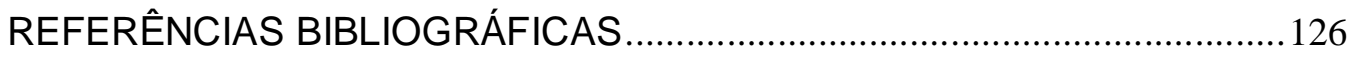


Capítulo 1

\section{INTRODUÇÃO}

O conhecimento de um robô pode ser entendido como a representação ${ }^{1}$ interna, tanto dos dados armazenados, quanto dos conjuntos de processamentos realizados sobre informações sensoriais instantâneas ou acumuladas ao longo do tempo. A representação de conhecimento ${ }^{2}$ é provavelmente o componente mais crítico em uma arquitetura e é a partir dela que as funcionalidades do robô são construídas, estando assim relacionada ao grau de autonomia concedido ao sistema (Vasudevan et al. 2007).

Como em robótica móvel pressupõe-se que um robô deve se movimentar pelo ambiente, mapas tornam-se representações muito empregadas, principalmente em tarefas de navegação, exploração e, obviamente, mapeamento. Sendo o alcance dos sensores limitado, as informações locais de distância devem ser acumuladas nesses mapas ao longo do tempo. Os mapas de ambiente possibilitam a um robô realizar diversos processos de tomada de decisão, como por exemplo o planejamento de uma trajetória ótima até o seu objetivo.

A tarefa de construir mapas precisos de ambientes estruturados com as informações obtidas dos sensores de um robô móvel - mesmo considerando o problema adicional da auto-localização simultânea e relativa ao mapa em construção - já produziu resultados muito significativos (Limketkai et al., 2005). No entanto, as representações comumente empregadas registram

\footnotetext{
${ }^{1}$ No intuito de facilitar a exposição das idéias nessa tese, mesmo incorrendo num abuso de linguagem, o termo representação irá se referir a elementos e relações entre esses elementos num sentido conceitual, e o termo modelo, à implementação dessa representação segundo uma teoria matemática que permita a manipulação coerente e consistente dos elementos e relações dentre eles.

${ }^{2}$ Não é uma referência à área de Knowledge representation, que utiliza essa expressão num sentido mais restrito.
} 
pouco mais que a disposição espacial do ambiente (Anguelov et al., 2002), desprezando outros tipos de informações necessárias para realizar tarefas mais complexas, como interpretar e representar qualquer ambiente, ou mesmo interagir e se comunicar, de uma maneira compatível com a dos seres humanos (Vasudevan et al., 2007). Para alcançar o sucesso nessas tarefas, os robôs móveis podem utilizar uma representação estruturada do meio, como por exemplo pela segmentação e categorização das informações sensoriais espaciais (Lookingbill et al., 2005; Ramos et al., 2006; Mozos et al., 2007, Vasudevan et al., 2007).

Percebendo isso, alguns esforços têm se voltado à separação automática de dados sensoriais com propriedades similares, seguida da atribuição de rótulos ou categorias às representações espaciais para agrupar e distinguir os diferentes elementos presentes no ambiente. A classificação dos dados das representações espaciais permite ao robô realizar distinções entre espaços físicos, como por exemplo entre um escritório e um corredor (Mozos et al., 2007), ou entre elementos menores, como portas e paredes (Limketkai et al., 2005), tomando ações específicas ao interagir com estes elementos.

Não é de hoje que se reconhece a importância da inclusão de rótulos ou da semântica desses elementos nas representações usadas em robótica móvel. Mas trabalhos pioneiros como os de Kuipers e Byun (1991) e Chatila e Laumond (1985) não apresentavam uma implementação formalizada para aquisição dessa semântica (Galindo et al., 2005), limitando assim a autonomia dos sistemas. Em trabalhos mais recentes, o diferencial está na obtenção da semântica diretamente dos sensores, como ocorre com a informação espacial. Sem uma nomenclatura definida, esse tipo de representação é foco de interesse renovado na literatura, principalmente pelo desenvolvimento alcançado na área de aprendizado de máquina (Getoor e Taskar, 2007).

Como não há até o momento nenhum trabalho de âmbito geral sobre o assunto, é objetivo desse trabalho analisar os conceitos por detrás dessa representação de conhecimento para robôs móveis, pelo viés da 
estruturação da informação espacial disponível e do emprego de aprendizado de máquinas, e apontar os efeitos sobre a autonomia e a possibilidade de realizar tarefas mais complexas.

A contribuição desta tese está:

- na análise e generalização conceitual das implementações de mapas semânticos que têm surgido nos últimos anos (Capítulo 2);

- no embasamento teórico da implementação relacionado à área de aprendizado estatístico relacional (Capítulos 3 e 4);

- na criação de um algoritmo de mapeamento semântico que considera uma etapa de segmentação de imagens para criar não apenas uma representação do conhecimento para robôs móveis, mas um elemento necessário sobre o qual muitas funcionalidades podem ser construídas, como uma arquitetura para aplicações gerais (Capítulo 4 e 5).

O presente trabalho é fruto da constatação de um rumo para o futuro desenvolvimento na área de mapeamento por robôs móveis, pelo acréscimo de informação semântica.

\subsection{Um breve histórico do mapeamento por robôs móveis}

Entre a década de 80 e o início dos anos 90, a área de mapeamento estava bem dividida entre abordagens métricas e topológicas (Thrun, 2002). Os mapas métricos consistem numa representação geométrica precisa do ambiente, mas naquela época estavam limitados pelas incertezas nas leituras dos sensores de distância e na odometria dos robôs móveis. Não havia como obter um mapa preciso com tanta imprecisão nos dados disponíveis.

Como alternativa apresentavam-se os mapas topológicos, que representam o ambiente por meio de lugares distintos e das conexões físicas entre os mesmos, formando um mapa mais esquemático. Com base na maneira 
como os seres humanos estruturam conceitos espaciais, essas representações incorporam naturalmente parte da estrutura semântica envolvida no problema do mapeamento. De qualquer maneira, devido às ambigüidades sensoriais, leituras semelhantes poderiam corresponder a lugares distintos, dificultando a construção de um mapa coerente (Kortenkamp e Weymouth, 1994).

Foi então que houve um grande desenvolvimento dos mapas métricos com o surgimento das grades de ocupação, de Moravec e Elfes (1985; Elfes, 1989) e dos modelos de incerteza para relações espaciais propostos por Smith, Self e Cheeseman (1990), ambos implementados segundo a teoria de probabilidade. O que tornava os modelos probabilísticos mais adequados para tal implementação era a capacidade de incorporar naturalmente a incerteza que existe em qualquer aplicação real. Estimando os erros nas leituras dos sensores e nas ações dos atuadores, a dinâmica do robô e do ambiente são melhor incorporadas ao modelo, tornando-o mais robusto e menos suscetível a falhas.

Desde então, a robótica móvel como um todo vêm apresentando uma rápida e constante evolução pelo emprego maciço de modelos probabilísticos combinados à técnicas de aprendizado de máquina, culminando em trabalhos significativos de desempenho em tempo real (Kwok et al., 2004). Quanto à área específica de mapeamento, o desenvolvimento ficou bastante concentrado em torno das representações métricas. Os mapas topológicos aparecem predominantemente em implementações híbridas (Thrun, 1998; Fabrizi e Saffiotti, 2000), sendo construídos a partir dos mapas métricos.

\subsection{A limitação das soluções empregadas}

Independente de todo o sucesso alcançado pelas representações espaciais implementadas com modelos que usam probabilidade, tanto mapas métricos quanto mapas híbridos métrico-topológicos têm sido desenvolvidos quase que exclusivamente para tarefas de navegação (Vasudevan et al., 2007). E a restrição não se limita ao tipo de tarefa, mas dentro da própria tarefa de 
navegação, onde muitas simplificações são adotadas, como por exemplo considerar ambientes estáticos, estruturados, pouco extensos, dentre outras, no sentido de obter modelos de probabilidade com os quais se possa trabalhar com uma maior eficiência computacional.

Em aplicações mais gerais, que visam robôs mais autônomos atuando em ambientes mais complexos com a interação de vários elementos, essas representações espaciais não são de todo adequadas pois os respectivos modelos mostram-se intratáveis computacionalmente. Mesmo o sucesso do veículo autônomo Stanley, no Grande Desafio promovido pela DARPA (Thrun et al., 2006), esteve relacionado a simplificações feitas ao problema da navegação autônoma: a trajetória a ser percorrida era fornecida pelos organizadores horas antes da largada e os veículos não precisavam ultrapassar uns aos outros em movimento. A grande dificuldade estava em realizar o percurso em terreno irregular a uma alta velocidade, o que nem de longe era algo trivial.

Analisando a evolução na área de mapeamento, mais especificamente em relação aos mapas métricos, percebe-se uma relação de dependência destes com os modelos probabilísticos. Seguindo esse raciocínio, a representação de mapas semânticos necessita de um modelo matemático apropriado para manipular os novos elementos e as relações representadas, de um modo computacionalmente eficiente.

\subsection{O destaque dos modelos probabilísticos}

No que diz respeito aos modelos, é interessante observar como a estatística e a teoria da probabilidade foram ganhando espaço nas comunidades que lidam com inteligência e autonomia de máquinas (Jones, 2006). No início, a área de aprendizado de máquina adotou como formalismo matemático os modelos lógicos, que intuitivamente parecem mais próximos do modo de raciocínio do ser humano. Já a robótica vinda da engenharia adotava na maior parte das vezes técnicas ad hoc. Num primeiro momento, a teoria da 
probabilidade estava relegada a um segundo plano por causa da dificuldade de manipulação, cálculo e representação de seus elementos básicos.

Apesar dos avanços conseguidos com o uso de modelos lógicos, logo ficou claro que aplicações reais necessitavam de algoritmos eficientes para lidar com cenários dinâmicos, e de um tratamento formal para a incerteza das informações e dos dados utilizados (Getoor e Taskar, 2007), abrindo assim várias frentes de investigação. Com o surgimento de alguns trabalhos como o de Pearl (1988), voltados a novas formas de se trabalhar e se enxergar os modelos probabilísticos, surgiram na área da robótica diversas implementações revolucionárias no final dos anos 80 , como visto anteriormente.

O que atualmente limita o uso de modelos probabilísticos em tarefas mais gerais e complexas é a impossibilidade destes de representar de maneira compacta toda a diversidade, quantitativa e qualitativa, presente nos ambientes reais. Os modelos largamente empregados são proposicionais (Mausam e Weld, 2003), ou seja, não existe uma maneira de se representar explicitamente com eles generalizações ou quantificações, tornando necessário enumerar todos os elementos e relações presentes no contexto da aplicação. Para ambientes complexos com centenas ou milhares de elementos, o emprego desses modelos torna-se inviável na medida em que o custo computacional cresce exponencialmente com o número de elementos, considerando todas as dependências envolvidas.

Em contraposição, existem modelos mais expressivos, associados à lógica relacional ou de primeira ordem, que permitem a representação de elementos por meio de suas características comuns, bem como de suas interações. Assim, é possível obter descrições compactas e genéricas para o ambiente e para o sistema como um todo, independente da quantidade de instâncias de um mesmo tipo de elemento (Grove et al., 1992). No entanto, métodos eficientes de inferência sobre esses modelos ainda estão em desenvolvimento. 
Há algumas décadas vêm sendo realizados trabalhos que tentam de alguma maneira contornar as limitações tanto dos modelos lógicos quanto dos probabilísticos, para combinar as suas qualidades. Qualquer estudo nesse sentido demanda uma compreensão dos limites do que pode ser representado por cada modelo, ou seja, quão expressivo eles são, quais características e particularidades do problema real podem ser modeladas e como isso pode ser feito, considerando uma estrutura final que o torne tratável computacionalmente. Pfeffer (1999) destaca três propriedades desejáveis em qualquer modelo a ser desenvolvido: a capacidade de representação, a eficiência dos algoritmos relacionados para se obter informações ou fazer inferências a partir do modelo, e a possibilidade de realizar aprendizado de máquina a partir de dados de observações sensoriais.

Visando aproveitar as descrições compactas e genéricas dos modelos lógicos de primeira ordem e o tratamento natural da incerteza dos modelos probabilísticos, recentemente têm sido propostos modelos híbridos, dentro de uma área conhecida como aprendizado estatístico relacional (Getoor e Taskar, 2007).

\subsection{Aprendizado estatístico relacional}

Como modelos que combinam probabilidade e lógica de primeira ordem são mais expressivos que os puramente probabilísticos, eles são uma escolha natural para a implementação das representações semânticas. A utilização de modelos mais expressivos tem como objetivo permitir que robôs móveis atuem em ambientes não estruturados cada vez mais complexos e que sejam capazes de realizar tarefas mais gerais, formuladas em níveis mais abstratos, como por exemplo, Atravesse a 'porta3'.

O estudo de alternativas para se combinar lógica e probabilidade não é atual, mas uma grande quantidade de modelos foram propostos recentemente devido ao sucesso alcançado por algumas iniciativas (Getoor e Taskar, 2007). Dentro desse cenário, uma possibilidade é empregar uma 
descrição relacional dos dados para o aprendizado dos parâmetros do modelo, mas instanciar um modelo proposicional para realizar as inferências, devido às complexidades computacionais de inferências com lógica de primeira ordem.

Partindo-se de um modelo desse tipo, é desenvolvido nesse trabalho um mapeamento semântico para robôs móveis que cria vínculos entre os obstáculos mapeados e os dados sensoriais correspondentes, para mostrar que um modelo probabilístico que incorpora lógica de primeira ordem é adequado para representar a semântica envolvida em problemas de navegação autônoma.

\subsection{O problema do vínculo}

Muitos sistemas robóticos possuem representação simbólica. Ela é necessária para atribuições de tarefas genéricas que podem ser instanciadas no momento da realização, como por exemplo a localização de um objeto em particular no ambiente. Nessas tarefas, o robô identifica alvos em potencial por meio dos seus sensores, e os compara segundo as propriedades sensoriais relacionadas em seu conhecimento simbólico.

Coradeschi e Saffiotti dão a esse problema o nome de vínculo (anchoring) e o definem da seguinte maneira: "Nós designamos vínculo o processo de criar e manter uma associação entre símbolos e dados sensoriais que se referem ao mesmo elemento físico" (2003). Assuntos correlacionados ao problema do vínculo na robótica são comuns na literatura de várias áreas, como por exemplo as tarefas de reconhecimento e rastreamento de objetos na comunidade de visão computacional.

Devido à presença de conhecimento simbólico, a quase totalidade dos trabalhos apresentados por Coradeschi e Saffiotti (2003) implementam o vínculo com lógicas de primeira ordem, o que parece ser natural dada a natureza do problema. Mas as inferências possíveis sobre esses modelos carecem da flexibilidade necessária ao lidar com tantas incertezas presentes 
em sensores e atuadores reais, e com um ambiente dinâmico. Em contrapartida, implementando o vínculo por meio de um modelo probabilístico com descrição relacional dos dados usando aprendizado estatístico relacional, as inferências são realizadas tendo como fundamento a teoria da probabilidade, com um tratamento eficiente das incertezas envolvidas.

\subsection{Proposta do trabalho}

Tradicionalmente, as informações de distância são utilizadas para criar uma representação espacial do ambiente, mas existe a possibilidade de se empregar a representação que está sendo construída para interpretar a própria informação espacial vinda dos sensores, transformando-a assim em informação semântica. Para o mapeamento semântico, é importante a presença de um sistema de visão, que gera uma grande quantidade de dados sobre o ambiente a cada aquisição de imagem. Estes dados contêm implicitamente diversas propriedades dos obstáculos presentes no meio. Os obstáculos que vão se definindo no mapa espacial, aparecem numa seqüência contínua nas imagens.

Assim, a posição dos obstáculos no mapa pode ser empregada para auxiliar a identificação visual dos mesmos nas imagens que o robô adquire, devido à existência de uma transformação geométrica entre o espaço físico e sua representação nas imagens, em câmeras calibradas. Tanto a representação no mapa quanto a imagem do sistema de visão, apesar das incertezas envolvidas nos dois processos de obtenção, dizem respeito ao mesmo elemento físico, um obstáculo nesse caso particular.

Este é o vínculo que a representação semântica proposta nesse trabalho procura implementar. De um lado, tem-se a segmentação e a classificação das células de uma grade de ocupação para instanciar um elemento simbólico denominado ObstáculoN, que pode ser usado como uma informação adicional para resolver tarefas comuns à robótica móvel, como a localização. Do outro, ocorre a segmentação e a classificação da imagem 
para atribuir uma identificação visual dos obstáculos correspondentes. A identificação visual consiste dos pixels classificados como Obstáculo nas imagens. Essa classificação é feita empregando um modelo que permite o aprendizado estatístico relacional, para que se possa modelar as várias dependências entre os pixels na imagem, obtendo um resultado mais preciso. Explorando esses vínculos é possível construir uma arquitetura geral para a realização de diversas tarefas, implementadas sobre o modelo probabilístico relacional, compacto e genérico, que permite também lidar com as incertezas envolvidas de maneira eficiente.

Na seqüência, no Capítulo 2 é exposto um panorama da utilização de mapas em robótica móvel, seguido de uma análise dos trabalhos recentes que incorporam semântica aos mesmos. O Capítulo 3 trata da modelagem matemática do mapeamento semântico proposto nessa tese, onde são apresentadas classes de modelos de probabilidade que permitem uma descrição relacional dos dados. O Capítulo 4 apresenta em detalhes a formulação do problema de mapeamento semântico com a representação do vínculo entre dados sensoriais e elementos simbólicos. O Capítulo 5 contém informações sobre a implementação, a descrição dos testes realizados e uma análise dos resultados obtidos. O último Capítulo expõe as conclusões do trabalho. 
Capítulo 2

\section{MAPEAMENTO EM ROBÓTICA MÓVEL}

O mapeamento de ambientes com robôs móveis é uma tarefa extremamente importante e um pré-requisito para sistemas realmente autônomos (Thorpe e Durrant-Whyte, 2001). As maiores dificuldades encontradas no desenvolvimento de algoritmos para esta e também outras tarefas autônomas são: a existência de incerteza nos dados dos sensores; a aquisição de informações parciais sobre o ambiente, a cada instante de tempo; a produção de uma grande quantidade de dados vinda de sensores distintos; e a dinâmica do ambiente (Vasudevan et al., 2007). No geral, para a obtenção de algum resultado, são adotadas muitas simplificações, como por exemplo tratar o ambiente como estático.

Além dessas dificuldades, um mapeamento robusto deve considerar também o problema da auto-localização do robô que se desloca pelo ambiente para obter informações sensoriais. Como os dados sensoriais são relativos às diversas posições intermediárias, a incerteza na movimentação do robô deve ser considerada na composição do mapa. Robôs que utilizam apenas a odometria para se localizar e que navegam por percursos muito extensos, da ordem de centenas de metros, apresentam um erro de posição acumulado que praticamente impossibilita a construção de qualquer tipo de representação espacial (Thrun, 2002). O mapeamento realizado simultaneamente com a localização é conhecido como SLAM (Simultaneous Localization and Mapping) ou CML (Concurrent Mapping and Localization).

Nesta tese, os mapas de ambiente são tratados como uma forma de representação do conhecimento que o robô adquire por meio de seus sensores. Tanto a percepção sensorial e a cognição espacial quanto as tarefas de localização e mapeamento fazem parte de um mesmo processo de aquisição, processamento, fusão e acúmulo de dados sensoriais para 
tomadas de decisão. Tradicionalmente, o único conhecimento representado nos mapas é a informação espacial do ambiente (Anguelov et al., 2002), devido ao emprego quase que exclusivo dos mesmos em tarefas de navegação e localização (Anguelov et al., 2004).

No entanto, com o uso de robôs móveis em ambientes cada vez mais complexos e em tarefas mais gerais, é necessário estender esses mapas na direção de um melhor aproveitamento dos dados produzidos pelos diversos sensores dos robôs. Uma alternativa é estruturar os dados por meio de categorias, de modo a separar e classificar a informação espacial, podendo assim tanto melhorar o desempenho no mapeamento espacial, na localização ou na navegação, quanto realizar outros tipos de tarefas com maior autonomia. É exatamente este tipo de estrutura, resultado do processo de categorização da informação espacial, ou dos dados brutos dos sensores, que se denomina nesta tese de informação semântica.

Assim, pode-se definir um mapa semântico como uma representação de conhecimento hierárquica que possui, em um de seus níveis, um mapa espacial do ambiente. Ao longo do texto serão usadas as expressões mapa e nível da representação de modo intercambiável. Assim, um mapa semântico é o nível semântico de uma representação de conhecimento hierárquica.

A seguir apresenta-se uma introdução ao mapeamento espacial e uma revisão bibliográfica do estado da arte em mapas semânticos.

\subsection{Mapeamento com informação espacial}

Segundo a definição dada em Thrun (2002), o mapeamento com robôs móveis é o processo de obtenção de uma representação espacial do ambiente físico. Dentre os mapas espaciais utilizados, dois se destacaram ao longo dos anos, como visto na introdução: o mapa métrico e o topológico. Apesar de ambos usarem informações métricas (Murphy, 2000), os mapas métricos são representações mais exatas do ambiente, em duas ou três 
dimensões, enquanto que os topológicos são abstrações da distribuição espacial representando locais distintos no ambiente e suas conexões físicas.

Tabela 1. Vantagens e desvantagens das abordagens topológicas e baseadas em grades para a construção de mapas (traduzido de Thrun, 1998).

\begin{tabular}{|c|c|}
\hline Mapas métricos & Mapas topológicos \\
\hline $\begin{array}{c}\text { + Fáceis de construir, representar e } \\
\text { manter }\end{array}$ & $\begin{array}{c}\text { + Permite planejamento eficiente, baixa } \\
\text { complexidade espacial (resolução } \\
\text { depende da complexidade do ambiente) }\end{array}$ \\
\hline $\begin{array}{c}\text { + Reconhecimento de locais (baseados } \\
\text { na geometria) não é ambíguo e é } \\
\text { independente do ponto de vista }\end{array}$ & + Não necessita determinação precisa da \\
posição do robô
\end{tabular}

A Tabela 1 contrasta as particularidades desses mapas (Thrun, 1998) ${ }^{3}$. Por representar de maneira detalhada um ambiente com um reticulado espacial, os mapas métricos são usados para navegações que exigem um posicionamento mais preciso do robô no meio. Mas a obtenção de uma consistência global do mapa exige o tratamento de problemas como o de fechamento de ciclos, quando o robô retorna a uma posição previamente visitada. Além disso, a grande quantidade de informação presente no mapa torna computacionalmente custosa qualquer manipulação do modelo, como o planejamento de trajetória. Já os mapas topológicos, que representam o ambiente de modo mais esparso com um grafo, são ideais para realizar planejamento de trajetória e tomadas de decisão em geral, mas apresentam

3 Apesar de desatualizada, a tabela serve para ilustrar as principais diferenças entre as duas abordagens. 
problemas como os da determinação automática de uma topologia mínima (Tapus e Siegwart, 2006). As implementações de mapas topológicos diferem entre si nos lugares distintos considerados para compor os nós do grafo.

Ambas as representações dependem de uma caracterização adequada dos dados sensoriais para evitar as ambigüidades nas leituras obtidas de locais fisicamente distintos (perceptual aliasing). Representações espaciais hierárquicas ou híbridas também foram propostas no sentido de combinar as potencialidades das duas representações, quando os mapas topológicos são construídos a partir dos métricos (Thrun, 1998; Fabrizi e Saffiotti, 2000; e Kouzoubov e Austin, 2004). Dessa maneira, aproveita-se a coerência espacial do mapa métrico para compor o mapa topológico e com este realizar o planejamento de trajetórias de maneira mais eficiente.

Com a bem sucedida introdução dos algoritmos de probabilidade na década de 90, houve maior interesse no uso de mapas métricos nos quais foram feitas essas implementações. A partir daí, o foco de interesse migrou das representações (mapas métricos e topológicos) para os modelos matemáticos (algoritmos) empregados nas implementações: filtros de Kalman, EM (Expectation Maximization) e algoritmos que identificam objetos no ambiente. Esses modelos matemáticos foram analisados no artigo de Thrun (2002), que é uma compilação do estado da arte no mapeamento por robôs móveis, uma referência amplamente citada.

No entanto, na época em que o artigo foi escrito, existiam poucos trabalhos relacionados aos algoritmos que identificam objetos no ambiente. Considerando os trabalhos e os interesses atuais entre os pesquisadores da área, é possível afirmar que os então chamados mapas de objetos resgatam uma preocupação em se representar conceitos abstratos sobre as informações espaciais em mapas métricos. Ou seja, marca uma transição de representações métricas puramente espaciais para representações que incorporam também informação semântica. A maneira de se incorporar a semântica nas representações espaciais pode ser interpretada como a criação de uma representação hierárquica. 
Todavia, é importante notar que desde o princípio os mapas topológicos foram concebidos com a intenção de criar modelos de ambientes físicos com elementos que representassem conceitos similares aos utilizados pelos seres humanos em seus modelos cognitivos espaciais. Assim, não existem mapas topológicos puramente métricos ou um nível claro de semântica neles. Nesse tipo de representação, não há uma hierarquia propriamente dita, os dois níveis se misturam, e a informação espacial é armazenada nos nós do grafo que por si só representam lugares distintos no ambiente, como salas.

Em resumo, na linha de representações espaciais o desenvolvimento chegou a tal ponto que já existem implementações bem sucedidas funcionando em tempo-real (Kwok et al., 2004). Já os mapas semânticos permanecem virtualmente inexplorados (Mozos et al., 2007), e apenas recentemente têm ganho certo destaque e atraído um maior número de pesquisadores (Semantic information in robotics, workshop do ICRA 2007; From Sensors to Human Spatial Concepts, edição especial da Robotics and Autonomous Systems, volume 55, número 5, 2007).

De qualquer modo, é preciso deixar claro que o interesse pela incorporação da semântica das relações espaciais no ambiente não é recente (Galindo et al., 2005). Mas as soluções anteriores nunca alcançaram muito destaque na literatura pela falta de um modelo adequado para implementar essa representação, e a informação semântica incorporada estava relacionada à manipulação simbólica de elementos do modelo. Em contrapartida, o que está sendo proposto atualmente é trabalhar tanto com a simples classificação da informação espacial em categorias semânticas (Mozos et al., 2007), quanto com a estrutura relacional dos dados para inferências direcionadas a objetos (Limketkai et al., 2005). 


\subsection{Mapeamento com informação semântica}

O sucesso dos robôs móveis e particularmente daqueles que interagem diariamente com seres humanos é baseado na capacidade de manipular informações além de simples relações espaciais (Galindo et al., 2005).

$\mathrm{Na}$ navegação e em muitas outras aplicações, os robôs móveis podem melhorar o seu desempenho se forem capazes de reconhecer lugares específicos e distinguir com maior exatidão um lugar do outro. Um robô que possui informação semântica sobre os diferentes tipos de lugares presentes em seu mapa pode facilmente ser instruído para se dirigir até um local específico (Mozos et al., 2007). Além disso, classificar as regiões de um mapa em divisões naturais não apenas adiciona uma ordem maior de significado a qualquer mapa construído por um robô, como também restringe a computação necessária para sua localização (Posner et al., 2006).

Ainda, os ambientes reais são formados por objetos, que podem mudar de posição com o passar do tempo. Modelando esses objetos é possível rastrear as mudanças no ambiente, e lidar com a dinâmica do mundo real (Anguelov et al., 2002).

Atuar em ambientes externos, não-estruturados e muito extensos (um campo de mineração, por exemplo) exige uma abordagem distinta da que se popularizou na década passada. Propõe-se que o robô deva ser capaz de estruturar os dados espaciais por meio da categorização em informação semântica. A interação humano-robô também pode ser favorecida se os robôs possuírem representações de conhecimento similares às nossas, por meio da informação semântica (Tapus e Siegwart, 2006).

Mesmo com a existência de alguns trabalhos recentes que se preocupam com a obtenção de informação semântica, pouco tem sido feito para analisar as propostas dessa área em franco desenvolvimento. Diversas representações têm sido propostas, sob diferentes denominações tais como mapas cognitivos (Tapus e Siegwart, 2006; Vasudevan et al., 2007), mapas de objetos (Martin e Thrun, 2002, Anguelov et al., 2004; Limketkai et al., 
2005) e mapas de atividades (Wolf e Sukhatme, 2006; Lookingbill et al., 2005) - acontecendo de representações conceitualmente diferentes adotarem a mesma nomenclatura.

Nesta tese busca-se reunir todas essas representações sob a denominação geral de mapas semânticos. É proposta aqui uma classificação tendo como base a relação da informação semântica com os elementos espaciais extraídos dos sensores:

- mapas cognitivos, que nada mais são do que as implementações atuais dos mapas topológicos (Tapus e Siegwart, 2006; Posner et al., 2006; Zivkovic et al., 2007);

- mapas anotados, que são mapas métricos onde cada unidade de discretização é classificada em categorias semânticas (Lookingbill et al., 2005; Wolf e Sukhatme, 2006; Mozos et al., 2007; Nüchter et al. 2005; Anguelov et al., 2005; Triebel et al., 2007);

- mapas de objetos, que são mapas métricos que representam os objetos que constituem 0 meio, permitindo dessa maneira a realização de inferências sobre os próprios objetos e o tratamento apropriado da dinâmica do meio (Ramos et al., 2006; Galindo et al., 2005; Vasudevan et al., 2007; Limketkai et al., 2005; Anguelov et al., 2004). 


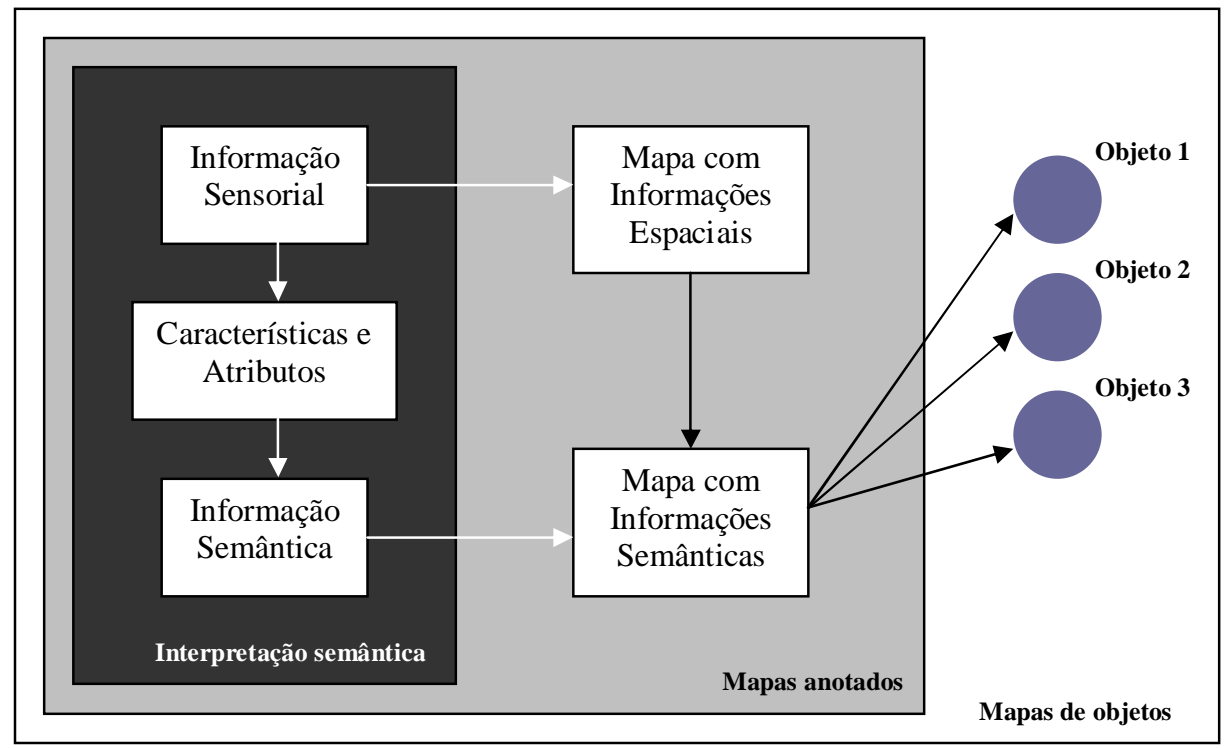

Figura 1. Sistematização proposta para classificar os trabalhos na área de mapeamento semântico.

Além dessa classificação, é importante considerar que qualquer processo de mapeamento semântico implica numa etapa inicial de interpretação semântica para a extração dessa informação diretamente dos dados sensoriais. Esta etapa está intimamente relacionada à trabalhos na área de visão computacional e reconhecimento de objetos, como os de Stauffer e Grimson (2000), Lou et al. (2002), e Makris e Ellis (2003). Nesses trabalhos é demonstrado como imagens podem ser processadas para que delas sejam obtidas características e atributos ${ }^{4}$ que descrevem ou caracterizem-na de maneira compacta. Essas características permitem a segmentação e a classificação, e são usadas para a obtenção de informação semântica, ao serem classificadas em categorias.

A Figura 1 mostra a classificação de mapas semânticos proposta nesta tese e a relação das categorias com a etapa de interpretação semântica. São consideradas apenas as extensões de mapas métricos com informação semântica, estando excluídos portanto os mapas cognitivos.

\footnotetext{
${ }^{4} \mathrm{Na}$ literatura de aprendizado estatístico, os termos atributos referem-se às quantidades originais do problema e características às quantidades introduzidas para se descrever os dados (Cristianini e Shawe-Taylor, 2000).
} 
$\mathrm{Na}$ seqüência são discutidos alguns trabalhos representativos do estado da arte na área de mapeamento semântico. É de interesse analisar quais sensores (ou combinação de sensores) são mais empregados, que atributos ou características são extraídos destes sensores e usados para produzir a informação semântica, quais as categorias semânticas criadas, e qual formalismo matemático é usado no processo de criação e utilização dos mapas.

\subsubsection{Mapas cognitivos}

O termo mapa cognitivo foi introduzido em $1948^{5}$ e levou à criação da representação de mapas topológicos. Tem sido empregado por alguns trabalhos recentes (Tapus e Siegwart, 2006; Vasudevan et al., 2007) que abordam o problema da inclusão de informação semântica nos mapas geométricos produzidos por robôs móveis. No entanto, não há uma diferença conceitual entre mapas cognitivos e mapas topológicos, apenas o emprego de imagens que permitem uma descrição menos ambígua dos lugares distintos representados por cada um dos nós. Opta-se por usar a denominação mapas cognitivos para deixar claro que o contexto da exposição são mapas semânticos.

Tapus e Siegwart (2006) propõem uma solução para o problema do SLAM em ambientes internos e externos no contexto da percepção e cognição espacial. Trata-se de um mapeamento topológico automático e incremental considerando os problemas de fechamento de ciclos e da dinâmica do ambiente, onde o mapa é atualizado com base na entropia da distribuição de probabilidade referente às possíveis posturas do robô. Cada nó do mapa contém um conjunto de toda informação sensorial obtida durante a navegação no espaço correspondente, e é representado por uma média desse conjunto. Um novo nó é acrescentado ao mapa quando uma comparação entre essas médias, baseada numa heurística, indica uma diferença significativa. A Figura 2 mostra o mapa topológico obtido (sobre

\footnotetext{
${ }^{5}$ Tolman, E. C. Cognitive maps in rats and men. In: Psychological Review, 55: 189-208.
} 
uma grade de ocupação, com o único propósito de dar uma referência da posição dos nós do grafo) e parte da informação sensorial (imagem omnidirecional) relacionada a cada nó do mapa. O processamento dos dados é off-line.

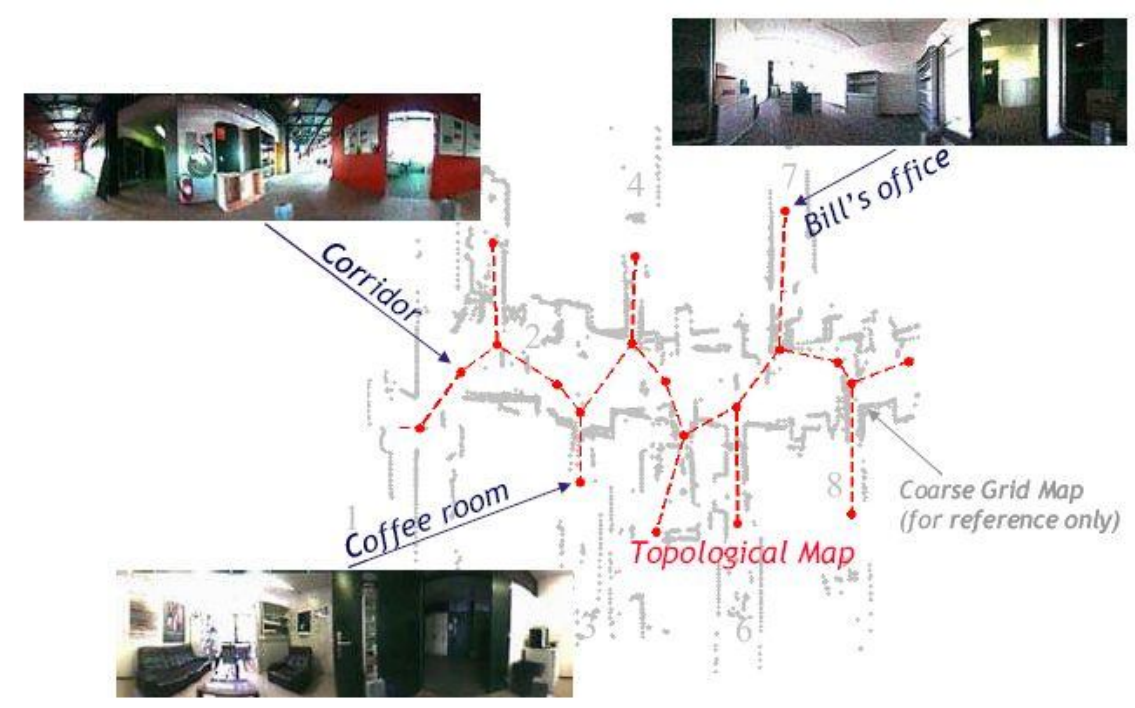

Figura 2. Mapa topológico de um ambiente interno (extraído de Tapus e Siegwart, 2006).

Posner et al. (2006) abordam o problema da classificação de cenas para segmentar o espaço de navegação de um robô móvel em ambientes externos. Como as imagens são obtidas conforme o robô se locomove no espaço, essa tarefa está relacionada ao problema de segmentação de um grafo em forma de cadeia. $O$ resultado pode ser interpretado como um mapa topológico, onde cenas diferentes correspondem a lugares espacialmente distintos (Figura 3). 


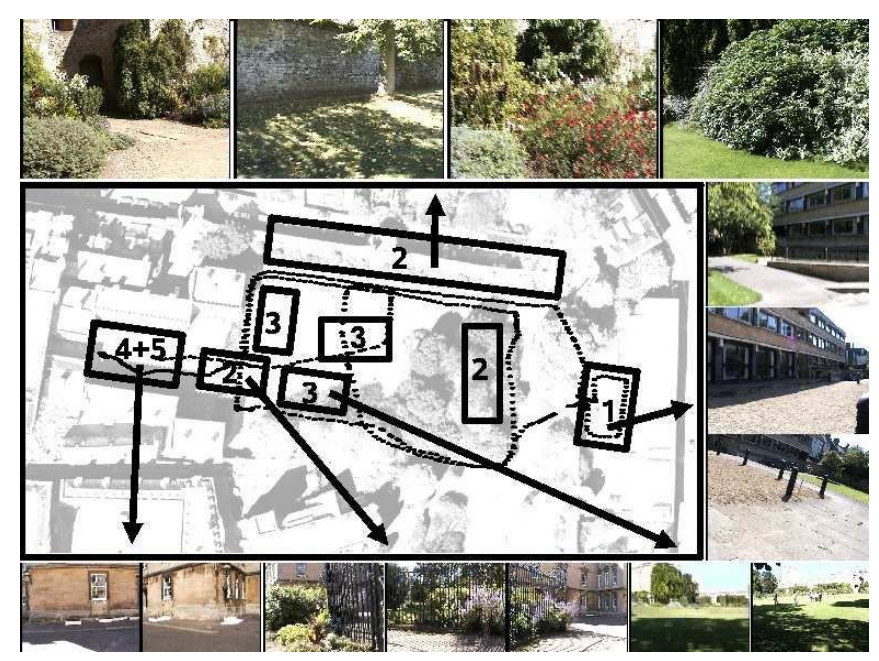

Figura 3. Exemplos de cenas obtidas durante navegação em ambientes externos (extraído de Posner et al., 2006).

Zivkovic et al. (2007) propõem uma solução para o problema do mapeamento topológico, considerando a possibilidade de realizar navegação entre os nós do grafo, por meio de um algoritmo servo-visual. A intenção é obter uma topologia associada ao conceito de espaços convexos, que representariam salas em ambientes internos, por meio do agrupamento de nós de um grafo. Como a informação sensorial é adquirida constantemente ao longo da trajetória desenvolvida pelo robô, o problema da falta de uma distribuição uniforme de informação no ambiente também é considerada. $A$ Figura 4 ilustra na primeira coluna o grafo inicial onde cada imagem adquirida representa um nó, podendo ser interpretado como um mapa topológico denso; na segunda, está o resultado do agrupamento de nós sem considerar uma alteração na quantidade de imagens por posição espacial; e a terceira é o resultado obtido ao considerar uma distribuição uniforme de informação sensorial durante a trajetória. Cada linha da Figura 4 indica um ambiente distinto. 


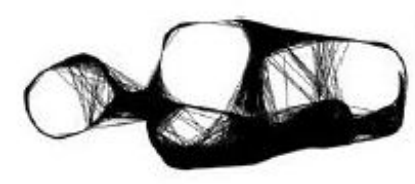

(a)

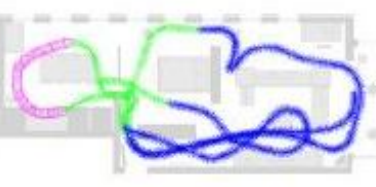

(b)

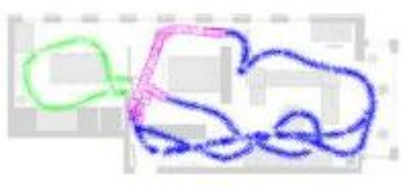

(c)

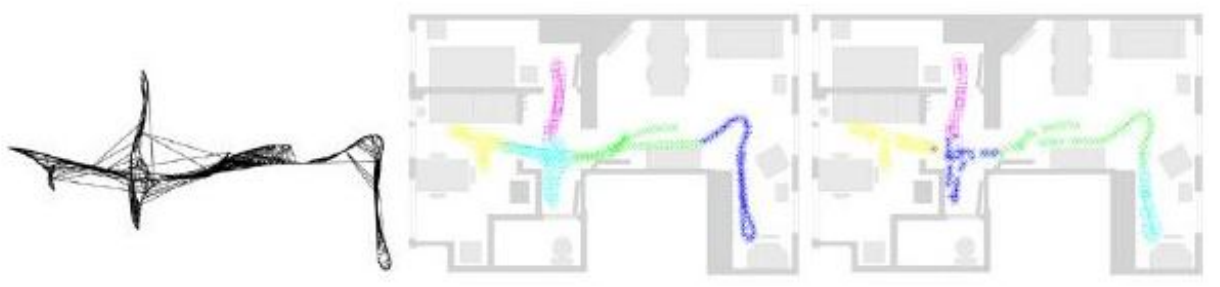

Figura 4. Segmentação topológica de ambiente interno (extraído de Zivkovic et al., 2007).

Com relação aos sensores empregados nesses trabalhos, Tapus e Siegwart (2006) usam uma câmera omnidirecional e dois sensores de varredura laser com alcance de 180; Posner et al. (2006) empregam uma câmera; e Zivkovic et al., (2007) usa um sistema de visão omnidirecional.

Para caracterizar a informação sensorial, Tapus e Siegwart (2006) utilizam um descritor (vetor de características) chamado de impressão digital de lugares (fingerprint of places), que consiste numa lista circular de características (relacionada aos $360^{\circ}$ em torno do robô) tanto da imagem omnidirecional (a distribuição de cores dos pixels e as linhas verticais) quanto do laser (que identifica cantos no ambiente). Posner et al. (2006) empregam o detector de regiões de interesse (ROI) Harris Affine na imagem - escolhido devido à ampla invariância com relação à linha de base (baseline) - seguido do descritor SIFT (Lowe, 1999), que produz um vetor de 128 dimensões e possui características invariantes à rotação e translação, e parcialmente invariantes à escala e luminosidade. Zivkovic et al. (2007) usam também o descritor SIFT para determinar quais imagens devem estar conectadas entre si para determinar o grafo inicial, com base na reconstrução 3D dos marcos em cada uma delas. A reconstrução é feita com o algoritmo de 8 pontos, restrito ao movimento planar da câmera, e do estimador RANSAC para dar robustez nas correspondências. 
Nesses trabalhos não existem categorias semânticas previamente definidas a serem atribuídas. Os problemas abordados estão mais relacionados ao agrupamento das informações espaciais segundo critérios de semelhança, e conseqüentemente ao aprendizado não-supervisionado.

Quanto ao formalismo matemático, a localização do robô em Tapus e Siegwart (2006) usa um modelo de processo decisório de Markov parcialmente observável (POMDP), onde é possível acrescentar a informação da movimentação do robô e as observações sensoriais obtidas. Posner et al. (2006) categoriza as cenas usando um classificador nearestneighbour baseado no critério de mean-linkage. O classificador considera uma matriz de similaridade, onde cada posição dessa matriz representa a similaridade entre a cena com o índice da linha com a cena com o índice da coluna. Existe uma etapa de treinamento off-line, considerando todos os descritores produzidos num determinado conjunto de imagens. $O$ treinamento consiste no agrupamento de descritores semelhantes para a definição de um alfabeto. Assim, cada cena é quantizada segundo esse alfabeto e a medida de similaridade é definida pelo cosseno do ângulo formado entre os vetores produzidos nas duas cenas consideradas. É com esta medida que se constrói a matriz de similaridade. Zivkovic et al. (2007) propõem um algoritmo de corte em grafos definindo a minimização do corte em um número pré-definido de sub-grafos considerando a soma dos arcos em cada sub-grafo gerado, normalizada pelo volume que corresponde à "força" da inter-conectividade dos nós interiores dos mesmos.

Nesses trabalhos, a informação semântica está diretamente associada à qualidade e à quantidade de informação sensorial, principalmente pelo emprego de imagens e descritores capazes de caracterizar de modo menos ambíguo as localidades do ambiente. Isso permite um melhor resultado na determinação de agrupamentos de informação espacial relacionados ao mesmo ambiente físico. 


\subsubsection{Mapas anotados}

O termo mapa anotado (Posner et al. 2006; Triebel et al. 2007) explicita a idéia de uma hierarquia na representação, onde a informação espacial discretizada está relacionada a um rótulo ou anotação, referente à informação semântica.

Os mapas anotados são portanto representações espaciais segmentadas em espaços delimitados fisicamente, e posteriormente classificados segundo categorias semânticas pré-estabelecidas. O propósito dessas classificações é separar as leituras sensoriais em grupos que apresentam semelhanças, onde cada grupo constituirá uma restrição do espaço de busca, podendo ser usada para facilitar a realização de diversas tarefas como localização, planejamento de trajetória e interação homem-máquina. Como exemplo da interação homem-máquina, seria possível usar essa informação semântica para dar comandos mais específicos ao robô, podendo ele saber onde é a cozinha num mapa ou quais corredores de um prédio público são mais movimentados durante o dia e vazios durante a noite (Galindo et. al., 2005).

Como em mapas anotados pressupõe-se a construção de um mapa métrico a partir de informação sensorial, é comum nesses trabalhos a utilização de sensores de distância e da combinação com outro sensor. Todos empregam sensores de varredura laser, à exceção de Lookingbill et al. (2005) que utilizam uma câmera. Wolf e Sukhatme (2006) e Mozos et al. (2007) usam sensores laser 2D, enquanto Nüchter et al. (2005) e Anguelov et al. (2005), usam sensores laser 3D. Triebel et al. (2007) apresentam aplicações com sensores laser 2D e 3D. Mozos et al. (2007) utilizam ainda um sistema de visão que adquire imagens panorâmicas para complementar os dados do laser.

A categoria de mapas anotados está subdividida em duas abordagens, segundo os elementos de discretização da informação espacial: a discretização em um reticulado espacial de duas dimensões ou em pontos no espaço tridimensional. Encaixam-se na primeira subdivisão os trabalhos 
de Lookingbill et al. (2005), Wolf e Sukhatme (2006), Mozos et al. (2007) e Triebel et al. (2007). Em todos eles a representação espacial utilizada é uma grade de ocupação onde cada uma das células recebe uma anotação ou rótulo.

Lookingbill et al. (2005) desenvolveram um método para aprender modelos do ambiente baseados na atividade observada no local. Esses modelos são empregados para melhorar o desempenho no rastreamento de objetos móveis no plano da imagem. A atividade é observada com uma câmera fixa em um helicóptero, que é um dos diferenciais desse trabalho. O mapa anotado (Figura 5) consiste na projeção sobre a imagem de histogramas em quatro dimensões representando a posição no solo, a velocidade e a direção do movimento registrado, caracterizando o fluxo de movimentação na área correspondente. O histograma é incorporado posteriormente ao algoritmo de rastreamento.

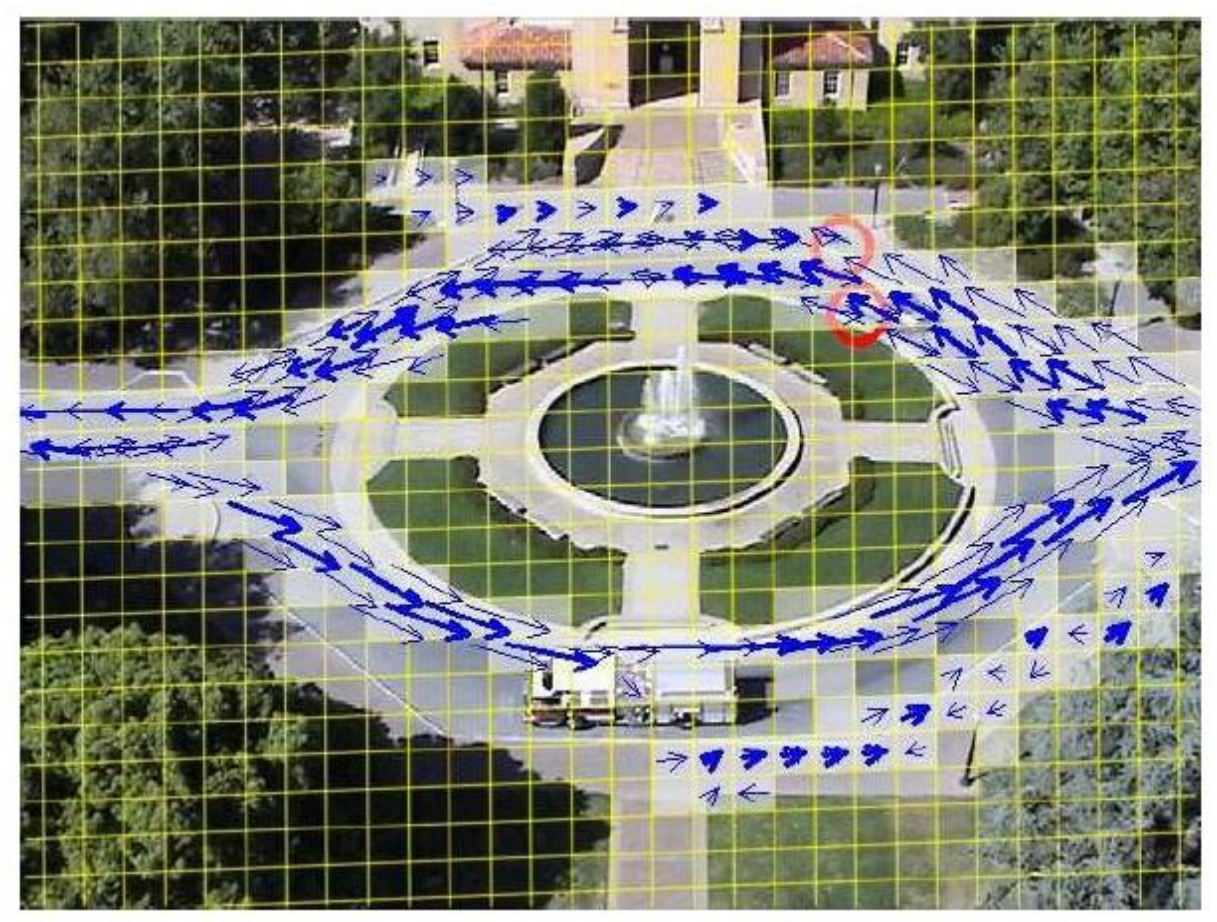

Figura 5. Mapa de atividades onde as setas indicam a direção de movimento associado à região e a espessura delas está relacionada à intensidade do fluxo (extraído de Lookingbill et al., 2005). 
Wolf e Sukhatme $(2006)^{6}$ apresentam uma grade de ocupação onde as células (com $20 \mathrm{~cm}$ de lado) são classificadas segundo o fluxo de movimento detectado nas áreas correspondentes do ambiente. O cenário dos experimentos é um ambiente urbano (Figura 6(b)), onde dois robôs em calçadas opostas registram o movimento do local (Figura 6(a)). É considerada uma área de $16 \times 18 \mathrm{~m}$, e os dados são coletados por períodos de 15 minutos, com uma freqüência de amostragem dos sensores laser de $10 \mathrm{~Hz}$.

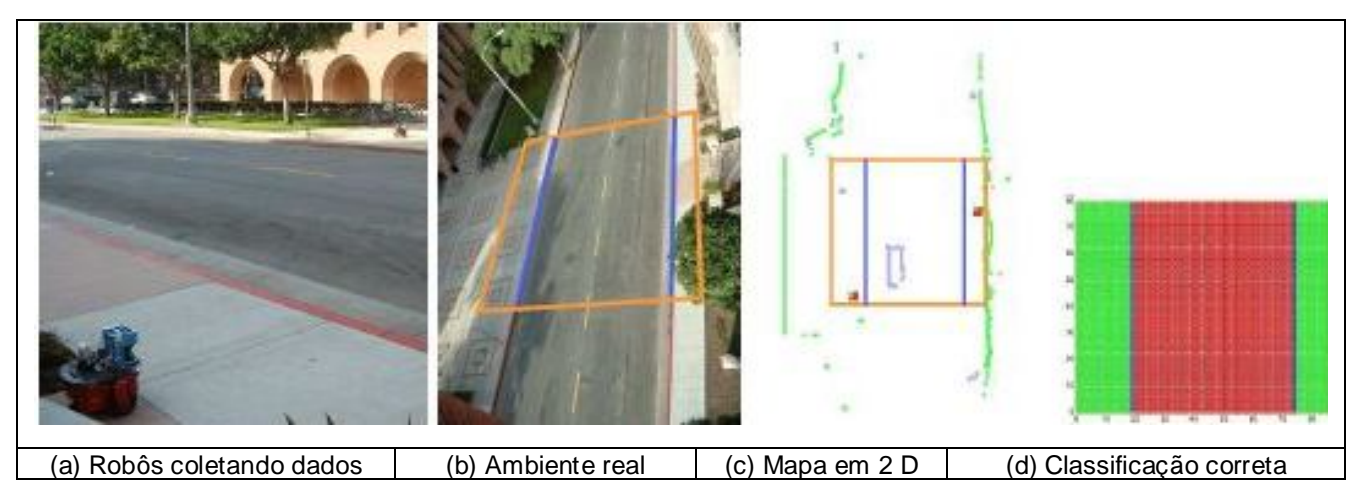

Figura 6. Anotação semântica apresentada na última coluna da figura ( extraído de Wolf e Sukhatme, 2006).

Mozos et al. (2007) apresentam duas aplicações a partir da classificação das células de uma grade de ocupação, com base nos dados do laser. A primeira aplicação é a classificação on-line da célula onde o robô se encontra, que emprega também como informação os objetos extraídos de imagens panorâmicas. A segunda é a construção de um mapa topológico a partir da grade de ocupação, combinando a classificação semântica com um método de relaxação probabilística. Assim, é criado um mapa híbrido métrico-topológico, onde os nós do mapa topológico são regiões que apresentam diferentes funcionalidades dentro de um ambiente interno (Figura 7).

\footnotetext{
${ }^{6}$ Vale mencionar que Wolf e Sukhatme denominam sua solução como um mapa de atividades. Mas como visto em Lookingbill et al. (2005), um mapa de atividade registra ou anota no mapa essa atividade, e não apenas a utilizam para dar uma classificação ou rótulo ao mapa métrico. Optou-se
} 


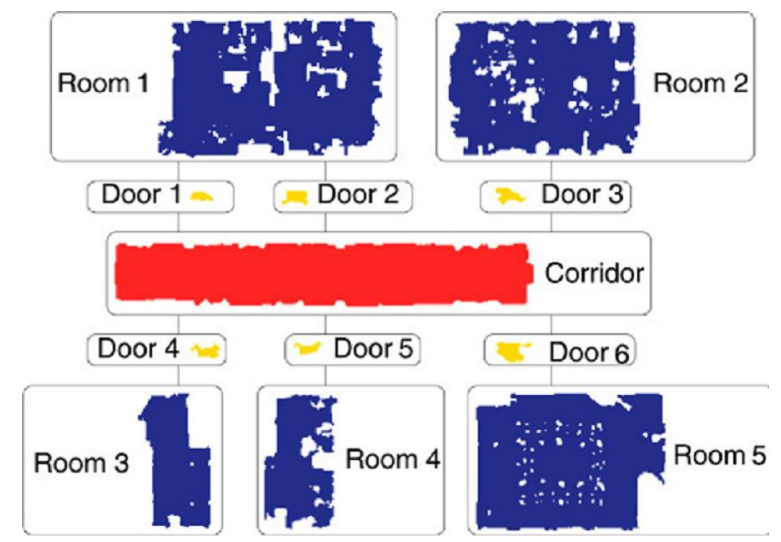

Figura 7. Mapa topológico construído com base na informação semântica (extraído de Mozos et al., 2007).

Triebel et al. (2007) demonstra uma aplicação para classificar as células de uma grade de ocupação do interior de um edifício. É uma aplicação simples e direta da categoria de mapas anotados. A Figura 8 mostra resultados comparativos entre classificadores distintos.

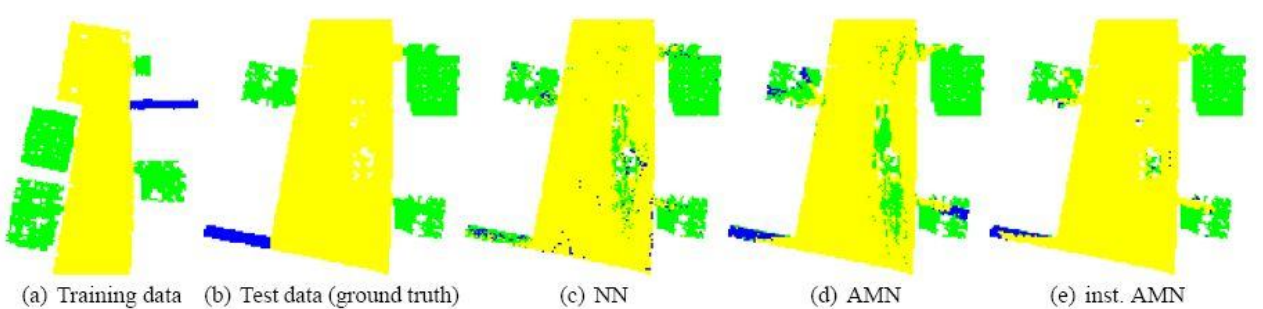

Figura 8. Classificação das células da grade (extraído de Triebel et al. 2007).

Quanto às características e atributos dos dados sensoriais empregados na classificação, Lookingbill et al. (2005) escolhe pontos da imagem que apresentam um alto gradiente espacial, em duas direções ortogonais. $O$ rastreamento dessas características em imagens consecutivas é obtido com uma implementação piramidal do rastreador proposto por Lucas-Kanade. Os vetores de deslocamento das características entre duas imagens consecutivas determinam um fluxo óptico, que é interpretado com o

por incluir os mapas de atividade na categoria de mapas anotados, onde as anotações são as atividades. 
algoritmo de EM para identificar as características que representam movimento real em solo (já que grande parte do fluxo é devido ao movimento da plataforma aérea na aquisição das imagens). Os pares de deslocamento obtidos do rastreador são usados para determinar a transformação afim relacionada ao movimento da câmera.

Wolf e Sukhatme (2006) extraem quatro propriedades dos sensores de distância: atividade, ocupação, tamanho médio e tamanho máximo. Os valores dessas propriedades são obtidos usando uma abordagem com três grades de ocupação, com uma fórmula de atualização das grades um pouco diferente da tradicional que incorpora o histórico anterior dos estados, para lidar com mapas não-estáticos. Uma das grades é para o mapa estático, outra para o mapa dinâmico, e a última é um mapa com os marcos usados na localização (Wolf e Sukhatme, 2005). A ocupação é percebida quando uma determinada área do espaço está ocupada; a atividade é percebida toda vez que uma determinada área muda de ocupada para livre ou viceversa. Os tamanhos médios e máximos das entidades dinâmicas que passaram por cada célula também são registrados.

Em Mozos et al. (2007) foram escolhidas características geométricas simples, por serem funções de valor escalar real, calculadas dos próprios feixes do sensor de varredura laser em 360 (o padrão de 360 é construído a partir da posição do robô e do mapa métrico local, já que o sensor laser do robô capta apenas $180^{\circ}$ ) ou da aproximação poligonal dos mesmos. Todas as características são invariantes à rotação para que a classificação só dependa da posição do robô, e não de sua orientação. Ao todo são usadas 321 características geométricas. Quando são consideradas as imagens vindas de um sistema de visão panorâmica que produz 8 imagens, as características de interesse são a quantidade de objetos previamente definidos que são identificados no conjunto de imagens. Essa identificação é feita por meio de classificadores baseados em características do tipo Haar. A combinação das características geométricas e da contagem de objetos é usado no algoritmo de AdaBoost, que escolhe dentre as diversas 
características aquelas que melhor discriminam os dados, para classificar as células da grade. Neste algoritmo é atribuído um peso diferente para cada característica (numa fase de treinamento) e usados posteriormente para a classificação. A idéia do algoritmo é utilizar classificadores "fracos" e combiná-los de uma determinada maneira para fortalecer a classificação. Triebel et al. (2007) segue exatamente a abordagem desenvolvida em Mozos et al. (2007).

As anotações ou categorias semânticas criadas por Lookingbill et al. (2005) referem-se ao fluxo da movimentação, ou seja, da atividade observada em cena; Wolf e Sukhatme (2006) utilizam as categorias de Rua e Calçada; Mozos et al. (2007) emprega as categorias Salas, Corredores e Portas (mais precisamente o vão livre deixado por uma porta aberta) para classificar os nós do mapa topológico, e considera os objetos Monitor Ligado, Monitor Desligado, Máquina de Café, Mesa de Café, Rosto Frontal, Rosto de Perfil, Corpo Humano por Inteiro e Tronco Humano. Triebel et al. (2007) usa Corredor, Sala e Lobby.

Quanto aos formalismos matemáticos, devido ao resultado ruidoso do rastreamento de objetos em Lookingbill et al. (2005), são empregados múltiplos filtros de partícula para identificar de maneira consistente 0 movimento dos mesmo, considerando posição e velocidade. As trajetórias resultantes alimentam o histograma que caracteriza as distribuições de velocidade e direção dos objetos em solo.

Em Wolf e Sukhatme (2006) a classificação das células é feita com duas técnicas: modelos ocultos de Markov (Rabiner, 1989) e support vector machines (Vapnik, 1995). Posteriormente, é implementado um algoritmo de segmentação baseado em campos aleatórios de Markov (MRF), para corrigir pequenos erros de classificação devido a ruídos e outros fatores. $\mathrm{Na}$ implementação do modelo oculto de Markov (HMM), cada linha do mapa é considerada como uma seqüência de estados acrescentando dependência espacial de primeira ordem. Na implementação por support vector machines (SVM), as células são consideradas independentes. O artigo mostra uma 
comparação do desempenho das duas técnicas com e sem a aplicação posterior do MRF, considerando a utilização individual de cada uma das quatro propriedades propostas. Nesta implementação particular do HMM, cada propriedade tinha de ser considerada em separado. Já no SVM, foi possível combiná-las numa única classificação.

Mozos et al. (2007) propõem uma tarefa de localização, onde é usado um HMM para modelar as transições possíveis entre as classes semânticas e garantir uma classificação contínua já que células próximas tendem a pertencer à mesma classe. Para essa classificação são utilizados o sensor de varredura laser e imagens do sistema de visão. A atribuição das classes semânticas é realizada testando uma seqüência de classificadores binários, e esta seqüência é interrompida quando um resultado positivo é encontrado. Como o número de classes possíveis é pequeno, é possível avaliar a melhor seqüência de apresentação dos classificadores.

Triebel et al. (2007) empregam o modelo de redes de Markov associativas ou AMNs (Taskar et al., 2004) modificadas, que considera uma transformação dos vetores de características segundo o princípio de classificação do classificador nearest-neighbor, realizando uma extração de característica baseada em instância.

A segunda subdivisão dentro da categoria de mapas anotados classificam pontos no espaço em 3D. Fazem parte desta subdivisão os trabalhos de Nüchter et al. (2005), Anguelov et al. (2005) e novamente Triebel et al.(2007).

Nüchter et al. (2005) abordam o problema do SLAM em três dimensões, onde ao invés da posição e da orientação no plano para localizar o robô, são necessárias sua posição e orientação no espaço, resultando num espaço de seis dimensões. A informação semântica é empregada para restringir as possibilidades de pontos candidatos para uma correspondência robusta entre os dados sensoriais obtidos em posições diferentes, obtendo assim um mapa tridimensional mais preciso (Figura 9). 

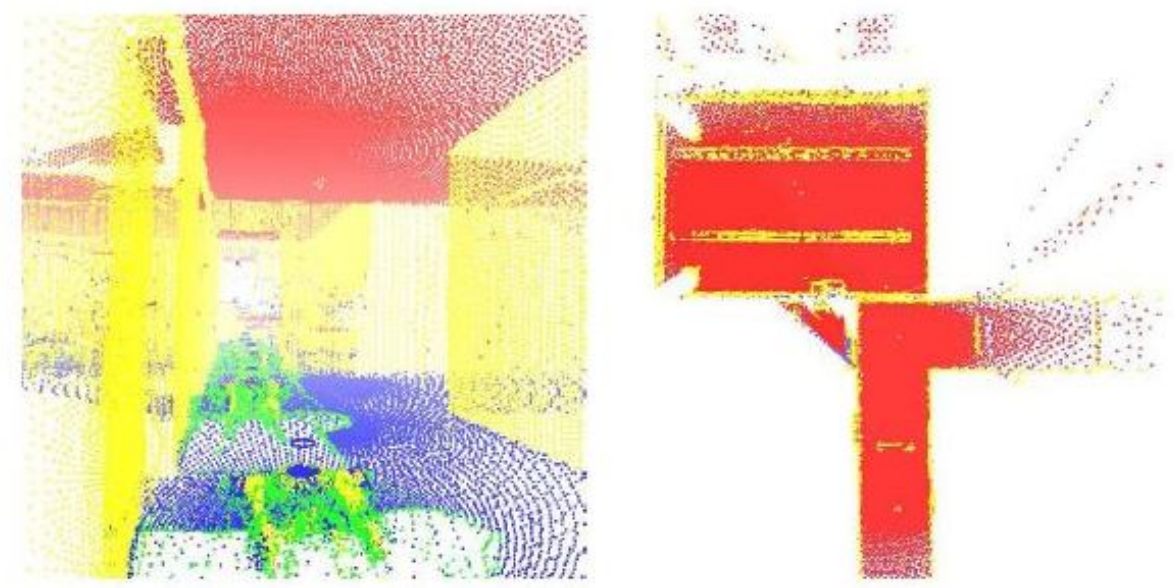

Figura 9. Mapa 3D do ambiente com as distinções de teto (vermelho), objetos (amarelo) e chão (azul) (extraído de Nüchter et al., 2005).

Anguelov et al. (2005) e Triebel et al. (2007) consideram o problema de segmentar dados de um sensor de varredura laser em 3D. As Figura $10 \mathrm{e}$ Figura 11 mostram comparações entre os resultados obtidos com os modelos propostos nos artigos em análise e outros classificadores conhecidos.
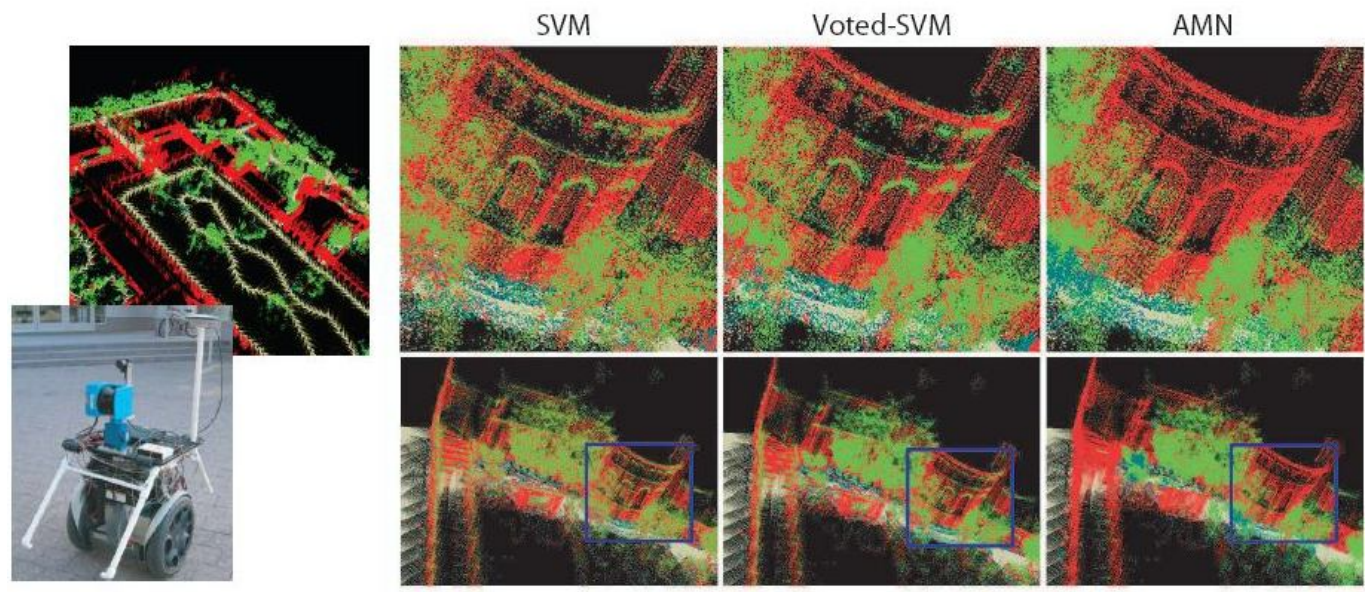

Figura 10. Resultados comparativos usando vários classificadores (extraído de Anguelov et al. 2005). 


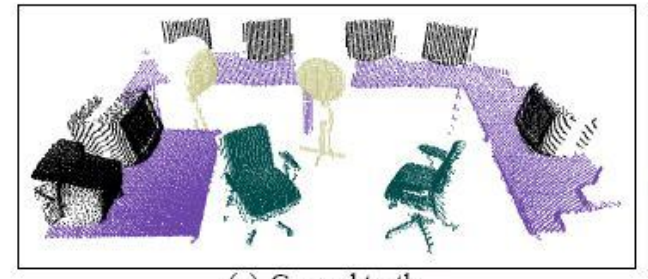

(a) Ground truth

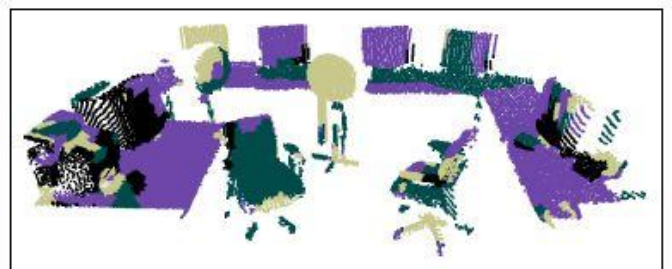

(c) AMN

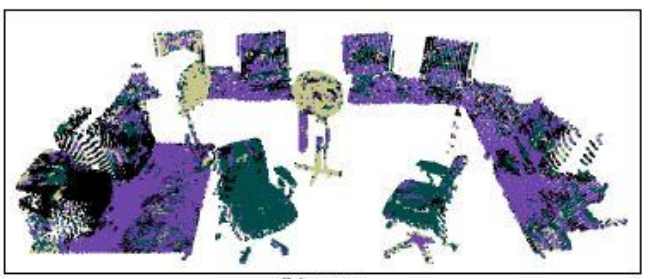

(b) $\mathrm{NN}$

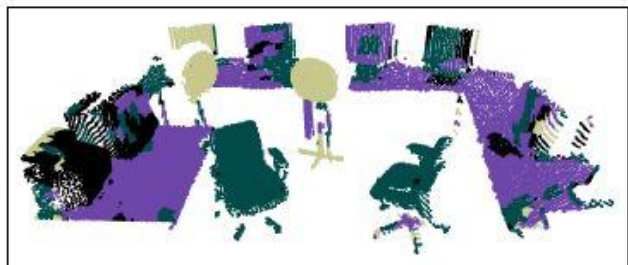

(d) inst. AMN

Figura 11. Objetos segmentados (extraído de Triebel et al. 2007).

Como características ou atributos, Nüchter et al. (2005) definem uma fórmula de gradiente para classificar os pontos de uma varredura laser baseada na relação geométrica de pontos vizinhos pertencentes a uma mesma leitura vertical. O valor é comparado com uma referência correspondente ao ângulo máximo de inclinação do terreno. Algumas adaptações são feitas para lidar com o problema de ruído e descontinuidade nas leituras.

Anguelov et al. (2005) considera três tipos de características: um plano principal ao redor de cada ponto, sobre o qual é orientado um cubo particionado em $3 \times 3 \times 3$ partes ao redor do ponto, onde é computada a porcentagem de pontos em cada uma dessas partes; uma coluna na forma de um cilindro de raio 0,25 $\mathrm{m}$ ao redor de cada ponto, onde é computada a porcentagem de pontos dentro de vários segmentos desse cilindro; e uma função indicador para dizer se um ponto está a menos de $2 \mathrm{~m}$ do chão. Para a determinação do plano principal de cada ponto são sorteados aleatoriamente 100 pontos de dentro do volume de um cubo de $1 \mathrm{~m}$ de aresta, centrado no ponto em consideração. Então, é utilizado o PCA (Principal Component Analysis) para determinar o plano composto pelos dois primeiros componentes principais. 
Triebel et al. (2007) usam o descritor chamado spin images (Lazebnik et al. 2003) com 5 x 10 partições.

As categorias semânticas empregadas por Nüchter et al. (2005) são Teto, Chão e Objeto; Anguelov et al. (2005) usam Chão, Prédio, Árvore e Moitas; e Triebel et al.(2007) utiliza Cadeira, Mesa, Tela, Ventilador e Lata de Lixo.

Quanto ao formalismo matemático, Nüchter et al. (2005) usa o algoritmo ICP (iterative closest points) para corresponder os pontos do laser entre leituras distintas do sensor. A idéia é minimizar uma função que depende da rotação e translação ocorrida entre as varreduras do laser e dos pontos escolhidos para serem pares. A busca é feita a partir da montagem de uma árvore $(k d-$ tree) para cada diferenciação semântica reduzindo assim o tempo de cálculo da minimização. Anguelov et al. (2005) e Triebel et al. (2007) utilizam um modelo de AMNs em cujo aprendizado ocorre a maximização da margem de classificação dos dados. Em Triebel et al. (2007) é necessária a redução do conjunto de dados (da ordem de 10.000 pontos) para a classificação. Durante o aprendizado supervisionado, busca-se a maximização da margem e por isso não é necessário calcular a função de partição, que aparece durante a maximização da verossimilhança condicionada em modelos de redes de Markov. Para a inferência podem ser usados graph-cuts (corte em grafos) ou programação linear, onde também não é necessário calcular a função de partição que não depende dos rótulos.

Como as representações espaciais são divididas em muitas parte a serem classificadas, são obtidos melhores resultados quando é possível descrever bem os dados do problema: quanto mais dependências entre os dados for possível incluir no modelo, melhor é o resultado, mesmo ao custo de um aumento do tempo no aprendizado.

\subsubsection{Mapas de objetos}

Mapas de objetos são representações espaciais caracterizadas sobretudo por um conjunto de objetos presentes no ambiente. Os objetos podem ser usados para distinguir entre regiões distintas num mapa pronto, como 
acontece nos mapas anotados. Dependendo da representação desses objetos no mapa, é possível manipulá-los e interpretar a dinâmica de cada um deles.

Essa categoria de mapas é importante porque os ambientes reais, por serem constituídos por objetos, são dinâmicos na medida em que alguns deles podem mudar de lugar com o passar do tempo. Portanto, representar objetos nos mapas criados por robôs móveis permite o rastreamento das mudanças no meio, melhorando assim o desempenho em ambientes dinâmicos (Anguelov et al., 2002; Limketkai et al., 2005). Ainda, é por meio de conceitos abstratos como objetos e relações entre eles que os seres humanos percebem o espaço físico. Dessa maneira, os mapas de objetos tornam-se interfaces mais naturais entre homens e máquinas (Galindo et al., 2005).

Informações semânticas como a classificação de um espaço ou o nome de um objeto fornecem entradas adicionais para tarefas de navegação, podendo determinar modos específicos de movimentação em cada espaço (Galindo et al., 2005). Essas representações permitem a realização de outras tarefas, como por exemplo a de encontrar vítimas de terremoto dentro de um edifício, a partir do momento que parte dos objetos considerados representam seres humanos (Ramos et al., 2006).

Dentro dessa categoria também é determinada uma subdivisão: algoritmos baseados na identificação de objetos em imagens e algoritmos que utilizam de linhas obtidas do processamento das leituras do laser. Na primeira subdivisão encontram-se os trabalhos de Galindo et. al. (2005), Ramos et al. (2006) e Vasudevan et al., (2007).

Galindo et al. (2005) estão interessados em realizar navegação por meio de comandos simbólicos como por exemplo, Vá até a cozinha. Descrevem uma representação composta por duas hierarquias distintas embora relacionadas: a espacial e a conceitual (Figura 12). As duas hierarquias, apesar de referirem-se às mesmas entidades físicas, possuem linguagens distintas no 
nível de implementação e relacionam-se por um vínculo entre informação sensorial e conhecimento simbólico (Coradeschi e Saffiotti, 2000).

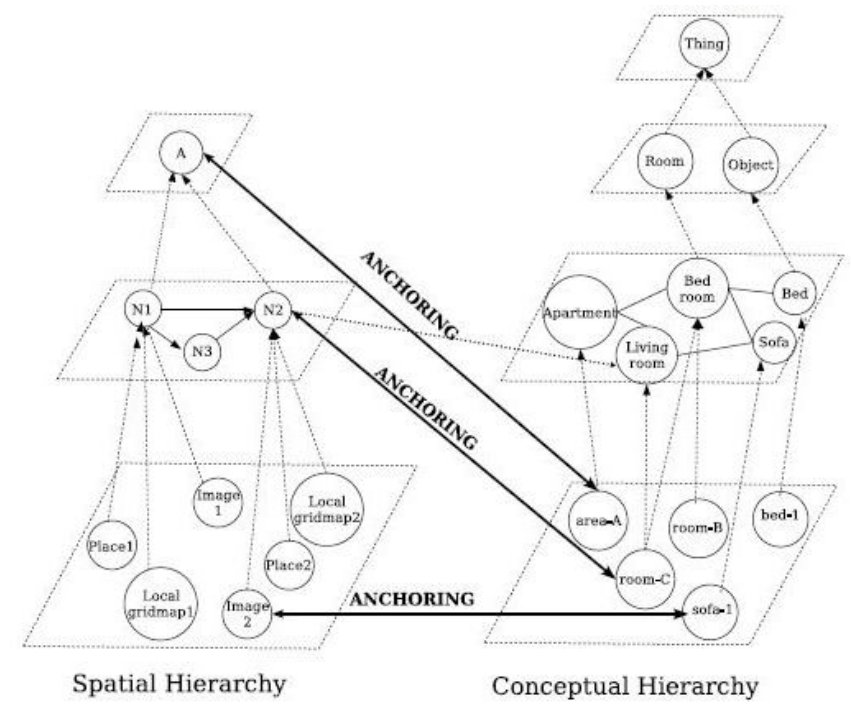

Figura 12. Esquema do mapa semântico multi-hierárquico (extraído de Galindo et al., 2005).

Ramos et al. (2006) abordam o problema do SLAM em ambientes dinâmicos, onde o robô detecta e rastreia marcos no ambiente usando-os no mapeamento e na localização simultânea. Duas dificuldades são destacadas nesse contexto: uma associação de dados robusta e a operação em ambientes dinâmicos. A associação está relacionada às correspondências dos marcos detectados em diferentes posições ou instantes de tempo. A complexidade do problema aumenta com a quantidade de marcos a serem rastreados. Além disso, ambientes dinâmicos podem apresentar objetos e pessoas que se movem ao longo do tempo e atrapalham representações estáticas que os consideram como marcos. Para superar essas dificuldades é proposta a utilização de representações individuais de objetos baseadas em modelos de sua aparência. A solução proposta inclui num mapa métrico os modelos da aparência dos objetos (Figura 13), para que seja possível mandar comandos ao robô do tipo, 'Encontre uma casa deste jeito' ou 'Construa um mapa com estes objetos'. 

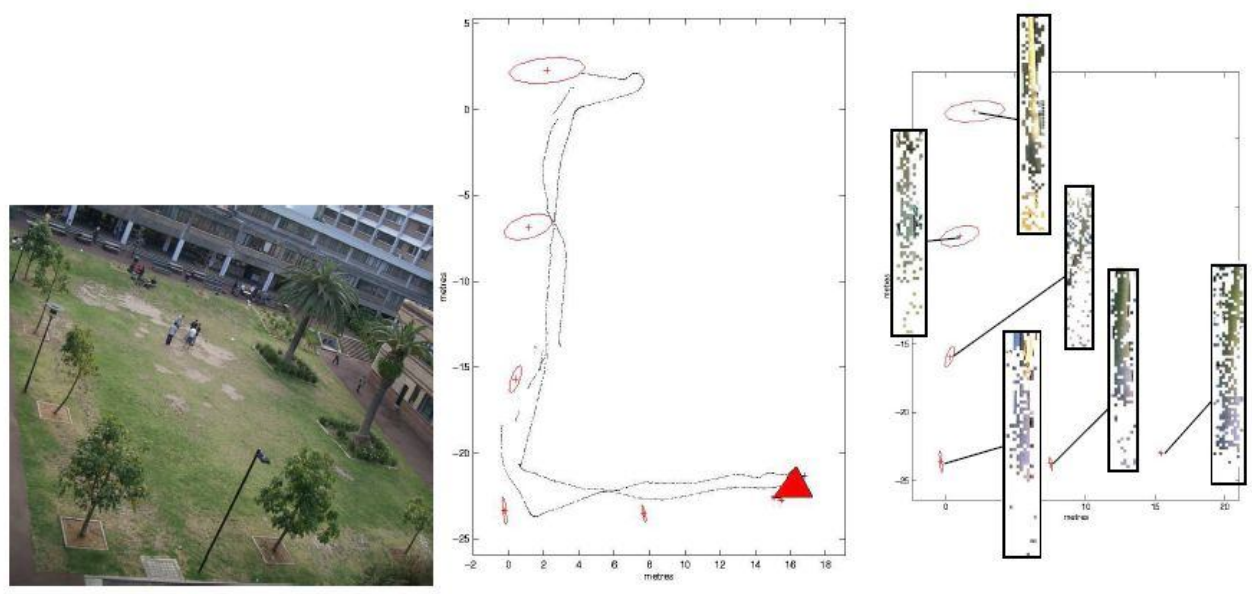

Figura 13. Exemplo do EKF-SLAM com os modelos de aparência de árvores (extraído de Ramos et al., 2006).

Vasudevan et al. (2007) constroem uma representação que consiste de um grafo probabilístico de objetos (Figura 14) que compõem mapas métricos locais. A parte probabilística está relacionada ao registro de duas crenças sobre a existência e a posição dos objetos. Consideram que um conjunto de objetos representa uma sala, e as salas estão relacionadas umas às outras por meio de portas.

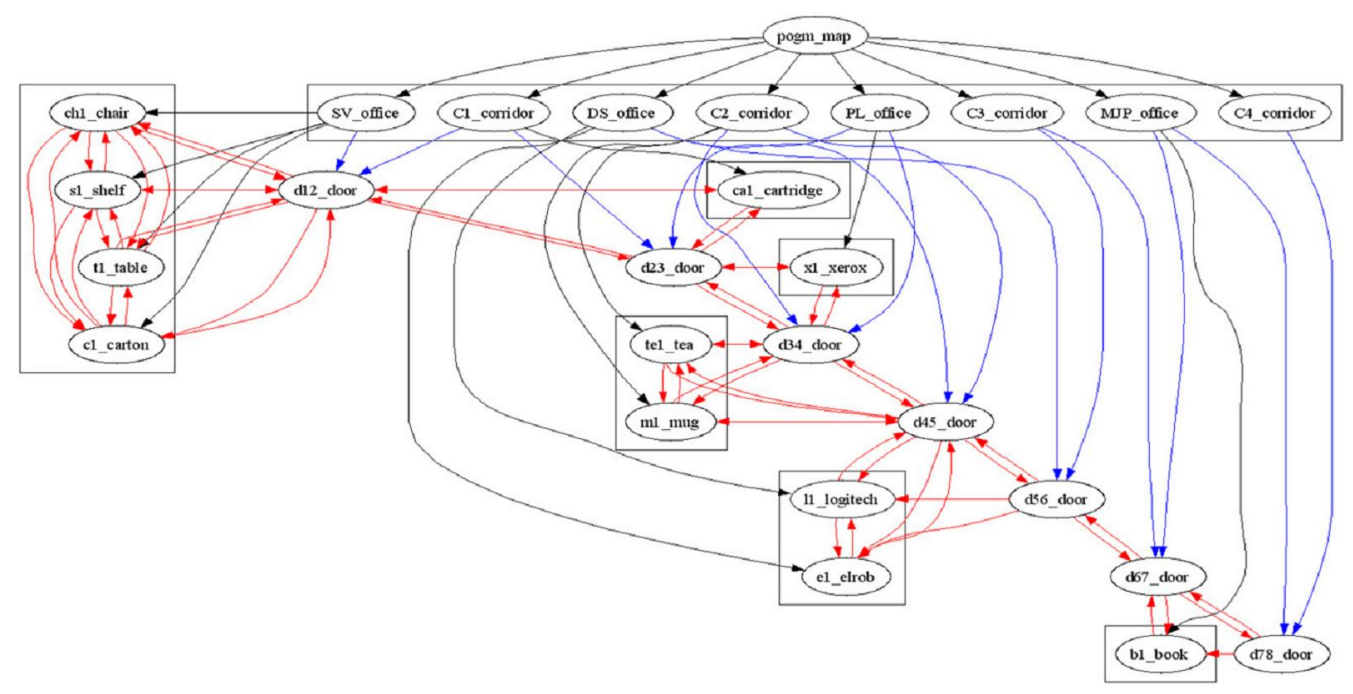

Figura 14. Grafo representando um mapa semântico de objetos (extraído de Vasudevan el al., 2007). 
Quanto aos sensores empregados nestes trabalhos, Galindo et al. (2005) utilizam um sistema de visão para identificar objetos por meio de formas e cores, e 16 sensores de ultra-som para montar grades de ocupação. Ramos et al. (2006) empregam um sistema calibrado entre um sensor de varredura laser e uma câmera, onde o primeiro restringe o espaço de busca nas imagens. Toda a identificação posterior é feita sobre a imagem. Vasudevan et al. (2007) usam uma câmera e um sensor de varredura laser.

Como informação semântica, Galindo et al. (2005) modelam salas e os objetos reais que podem caracterizá-la, como sofá, banheira, dentre outros. Ramos et al. (2006) considera em seus experimentos árvores, que são usadas como marcos para localização. Vasudevan et al. (2007) usa um sistema de visão estéreo para identificar objetos típicos de uma casa (diferentes tipos de caixas, mesas, cadeiras, prateleiras e canecas) e calcular suas posições em 3D, e um sensor de varredura laser, para detectar portas.

As características usadas por Galindo et al. (2005) para reconhecer os objetos nas imagens são as cores e formas dos mesmos (nos experimentos são usados caixas e cilindros coloridos para representar objetos distintos). Em Ramos et al. (2006), o processamento das imagens para obtenção das características divide as imagens de $640 \times 480$ em regiões de interesse de tamanho $9 \times 9$, resultando em 3763 regiões. Em cada região é feita uma convolução com um conjunto de wavelets de Gabor, que representa duas escalas e duas orientações diferentes. Então, cada região pode ser representada como um ponto $9 \times 9 \times(3+4)$ dimensional, onde o número 3 refere-se às três cores de cada pixel e 4 ao número de filtros de Gabor do conjunto. No total, cada ponto possui 567 dimensões. Esse conjunto de pontos é então projetado num espaço com menos dimensões usando PCA. Os pontos neste espaço dimensional menor são as características extraídas, acrescidas da norma das regiões vizinhas, considerando vizinhança-4, para melhorar o desempenho na segmentação da imagem. Vasudevan et al. (2007) emprega um reconhecimento de objeto baseado no descritor SIFT, 
registrando a distância e o ângulo dos mesmos relativos ao robô (usa-se a odometria), e um método baseado na extração de linhas com a aplicação de uma certa heurística para detectar as portas.

Quanto aos formalismos matemáticos, os níveis mais baixos da hierarquia espacial proposta por Galindo et al. (2005) são compostos por grades de ocupação. No nível acima, existe um mapa topológico extraído a partir das grades. O nível mais alto é um nó representando o ambiente como um todo. A partir das grades de ocupação, usam técnicas de morfologia matemática para determinar o mapa topológico referente. Esse mapa topológico segue a topologia matemática, diferentemente de outras abordagens com mapas topológicos (Kuiper, 2000; Thrun, 1998) onde a topologia não está bem definida. Já a hierarquia conceitual é formada por diversos níveis onde cada nível é uma instância ou especificação de uma classe anterior mais geral. A informação semântica é incorporada por meio da utilização da representação de conhecimento (knowledge representation) relacionada à área de inteligência artificial. É usada no modelo conceitual a linguagem NeoClassic baseada em lógica descritiva.

Ramos et al. (2006) usam técnicas de reconhecimento de objetos e segmentação em conjunto com o EKF-SLAM para estender a representação do ambiente. $O$ algoritmo possui duas fases: uma off-line onde imagens dos objetos a serem incorporados ao mapa devem ser utilizadas para criar uma representação para eles; e outra on-line onde instâncias dos objetos são segmentados usando a câmera e o laser. O aprendizado do modelo gerativo no espaço dimensional criado pelo uso do PCA é feito com o VBEM (Variational Bayesian Expectation Maximisation), que permite encontrar a melhor estrutura e os melhores parâmetros do modelo probabilístico. É usado para descobrir o número de componentes de um modelo de mistura de gaussianas, relacionado à verossimilhança de encontrar um ponto no espaço de dimensões reduzidas. Dois modelos são aprendidos, um para regiões da imagem pertencendo à objetos e outro para regiões pertencendo ao fundo da imagem. Os objetos são detectados primeiramente pela análise 
da leitura do sensor de varredura laser, procurando por descontinuidades que podem representar objetos. Desse modo, o espaço da procura realizada pelo algoritmo de segmentação é reduzido significativamente. O agrupamento de pontos descontínuos é identificado quando a distância deles para com os demais é acima de um determinado limiar. Então, as regiões da imagem associadas à essas medidas são extraídas juntamente com todos as regiões na mesma coluna. Cada região é classificada segundo o modelo aprendido para objetos e fundo da imagem. A associação de dados considera a posição global dos marcos juntamente com a região da imagem a ele associada, gerando uma função densidade de probabilidade, e usa o divergente Kullback-Leibler.

Em Vasudevan et al. (2007), a classificação das salas em diversas categorias é feita por meio de estatísticas relacionadas ao número, tipo e relações entre os objetos encontrados.

A outra subdivisão compreende os trabalhos de Anguelov et al. (2004) e Limketkai et al. (2005). Ambos utilizam um mapa previamente construído para definir os objetos do ambiente e realizam a classificação dos segmentos de reta obtidos do processamento dos dados de um sensor de varredura laser, sendo que este último emprega uma câmera omnidirecional para incorporar as cores dos objetos na representação.

Os objetos ou categorias semânticas considerados em Anguelov et al. (2004) e Limketkai et al. (2005) representam paredes e portas, sendo que a dinâmica destas encontra-se representada pelos estados aberta ou fechada. Na representação de Limketkai et al. (2005) é possível a criação de objetos mais complexos formados a partir de objetos simples, como a aglomeração de diversas paredes para gerar um corredor.

A implementação desses mapas usa modelos conceitualmente distintos. Anguelov et al. (2004) considera um modelo probabilístico que utiliza o algoritmo EM para aprendizado dos parâmetros com base em dados sensoriais. Os objetos representados são definidos por meio de classes com 
parâmetros próprios que podem ser determinados por aprendizado computacional. A idéia principal é de usar informações sensoriais tanto da movimentação dos objetos ao longo do tempo quanto das aparências dos mesmos. Cada uma dessas classes é associada com um conjunto de parâmetros, que podem ser de dois tipos: estáticos e dinâmicos. A forma e a cor dos objetos são parâmetros estáticos pois tendem a ser os mesmos independente do instante de tempo. Os parâmetros de posição podem ser estáticos para objetos como Parede e dinâmicos para objetos como Porta. Ainda, os parâmetros estáticos podem ser globais, que são definidos para todos os objetos de uma classe, ou locais, que são específicos para cada objeto.

Um objeto Parede é modelado por um conjunto de segmentos alinhados ao longo de uma linha reta. A linha é descrita por dois parâmetros, o vetor unitário normal à linha e o deslocamento escalar entre a linha e a origem do sistema de coordenadas. Cada segmento ao longo da linha é representado pela especificação dos seus pontos extremos. Assim, são necessários 2 parâmetros para cada segmento do conjunto e mais outros dois representando o conjunto. Esses parâmetros são estáticos e locais.

Um objeto Porta é representado por um segmento que pode rotacionar ao redor do ponto que modela a dobradiça. Essa classe é associada a três parâmetros: um vetor bidimensional que denota a localização da dobradiça da porta, um escalar que denota a largura da porta, e o ângulo da porta num instante qualquer. Os parâmetros são estáticos à exceção do ângulo da porta, que é dinâmico. Todos os parâmetros são locais, exceto a largura da porta, que é global.

A Figura 15 ilustra uma instância desse mapa. O mapa é um conjunto de objetos dos tipos porta e parede. 


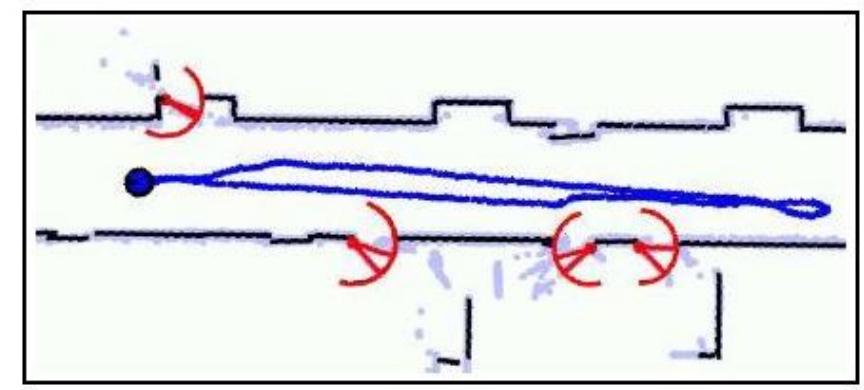

Figura 15. Exemplo do mapa proposto (Anguelov et al., 2004).

Limketkai et al. (2005) apresenta o mapa relacional de objetos (Relational Object Maps ou RO-maps). A representação é implementada com o modelo de redes de Markov relacionais. Os nós da rede de Markov gerada correspondem aos objetos. As classes do esquema são os tipos de objetos considerados, no caso, portas e parede, e os atributos são as propriedades físicas de cada tipo; conjunto de templates de cliques relacionais e os potenciais correspondentes.

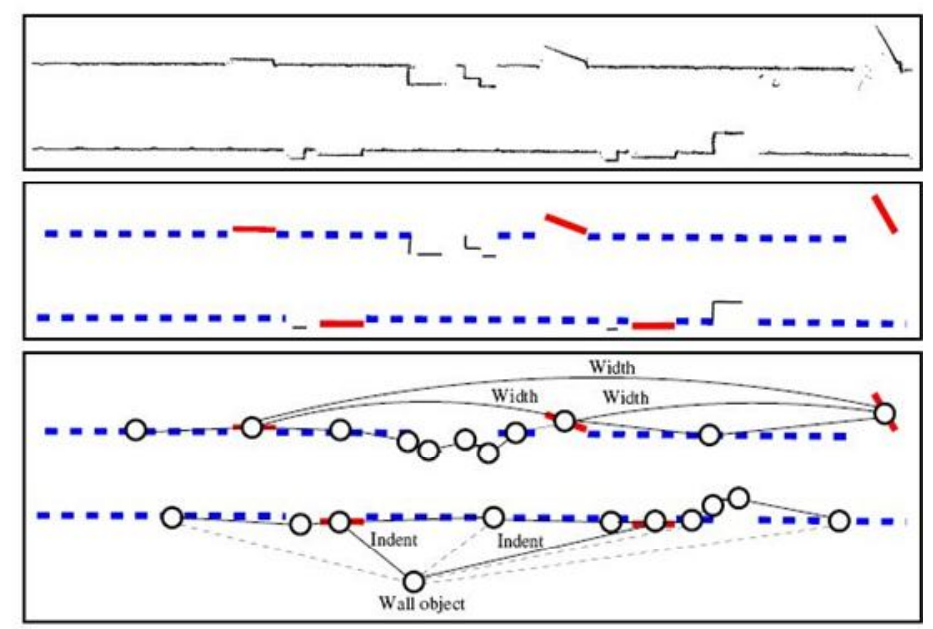

Figura 16. Exemplo de um RO-map (Limketkai et al., 2005).

Esses objetos são detectados através de uma combinação de características incluindo: 
- Aparência, como comprimento de uma porta para caracterizar a aparência dos objetos. As funções de características retornam o logaritmo da verossimilhança de um comprimento específico dado por uma gaussiana representando a distribuição sobre os comprimentos, condicionado ao tipo de objeto. As médias e variâncias das gaussianas para portas, paredes e outras são estimadas de mapas classificados manualmente;

- Vizinhança, descrevendo que tipos de objetos podem estar próximos uns dos outros. A vizinhança é determinada considerando todos os segmentos cujo ponto final está dentro de $40 \mathrm{~cm}$ (uma função indicador binária para os pares de classificação possíveis, paredeparede, parede-porta e porta-parede);

- Espacial, como a abertura de uma porta ou relações espaciais como a distância entre os objetos. A abertura é medida pela distância mínima entre os extremos da linha porta e a linha da parede. Essa função retorna o logaritmo da verossimilhança sobre um modelo gaussiano. Considera a distância e o ângulo de alinhamento à parede mais próxima. A verossimilhança de distâncias e ângulos específicos são obtidos por distribuições discretas dos mapas de treinamento (que tipicamente não são gaussianas);

- Características globais que dependem de múltiplos objetos que estão potencialmente longe um do outro. É medida a similaridade da abertura de todas as portas pelo cálculo da variância;

- Para o objeto agregado corredor, a característica referente é o alinhamento entre os segmentos que compõem a parede. Esse alinhamento é medido pela distância média dos segmentos de linha relativos à linha Parede agregada;

Para o aprendizado e as inferências, Limketkai et al. (2005) usam métodos de Monte Carlo (MCMC) - Gibbs sampling mais especificamente - devido a presença de cliques que dependem do rótulo do objeto. 


\subsection{Considerações finais}

Os trabalhos apresentados acima enquadram-se na área de mapeamento semântico e foram selecionados da literatura científica para ilustrar as três categorias propostas nesta tese: mapas cognitivos, mapas anotados e mapas de objetos. Levando em consideração a definição adotada de que mapas semânticos são representações hierárquicas, ressalta-se que a categoria de mapas cognitivos não representa necessariamente uma hierarquia, como acontece nas outras duas categorias, por tratar-se de um mapa topológico apenas. Nas demais existe um mapa métrico no nível de informação espacial.

A maior parte dos trabalhos preocupa-se somente com o processo de mapeamento semântico, ou melhor, a categorização da informação espacial, dando como certa a existência de um mapa métrico consistente. Alguns artigos apenas indicam possíveis aplicações para as representações criadas (Zivkovic et al. 2007; Posner et al. 2006; Wolf e Sukhatme, 2006; Anguelov et al. 2005; Triebel et al. 2007; Anguelov et al. 2004; Limketkai et al. 2005; Vasudevan et al., 2007), enquanto outros demonstram a funcionalidade de suas representações (Tapus e Siegwart et al. 2005; Lookingbill et al. 2005; Ramos et al. 2006, Nüchter et al. 2005; Galindo et al. 2005).

Os trabalhos pioneiros com mapas semânticos, então chamados mapas de objetos, começaram a aparecer há menos de dez anos atrás, mas foi apenas nesses últimos anos que o interesse pelo tema se espalhou pela comunidade científica. Os trabalhos iniciais apresentavam uma convergência de problemas com a literatura de visão computacional e fotogrametria, ainda que pouco explorada (Thrun, 2002).

Provavelmente para contornar as dificuldades computacionais de se trabalhar com sistemas de visão naquela época, predominaram posteriormente trabalhos com o uso de sensores de varredura laser para construção de mapas semânticos. No entanto, com o grande desenvolvimento da área de visão computacional alcançado nos últimos 
anos, associado à redução do custo de equipamentos e ao aumento da capacidade computacional das máquinas utilizadas, surgiu um interesse renovado no emprego de sistemas de visão na robótica. A criação de mapas semânticos tirou proveito dessa situação para acrescentar parte da informação visual e espacial produzida em suas representações, já que uma imagem fornece muito mais dados que um sensor de distância.

Mesmo assim, ainda poucos trabalhos lidam com a complexa extração de informação das imagens (como o processo de segmentação de imagens) para o mapeamento semântico - um exemplo é o trabalho de Ramos et al. 2006, que segmenta árvores nas imagens para usá-las como marcos naturais na localização de um robô móvel num ambiente dinâmico. Além disso, o emprego de modelos que combinam de alguma forma probabilidade e lógica relacional está longe de ser uma unanimidade na área de robótica móvel, apesar de todo potencial demonstrado em outras áreas e da adequação destes modelos expressivos aos problemas de navegação, localização e mapeamento, dentre outros. De todos os trabalhos apresentados, apenas Anguelov et al. 2005, Triebel et al. 2007 e Limketkai et al. 2005 consideram em suas representações modelos dentro da área de aprendizado estatístico relacional: AMNs nos dois primeiros e RMNs no último. Mas quando o fazem, trabalham apenas com dados de distância vindos de um laser, porque integrar informação espacial e com informação visual de imagens num modelo relacional ainda é um problema em aberto.

O mapa semântico proposto nesta tese pertence à categoria de mapas de objetos, por extrair obstáculos da grade de ocupação e das imagens do sistema de visão. Um diferencial está no emprego de um modelo probabilístico relacional para especificar o problema do mapeamento semântico, tratando da segmentação da imagem referentes a obstáculos quaisquer que o laser identifica e que aparecem na imagem. A proposta é lidar com todas as dificuldades da interpretação semântica em imagens.

A Tabela 2 resume os artigos relacionados a esta categoria para uma comparação mais imediata. 
Tabela 2. Mapas de objetos

\begin{tabular}{|c|c|c|c|c|}
\hline Mapas semânticos & $\begin{array}{c}\text { Modelo } \\
\text { matemático }\end{array}$ & $\begin{array}{c}\text { Categorias } \\
\text { semânticas }\end{array}$ & Destaque & Sensores \\
\hline $\begin{array}{c}\text { Object maps } \\
\text { (Anguelov et al., 2004) }\end{array}$ & Probabilístico & $\begin{array}{c}\text { Portas e } \\
\text { paredes }\end{array}$ & $\begin{array}{c}\text { Classifica os } \\
\text { objetos }\end{array}$ & $\begin{array}{c}\text { Laser, } \\
\text { câmera }\end{array}$ \\
\hline $\begin{array}{c}\text { RO-maps } \\
\text { (Limketkai et al., 2005) }\end{array}$ & $\begin{array}{c}\text { Redes relacionais } \\
\text { markovianas }\end{array}$ & $\begin{array}{c}\text { Portas e } \\
\text { paredes }\end{array}$ & $\begin{array}{c}\text { Restrições } \\
\text { espaciais }\end{array}$ & Laser \\
\hline $\begin{array}{c}\text { Mapa semântico multi- } \\
\text { hierárquico } \\
\text { (Galindo et al., 2005) }\end{array}$ & $\begin{array}{c}\text { Modelos lógicos e } \\
\text { modelos } \\
\text { probabilísticos em } \\
\text { separado }\end{array}$ & $\begin{array}{c}\text { Objetos e } \\
\text { salas }\end{array}$ & $\begin{array}{c}\text { Implementam um } \\
\text { vínculo sensório- } \\
\text { simbólico }\end{array}$ & $\begin{array}{c}\text { Ultra-som, } \\
\text { Câmera }\end{array}$ \\
\hline $\begin{array}{c}\text { SLAM } \\
\text { (Ramos et al., 2006) }\end{array}$ & $\begin{array}{c}\text { EKF-SLAM } \\
\text { incerteza na } \\
\text { posição }\end{array}$ & $\begin{array}{c}\text { Laser, } \\
\text { câmera }\end{array}$ \\
\hline $\begin{array}{c}\text { Mapa hierárquico } \\
\text { (Vasudevan et al., } \\
\text { 2007) }\end{array}$ & $\begin{array}{c}\text { Árvores } \\
\text { Probabilístico }\end{array}$ & Objetos e \\
salas & $\begin{array}{c}\text { Reconhecimento de } \\
\text { objetos }\end{array}$ & $\begin{array}{c}\text { Laser, } \\
\text { câmera }\end{array}$ \\
\hline $\begin{array}{c}\text { Vínculo sensório- } \\
\text { simbólico (Tese) }\end{array}$ & $\begin{array}{c}\text { Campos } \\
\text { aleatórios } \\
\text { condicionados }\end{array}$ & Obstáculos & $\begin{array}{c}\text { Implementa } \\
\text { associações } \\
\text { sensório-simbólicas }\end{array}$ & $\begin{array}{c}\text { Laser, } \\
\text { câmera }\end{array}$ \\
\hline
\end{tabular}


Capítulo 3

\section{MODELAGEM MATEMÁTICA}

O mapeamento semântico como processo de estruturação da informação espacial pode ser formulado como um problema de classificação - termo empregado na literatura de reconhecimento de padrões e aprendizado de máquina. $O$ objetivo da classificação é atribuir uma dentre $K$ classes discretas $y_{k}^{7} \in\{1, \ldots, K\}$, independentemente para cada ponto $x$ de entrada. No caso do mapeamento proposto nesse trabalho, o vetor $\mathbf{x}$ de entrada corresponde aos valores das variáveis aleatórias observáveis do problema (os pixels das imagens omnidirecionais e os pontos das leituras do sensor laser), e a tarefa de classificação 8 é a determinação dos valores do vetor $\mathbf{y}$ das variáveis aleatórias não-observáveis ${ }^{9}$ (as classes ou rótulos dos pixels e o estado da grade de ocupação).

Modelos lineares generalizados (McCullagh e Nelder, 1989) definem superfícies de decisão que dividem o espaço $D$-dimensional de entrada em diferentes regiões, cada uma contendo uma das classes $y_{k}$. As superfícies definidas são funções lineares de $x$. Estes modelos estatísticos "planos" ("flat") consideram que as variáveis não-observáveis do problema são independentes e identicamente distribuídas, desconsiderando assim a estrutura $^{10}$ interna do problema. No entanto, tratar os dados de entrada como pontos num espaço $D$-dimensional esconde a rica estrutura lógica

\footnotetext{
${ }^{7}$ As letras em negrito denotam conjuntos: quando maiúsculas, representam as variáveis aleatórias e quando minúsculas, os valores atribuídos às variáveis. Em letras minúsculas e em itálico serão denotadas as variáveis determinísticas.

${ }^{8}$ Para ser mais preciso, nesse contexto o termo correto é inferência, pois é calculada uma distribuição de probabilidades, e não apenas os valores das variáveis não-observadas.

${ }^{9}$ Também chamadas de ocultas ou latentes.

${ }^{10} \mathrm{O}$ termo estrutura no contexto de modelos probabilísticos denota o grafo associado à distribuição conjunta das variáveis aleatórias representadas no modelo.
} 
subjacente que é crucial na resolução de problemas mais gerais e complexos (Getoor e Taskar, 2007).

Por outro lado, os modelos de grafos de probabilidade como as redes de Markov e as redes bayesianas (Pearl, 1988) representam dependências, como por exemplo não-causais e de causa-efeito respectivamente, entre as variáveis não-observáveis do problema ao especificar uma distribuição conjunta das mesmas. Dessa maneira, é possível realizar uma classificação coletiva do vetor $\mathbf{x}$. A classificação coletiva determina as classes $\mathbf{y}$ de todos os pontos $\mathbf{x}$ envolvidos no problema ao mesmo tempo, levando em consideração as dependências do modelo e atingindo assim melhores resultados.

Recentemente têm surgido na literatura de aprendizado de máquina modelos como as redes de Markov relacionais (Taskar et al., 2002) e os modelos probabilísticos relacionais (Koller e Pfeffer, 1998; Friedman et al., 1999) que combinam grafos de probabilidade que representam uma descrição relacional das variáveis aleatórias, possibilitando o emprego de entidades com estruturas diferentes, e alcançando dessa forma uma classificação ainda mais precisa dos dados do problema (Getoor e Taskar, 2007).

A seguir são introduzidos alguns tópicos para que seja possível, no próximo capítulo, desenvolver o modelo para o mapeamento semântico. A primeira seção trata do aprendizado de máquina e dos problemas de classificação e agrupamento de dados. A segunda seção descreve as mudanças introduzidas na área de aprendizado de máquina com o surgimento do aprendizado estatístico relacional. $\mathrm{Na}$ última seção são apresentados três modelos de redes de Markov (MRF, CRF e RMN), enfatizando as dependências consideradas por cada um, seguidos dos algoritmos para aprendizado de parâmetros e inferência em um CRF. 


\subsection{Aprendizado de máquina}

A área de aprendizado de máquina (machine learning) compreende algoritmos computacionais que generalizam a partir de um conjunto de dados. Os exemplos a partir dos quais o algoritmo obtém a generalização compõem o conjunto de treinamento.

Algoritmos deste tipo são empregados em problemas onde a função que associa os dados de entrada aos resultados desejados é difícil de ser especificada. Esta dificuldade é contornada pelo processamento de uma quantidade de exemplos representativa do problema em questão.

O processo de generalização só é possível pela escolha de uma classe de modelos que determinará o espaço das soluções possíveis. Dentro de uma mesma classe, os modelos se diferenciam pelos valores do conjunto de parâmetros associados. Por exemplo, polinômios de segundo grau e de terceiro grau são classes de modelos distintas, e os coeficientes dos polinômios são o conjunto de parâmetros que diferencia um modelo do outro.

A generalização pode ser entendida nesse contexto como a otimização de uma função dos parâmetros do modelo sobre os dados do conjunto de treinamento. Desse modo, os algoritmos de generalização realizam uma busca no espaço dos parâmetros, considerando algum conhecimento prévio sobre o problema e a estrutura inerente ao espaço. Algoritmos eficientes tiram proveito dessa estrutura para organizar e otimizar a busca. Para os modelos de grafos de probabilidade, procura-se determinar funções côncavas dos parâmetros para serem maximizadas, o que garante que um máximo local é também um máximo global.

Para escolher adequadamente uma classe de modelos, é necessário considerar um compromisso com o processo de generalização. Quanto mais expressiva ou complexa a classe, maior é o espaço de soluções consideradas, mas também maior é a chance de ocorrer o chamado overfitting. Esse comportamento do algoritmo de generalização aparece 
quando ocorre a especialização sobre os dados do conjunto de treinamento, e o modelo obtido deixa de representar os casos que ainda não foram apresentados ao sistema. O que ocorre nestes casos é que os parâmetros do modelo encontrados têm valores tão altos que a solução acaba por reproduzir um ruído aleatório que passa exatamente sobre todos os exemplos apresentados (Bishop, 2007).

O overfitting é menos crítico conforme aumenta-se o número de exemplos do conjunto de treinamento. Para contornar o fato da complexidade da classe de modelos estar associada ao tamanho do conjunto de treinamento, que ocorre quando se usa a maximização da verossimilhança, pode-se empregar uma abordagem bayesiana. Uma técnica neste sentido é chamada de regulação (regularization) que consiste no acréscimo de um termo de penalização à função a ser otimizada, para evitar valores altos nos parâmetros do modelo (Bishop, 2007).

\subsubsection{O problema da classificação}

O problema da classificação faz parte dos algoritmos de aprendizado supervisionado, que consiste num conjunto de treinamento formado por pares ordenados compostos por um ponto $x$ de entrada e a respectiva classe $y_{k}$. A formulação apresentada abaixo corresponde à classificação coletiva dos dados do problema, mas o princípio é o mesmo para a classificação individual.

Segundo a óptica da probabilidade e da teoria de decisão, a classificação pode ser dividida em dois estágios distintos: o estágio de inferência, no qual os dados de treinamento são usados para aprender um modelo para $\mathrm{P}_{k}(\mathbf{Y} \mid \mathbf{X})$; e o estágio de decisão, no qual estas probabilidades a posteriori são usadas para otimizar a classificação (Bishop, 2007).

A seguir são apresentadas duas abordagens distintas para esse problema, que aparecerão na discussão sobre os modelos de redes de Markov. 
A abordagem mais complexa considera $\mathrm{P}_{k}(\mathbf{X} \mid \mathbf{Y})$ para cada classe $y_{k}$ e a distribuição a priori $\mathrm{P}_{k}(\mathbf{Y})$. Usando o teorema de Bayes na forma, tem-se

$\mathrm{P}_{k}(\mathbf{Y} \mid \mathbf{X})=\mathrm{P}_{k}(\mathbf{X} \mid \mathbf{Y}) \cdot \mathrm{P}_{k}(\mathbf{Y}) / \mathrm{P}(\mathbf{X})$

Em alguns casos pode-se considerar diretamente $P_{k}(\mathbf{X}, \mathbf{Y})$ que é igual a

$\mathrm{P}_{k}(\mathbf{X}, \mathbf{Y})=\mathrm{P}_{k}(\mathbf{X} \mid \mathbf{Y}) \cdot \mathrm{P}_{k}(\mathbf{Y})$

Esses modelos são chamados gerativos, por incluírem o processo de geração das observações $\mathbf{x}$ a partir de $\mathbf{y}$.

No entanto, a distribuição de interesse na tarefa de classificação é a distribuição condicionada $\mathrm{P}_{k}(\mathbf{Y} \mid \mathbf{X})$. Portanto, na abordagem gerativa resolvese um problema maior do que o necessário, o que exige na prática adotar muitas simplificações nas dependências envolvidas entre $\mathbf{X}$ e $\mathbf{Y}$ para que o cálculo seja eficiente computacionalmente.

A abordagem mais simples determina diretamente $\mathrm{P}_{k}(\mathbf{Y} \mid \mathbf{X})$, e os modelos que empregam esse tipo de aprendizado são chamados de discriminativos. Dessa maneira é possível incluir muitas dependências entre $\mathbf{X}$ e $\mathbf{Y}$, resultando num melhor resultado de classificação.

A intuição que prevalece é a de que o aprendizado discriminativo apresenta um erro assintótico menor, quando existem dados de treinamento suficientes (Vapnik, 1995), mas o aprendizado gerativo pode ser melhor na presença de poucos dados (Liang e Jordan, 2008).

No mapeamento semântico a ser desenvolvido no próximo Capítulo, a classificação é aplicada no domínio das imagens onde recebe o nome de segmentação ${ }^{11}$. A segmentação da imagem consiste na classificação de seus pixels segundo rótulos pré-determinados. Nesse trabalho é considerada a classificação binária dos pixels em Obstáculos ou não-

\footnotetext{
${ }^{11}$ Alguns autores chamam de classificação ao problema de segmentar e rotular os pixels de uma imagem (por exemplo, Kumar e Hebert (2003)). Aqui os três termos serão usados com o mesmo significado.
} 
Obstáculos. Na seqüência são introduzidas medidas para avaliar o resultado da segmentação.

\subsubsection{Critérios de avaliação do resultado da classificação}

Foram escolhidas três medidas para avaliar o resultado da segmentação das imagens: cobertura (recall), precisão (precision) e exatidão (accuracy). Estas medidas são comuns nas áreas de cobertura de informação (information retrieval) e categorização de textos (Joachims, 1999).

Seja A o conjunto dos pontos que são obstáculos e B o conjunto dos pontos que não são. Considere ainda que $C$ é o conjunto dos pontos (em verde) que - classificador atribui o rótulo de obstáculo. Na Figura 17 estão representados os diagramas destes conjuntos. Em vermelho estão os pontos que, mesmo sendo obstáculos, o classificador erra na atribuição de rótulo. Em azul estão os pontos que não são obstáculos e que o classificador acerta na atribuição de rótulo. Em verde estão tanto pontos que são obstáculos (e que pertencem ao conjunto $A$ ) quanto pontos que não são obstáculos (e que pertencem ao conjunto $\mathrm{B}$ ), para ilustrar que um classificador não concede cobrir todo o conjunto $A$ (dos pontos que são obstáculos) e que acaba por incluir pontos que não são obstáculos, pertencentes ao conjunto B.

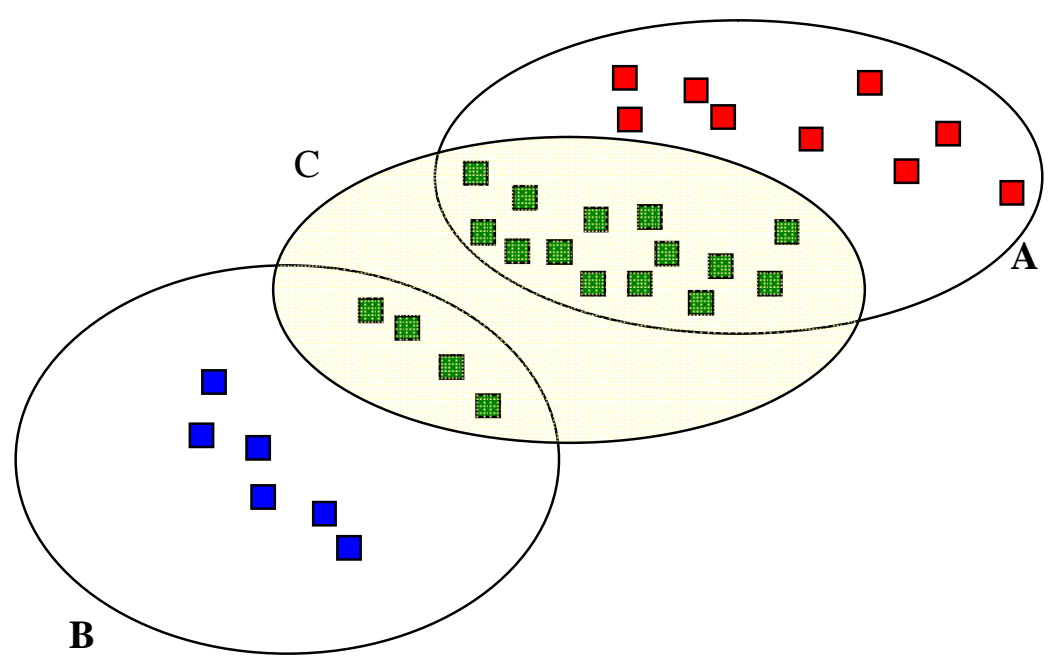

Figura 17. Representação das medidas de cobertura e precisão. 
A medida de desempenho $\operatorname{Cobertura}(\mathbf{x})$ é o percentual dos pixels que o classificador consegue recuperar, que são realmente obstáculos

$\operatorname{Cobertura}(X)=\frac{|C \cap A|}{|A|}$

onde $|\mathrm{A}|$ é a quantidade de elementos do conjunto $A$. Se o classificador atribuir o rótulo de obstáculo a todas as variáveis, o valor do Cobertura será de $100 \%$.

A medida de desempenho Precisão(x) é o percentual dos pixels que são realmente obstáculos dentre os pixels classificados como obstáculo

$\operatorname{Precisão}(x)=\frac{|C \cap A|}{|C|}$

A medida de desempenho Exatidão(x) é o acerto do classificador, considerando se cada variável foi classificada corretamente em obstáculo e não obstáculo.

$\operatorname{Exatidão}(x)=\frac{1}{n} \sum_{n} \delta_{n}\left(y_{k}\right)$

onde $\delta_{n}\left(y_{k}\right)=1$ se e somente se $y_{k}$ é o rótulo correto do ponto $x_{n}$.

\subsubsection{O problema do agrupamento}

Antes de avançar para o aprendizado estatístico relacional, é necessário tratar do problema do agrupamento (clustering) de dados que faz parte dos algoritmos de aprendizado não-supervisionado. Ele consiste na identificação de similaridades nos dados de entrada e na partição desse conjunto em um número $K$ de grupos.

O algoritmo exposto a seguir será utilizado para agrupar um conjunto de pontos obtidos do laser, referentes a um mesmo obstáculo. Isso é necessário já que a segmentação de imagem proposta classifica os pixels 
em obstáculos, mas não determina que dois pixels correspondem a um mesmo obstáculo.

Escolheu-se o algoritmo K-means onde, na solução final, cada grupo conterá um conjunto de pontos cujas distâncias entre si são pequenas quando comparadas às distâncias com os pontos de fora do grupo.

Considere um conjunto $D$-dimensional de vetores $\mu_{\mathbf{k}}, k=1, \ldots, K$, que podem ser vistos como se fossem os centros dos $K$ grupos. $O$ algoritmo determina um grupo para cada dado de entrada e também os vetores $\mu_{\mathrm{k}}$ que caracterizam cada grupo.

Para cada ponto de entrada $x_{n}$, existe um conjunto de variáveis indicador binárias $r_{n k} \in\{0,1\}$, onde $k$ indica a qual grupo $x_{n}$ pertence. Se $x_{n}$ é considerado como pertencente ao grupo $k, r_{n k}=1$ e $r_{n j}=0$ para $j \neq k$.

Pode-se definir a função objetivo $\mathrm{J}$, chamada medida de distorção (Bishop, 2007) como

$J=\sum_{n=1}^{N} \sum_{k=1}^{K} r_{n k}\left\|\mathbf{x}_{\mathbf{n}}-\boldsymbol{\mu}_{\mathbf{k}}\right\|^{2}$

que representa a soma dos quadrados das distâncias de cada ponto ao vetor $\mu_{\mathbf{k}}$ do grupo $k$ ao qual foi considerado pertencente. O objetivo é encontrar valores para $\left\{r_{n k}\right\}$ e $\left\{\mu_{k}\right\}$ que minimizem $J$.

Isso é feito num processo iterativo em que cada iteração possui dois passos correspondendo a sucessivas otimizações de $r_{n k}$ e $\boldsymbol{\mu}_{\boldsymbol{k}}$. Primeiro são escolhidos valores iniciais de $\mu_{\mathbf{k}}$. Então, $J$ é minimizada com relação a $r_{n k}$, mantendo-se $\mu_{\mathbf{k}}$ fixo. No segundo passo, $J$ é minimizada com relação a $\mu_{\mathbf{k}}$, mantendo $r_{n k}$ fixo.

A determinação de $r_{n k}$ é realizada facilmente, pois $J$ é uma função linear de $r_{n k}$. Como os termos envolvendo $n$ diferentes são independentes, tem-se 
$r_{n k}=\left\{\begin{array}{ccc}1 & \text { se } & k=\arg \min _{j}\left\|x_{n}-\mu_{j}\right\|^{2} \\ 0 & \text { caso } & \text { contrário }\end{array}\right.$

No entanto, a função $J$ é quadrática em $\mu_{k}$, o que exige a minimização da mesma, determinando que a derivada com relação a $\mu_{k}$ é zero

$2 \sum_{n=1}^{N} r_{n k}\left(\mathbf{x}_{\mathbf{n}}-\boldsymbol{\mu}_{k}\right)=0$

que pode ser facilmente resolvida para dar

$\boldsymbol{\mu}_{k}=\frac{\sum_{n} r_{n k} \mathbf{x}_{\mathbf{n}}}{\sum_{n} r_{n k}}$

Estes dois passos são repetidos até que não haja mais nenhuma mudança de pontos entre os grupos ou que um número máximo de iterações seja atingido.

\subsection{Aprendizado estatístico relacional}

A evolução dos algoritmos de aprendizado estatístico e inferência probabilística e a grande quantidade de dados heterogêneos envolvida em aplicações de diferentes áreas têm fomentado a iniciativa de considerar modelos cada vez mais complexos nos algoritmos de aprendizado. Esta complexidade está contida na estrutura relacional que associa as diferentes entidades representadas no problema.

Recentemente, foi estabelecida a área de aprendizado estatístico relacional (Statistical Relational Learning - SRL) como resultado de pesquisas com modelos que combinam probabilidade e lógica relacional ou de primeira ordem. Embora represente uma convergência de trabalhos de origens 
distintas, a exposição a seguir trata apenas dos modelos de grafos de probabilidade estendidos com aspectos relacionais ${ }^{12}$.

$\mathrm{Na}$ tentativa de unir as descrições genéricas e compactas de modelos lógicos de primeira ordem, com o tratamento da incerteza dos dados e as técnicas de aprendizado de máquina atuais, foram propostos diversos modelos nessa última década, como por exemplo os modelos de Markov relacionais (RMM) (Anderson et al., 2002) e as redes de Markov relacionais (RMN) (Taskar et al., 2002); os modelos probabilísticos relacionais (PRM) (Koller e Pfeffer, 1998; Friedman et al., 1999) e as redes bayesianas relacionais (RBN) (Jaeger, 1997); os modelos probabilísticos relacionais dinâmicos (DPRM) (Friedman et al., 1998); as redes de dependência relacionais (RDN) (Neville e Jensen, 2007); e por fim os processos decisórios de Markov relacionais (RMDP) (Guestrin et al., 2003).

A vantagem desses modelos que consideram a estrutura presente nos dados do problema está no compartilhamento ou amarração dos parâmetros durante 0 treinamento. A amarração ocorre quando parâmetros potencialmente distintos do modelo são restringidos a terem os mesmos valores. Com isso, é possível obter um modelo compacto de ricas classes de distribuições (Getoor e Taskar, 2007). Um dos benefícios diretos do compartilhamento de parâmetros é a possibilidade de realizar uma classificação coletiva, mencionada no início do Capítulo.

Essa estrutura relacional que permite o compartilhamento de parâmetros dentro do modelo está presente tanto num HMM, que devido à propriedade de Markov amarra os parâmetros que determinam a transição de um estado atual para o estado seguinte do sistema independentemente do instante considerado (Getoor e Taskar, 2007); quanto numa RMN, cuja amarração

\footnotetext{
${ }^{12}$ A outra perspectiva é a da Programação Lógica Indutiva (Inductive Logic Programming - ILP) ou Multi-Relational Data Mining, que é uma área entre o aprendizado de máquina e a programação lógica, onde é proposta uma extensão para lidar com probabilidades.
} 
está na aplicação de templates de cliques para a instanciação de redes de Markov.

A semântica de muitos dos sistemas de SRL é dada em termos de um modelo de grafo instanciado. Assim, os modelos tratados a seguir empregam a lógica relacional apenas na especificação de templates para instanciar grafos de distribuições de probabilidade proposicionais. Apesar de não contemplarem todos os desafios propostos pelos pesquisadores da área de SRL, ainda assim esses modelos apresentam um melhor desempenho por considerarem no aprendizado dos parâmetros ou da estrutura, mais dependências entre as variáveis.

As diferenças entre o aprendizado estatístico e o estatístico relacional serão detalhadas nas seções seguintes, considerando especificamente os modelos de redes de Markov.

\subsubsection{Exemplo da descrição relacional no domínio de imagens}

No domínio das imagens, um modelo proposicional pode ser especificado por uma tabela única (Tabela 3), onde as instâncias da entidade pixel são representadas por um conjunto ou vetor de valores (características). Note que ao especificar uma única tabela, qualquer entidade representada deve possuir a mesma estrutura da entidade pixel.

Na Tabela 3, Pixel $n$ é uma variável não observável e corresponde a uma posição no reticulado definido pela imagem. As características ou variáveis observáveis desta posição podem ser quaisquer quantidades calculadas com base nos valores de intensidade dos pixels. Exemplos de características são a intensidade do pixel correspondente, uma das intensidades no plano RGB, ou mesmo o resultado da aplicação do gradiente na imagem, e assim por diante. 
Tabela 3. Modelo proposicional para classificação de pixels de uma imagem.

\begin{tabular}{|c|c|c|c|}
\hline $\begin{array}{c}\text { variáveis não } \\
\text { observáveis }\end{array}$ & característica 1 & $\ldots$ & característica m \\
\hline pixel 1 & $\mathrm{x}_{1,1}$ & $\ldots$ & $\mathrm{x}_{1, \mathrm{~m}}$ \\
\hline$\ldots$ & $\ldots$ & $\ldots$ & $\ldots$ \\
\hline pixel $\mathbf{n}$ & $\mathrm{x}_{\mathrm{n}, 1}$ & $\ldots$ & $\mathrm{x}_{\mathrm{n}, \mathrm{m}}$ \\
\hline
\end{tabular}

Se forem consideradas as dependências espaciais numa imagem, onde pixels próximos uns aos outros tendem a possuir o mesmo rótulo (pela continuidade presente nas imagens), deve ser incluída no modelo outra tabela, onde cada instância aparece relacionada aos seus vizinhos. A quantidade máxima de vizinhos por pixel é determinada pela quantidade de colunas da tabela, onde cada elemento é uma referência à tabela inicial. A Tabela 4 mostra um exemplo para o caso de vizinhança de primeira ordem.

Tabela 4. Modelo relacional para um imagem considerando quatro pixels na vizinhança.

\begin{tabular}{|c|c|c|c|c|}
\hline $\begin{array}{c}\text { variáveis não } \\
\text { observáveis }\end{array}$ & $\begin{array}{l}\text { vizinho } \\
\text { superior }\end{array}$ & $\begin{array}{l}\text { vizinho } \\
\text { inferior }\end{array}$ & $\begin{array}{l}\text { vizinho } \\
\text { esquerdo }\end{array}$ & $\begin{array}{l}\text { vizinho } \\
\text { direito }\end{array}$ \\
\hline pixel 1 & - & $\begin{array}{c}\text { pixel } \\
(\text { largura+1) }\end{array}$ & - & pixel 2 \\
\hline pixel 2 & - & $\begin{array}{c}\text { pixel } \\
\text { (largura+2) }\end{array}$ & pixel 1 & pixel 3 \\
\hline
\end{tabular}

Ressalta-se que no contexto de processamento de imagens, essa é a abordagem tradicional ao usar redes de Markov. Mas a formalização relacional permite que sejam consideradas outras entidades e dependências espaciais mais flexíveis entre entidades diferentes na forma de um banco de dados. 


\subsection{Redes de Markov}

A exploração da dualidade entre as distribuições de probabilidade e a estrutura de grafos, com o intuito de produzir um modelo capaz de explicitar as dependências entre as variáveis aleatórias do problema, surgiu independentemente dentro de diferentes comunidades de pesquisa. Na área de inteligência artificial, Pearl (1988) procurou formalizar o emprego de grafos para representar a estrutura dos modelos probabilísticos buscando um paralelo com o raciocínio humano, popularizando o emprego da teoria da probabilidade ao simplificar a representação e os cálculos de distribuições entre conjuntos de variáveis aleatórias.

Dentre os tipos de grafos associados à distribuições de probabilidade, um é de interesse particular nessa tese: os grafos não-direcionados. Modelos baseados em grafos não-direcionados, chamados de redes de Markov (MN) ou campos aleatórios de Markov (MRF), permitem a inclusão de dependências não-causais como as espaciais (VanMarcke, 1983).

Uma rede de Markov é composta por uma parte qualitativa, referente à estrutura de dependências entre as variáveis aleatórias envolvidas (grafo não-direcionado), e por outra quantitativa, que estabelece um valor de probabilidade para cada conjunto de interesse envolvendo as variáveis do grafo (os potenciais associados aos cliques). Os nós dos grafos representam as variáveis aleatórias e os arcos indicam uma dependência entre as variáveis conectadas.

Como as redes de Markov são usadas nessa tese para modelar imagens, a estrutura do grafo está associada a um reticulado retangular, onde as variáveis aleatórias encontram-se em posições eqüidistantes no espaço e apresentando dependências espaciais entre si, consistindo estas dependências na propriedade de Markov. Quanto mais vizinhos um pixel possuir, maior o grau de dependência espacial. A dependência espacial precisa ser definida artificialmente, fazendo-se necessário introduzir o conceito de vizinhança. 
Um sistema de vizinhança associado ao reticulado é uma coleção de vizinhanças, uma para cada variável do conjunto. A vizinhança de uma variável aleatória é um conjunto de posições espacialmente próximas no reticulado, centrado na posição da própria variável. A posição de uma variável não pertence à própria vizinhança, mas pertence à vizinhança de cada uma das variáveis vizinhas. Esse sistema de vizinhanças tem duas propriedades: uma estrutura simétrica circular com relação à variável que determina a vizinhança, e igual para todas as variáveis ao longo do reticulado - exceto nas bordas, que recebem um tratamento especial (Won e Gray, 2004).

A Figura 18 representa sistemas de vizinhança hierárquica de ordem um até três aplicados no processamento de imagens, onde a variável que determina a vizinhança está marcada com um 's' e seus vizinhos são mostrados em cinza.

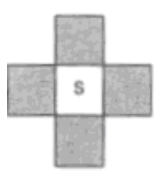

(a)

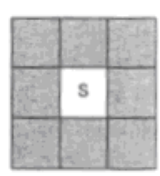

(b)

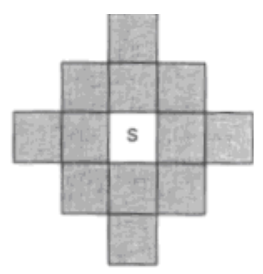

(c)

Figura 18. Vizinhança: a) primeira ordem ou vizinhança-4; b) segunda ordem ou vizinhança-8; c) terceira ordem ou vizinhança-12 (extraído de Won e Gray, 2004).

\subsubsection{Campos aleatórios de Markov (MRF)}

Os MRFs, no contexto de processamento de imagens, foram introduzidos por Geman e Geman (1984). Desde então, têm sido muito empregados na literatura. O objetivo de se representar imagens com um modelo de probabilidade é tanto o de tratar o ruído presente na aquisição das imagens, quanto o de incluir dependências espaciais entre as variáveis aleatórias do reticulado, fazendo com que seja possível definir propriedades locais (ou de contexto), como continuidade na classificação das variáveis. No entanto, 
devido à complexidade da inferência e da estimação de parâmetros em modelos que consideram uma ampla vizinha, apenas relações espaciais locais de ordem um ou dois costumam ser incorporadas no modelo.

Considere um conjunto de variáveis aleatórias discretas $\mathbf{V}=\mathbf{X} \cup \mathbf{Y}$. Ainda, $\mathbf{v}$ é uma atribuição de valores às variáveis de $\mathbf{V}$.

Definição $3.1^{13}$ (Li, 1995): Uma família de variáveis aleatórias $\mathbf{V}=$ $\left\{V_{1}, V_{2}, \ldots, V_{n}\right\}$ e uma atribuição de valor $\mathbf{v}$ a esse conjunto, dispostas num reticulado indexado por um conjunto $S=\{1,2, \ldots, i, \ldots, n\}$, formam um MRF com relação ao conjunto de vizinhança $N=\left\{N_{1}, N_{2}, \ldots, N_{i}, \ldots, N_{n}\right\}$ se:

- $\mathrm{P}(\mathbf{v})>0$ (positividade), para qualquer $\mathbf{v} \in \operatorname{Dom}(\mathbf{V})$.

- $\mathrm{P}\left(\mathbf{V}_{\mathbf{i}} \mid \mathbf{V}_{\mathbf{S}-\{i\}}\right)=\mathrm{P}\left(\mathbf{V}_{\mathbf{i}} \mid \mathbf{V}_{\mathbf{N i}}\right)$ (propriedade de Markov)

Com esta definição, a parte qualitativa do modelo de redes de Markov está definido, faltando apenas a parte quantitativa. Para isso, é necessária a definição de clique.

Dado um grafo $G$, um clique é um conjunto de nós $V_{c}$ em $G$, tal que cada $V_{i}$, $\ldots, \mathrm{V}_{\mathrm{j}} \in \mathbf{V}_{\mathrm{c}}$ estão conectados dois a dois por um arco em $\mathrm{G}$. Um nó sozinho também é considerado clique. Os cliques de duas ou mais variáveis estão associados a um subconjunto da vizinhança considerada. A Figura 19 mostra os dez tipos de cliques existentes num sistema de vizinhanças de segunda ordem, sendo que alguns cliques são usados mais de uma vez para cada variável no modelo - por exemplo, o clique que associa a variável central com a variável à sua direita é o mesmo que associa a variável central com a da sua esquerda, por isso a propriedade de simetria mencionada na definição de vizinhança.

\footnotetext{
${ }^{13}$ Todas as definições foram alteradas para manter uma notação uniforme ao longo do texto.
} 


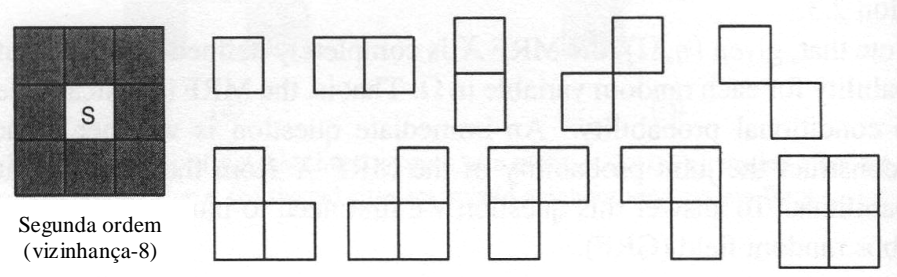

Figura 19. Conjunto de cliques possíveis para sistema de vizinhança de segunda ordem (traduzido de Won e Gray, 2004).

Um clique agrupa o conjunto de variáveis, mas é a função potencial associada a ele que dá a probabilidade de cada combinação dos valores das variáveis envolvidas. Portanto, a função potencial quantifica a interação ou dependência entre os valores atribuídos ao conjunto de variáveis presentes no clique.

Definição 3.2 (Getoor e Taskar, 2007): Seja $G=(V, E)$ um grafo nãodirecionado com um conjunto de cliques $\mathrm{C}(\mathrm{G})$. Cada clique $c \in C(G)$ é associado a um conjunto de nós $\mathbf{V}_{c}$ e a um potencial $\phi_{c}\left(\mathbf{V}_{c}\right)$, que é uma função não-negativa definida no domínio de $\mathbf{V}_{\mathrm{c}}$. Seja $\Phi=\left\{\phi_{\mathrm{c}}\left(\mathbf{V}_{\mathrm{c}}\right)\right\}_{\mathrm{c}} \in \mathrm{C}(\mathrm{G}) \mathrm{O}$ conjunto de potenciais associados ao grafo. A rede de Markov $(G, \Phi)$ define a distribuição:

$P(v)=\frac{1}{Z} \prod_{c \in C(G)} \phi_{c}\left(v_{c}\right)$

onde Z é uma constante de normalização chamada função de partição:

$Z=\sum_{v_{c}^{\prime}} \prod \phi_{c}\left(v_{c}^{\prime}\right)$.

A normalização é necessária para que $\mathrm{P}(\mathbf{v})$ seja um valor de probabilidade válida, e dá flexibilidade na definição dos potenciais. No entanto, deve-se notar que a normalização é global, e é isso o que atrapalha os cálculos de probabilidade com os modelos associados a grafos não-direcionados.

Cada potencial $\phi_{c}$ é simplesmente uma tabela de valores para cada atribuição $\mathbf{v}_{\mathrm{c}}$ que define a compatibilidade entre os valores de variáveis no clique. O potencial permite acrescentar a propriedade de continuidade entre 
pixels de uma imagem, quando variáveis de mesmo rótulo apresentam um potencial maior do que variáveis de rótulos diferentes. O potencial é freqüentemente representado por uma combinação log-linear de um conjunto de características:

$\phi_{c}\left(v_{c}\right)=\exp \left\{\sum_{i} w_{i} f_{i}\left(v_{c}\right)\right\}=\exp \left\{w_{c} \cdot f_{c}\left(v_{c}\right)\right\}$

onde $w_{i}$ é o peso atribuído à característica $f_{i}\left(v_{c}\right)$ e $w_{c}$ é o vetor de pesos associado ao vetor de características $f_{c}\left(v_{c}\right)$. Dado que essa função é exponencial, mesmo que as características sejam negativas, o potencial permanecerá positivo.

Substituindo a equação 3.13 no logaritmo de 3.11, tem-se:

$\log P(v)=\sum_{c \in C(G)} w_{c} \cdot f_{c}\left(v_{c}\right)-\log Z$

Até aqui não foi feita uma diferenciação entre as variáveis observáveis e as não-observáveis no modelo. A Figura 20 exemplifica um modelo de MRFs separando a representação das variáveis não-observáveis $\mathbf{Y}$ como círculos brancos e variáveis observáveis $\mathbf{X}$ como círculos em negrito.

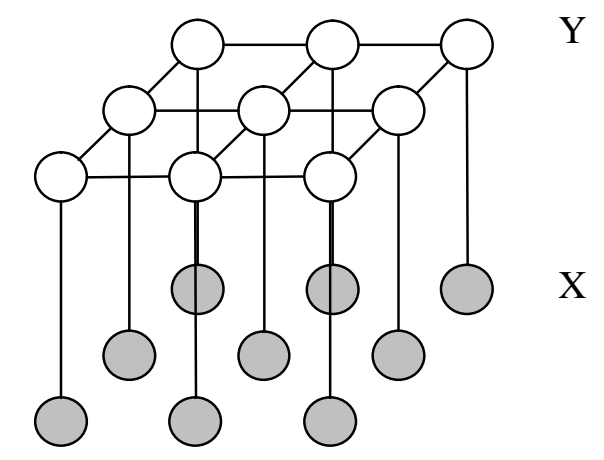

Figura 20. MRFs no contexto de processamento de imagens.

Normalmente, é empregado nesses modelos o campo aleatório sobre as variáveis não-observáveis do rótulo, permitindo a obtenção de padrões mais contínuos na classificação final (Kumar e Hebert, 2003). As variáveis 
observáveis, que representam a intensidade ou cor de cada pixel, são consideradas independentes umas das outras quando condicionadas aos respectivos rótulos. Assim, a distribuição das variáveis observáveis dadas as ocultas pode ser decomposta segundo o modelo gerativo

$P(\mathbf{X} \mid \mathbf{Y})=\Pi_{i} P\left(X_{i} \mid Y_{i}\right)$

simplificando a obtenção de $\mathrm{P}(\mathbf{X} \mid \mathbf{Y})$.

Essa simplificação é necessária porque os MRFs especificam uma distribuição conjunta de $\mathbf{Y}$ e $\mathbf{X}$, e a quantidade de combinações envolvidas entre observações (valores de $\mathbf{X}$ ) e rótulos (valores de $\mathbf{Y}$ ) tornaria o modelo intratável computacionalmente. Por causa disso, os potenciais que associam duas ou mais das variáveis $\mathbf{Y}$ não podem considerar juntamente as variáveis de $\mathbf{X}$, ou seja, a quantificação da associação entre variáveis distintas de $\mathbf{Y}$ independe das observações serem semelhantes ou díspares.

Os MRFs foram também empregados de outras formas para tratar de processamento de imagens. No conteúdo de uma imagem, é interessante considerar tanto propriedades locais como também globais, que envolvem um conjunto grande de dependências entre variáveis aleatórias. Propriedades globais capturam dependências em escalas maiores, e são necessárias para uma classificação mais precisa dos objetos em cena (He et al., 2004).

Para contornar a dificuldade de se trabalhar com propriedades globais ou em diversas escalas, foram propostos os MRF hierárquicos (Bouman e Shapiro, 1994). A Figura 21 representa a interação entre os pixels em diferentes resoluções de uma mesma imagem. Cada pixel em um nível representa quatro no nível abaixo, permitindo assim compactar o problema e contornar as dificuldades computacionais. 


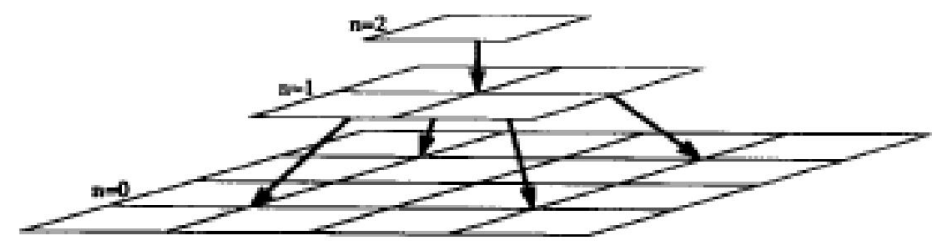

Figura 21. MRF hierárquico.

Ainda assim, os MRFs continuam considerando a independência das variáveis observadas condicionadas às variáveis de rótulo. As limitações do modelo gerativo são sempre as mesmas: muitas independências devem ser introduzidas para tornar o modelo tratável computacionalmente.

\subsubsection{Campos aleatórios condicionados (CRF)}

Como no problema da classificação com modelos gerativos, a distribuição conjunta de $\mathbf{X}$ e $\mathbf{Y}$ é usada apenas para obtenção de uma distribuição condicionada de $\mathbf{Y}$ dado $\mathbf{X}$, surgiu recentemente um modelo que representa diretamente a distribuição de interesse evitando a especificação conjunta de $\mathrm{X}$ e $\mathrm{Y}$ que impede a utilização de maiores dependências no modelo.

Os campos aleatórios condicionados (CRF) foram introduzidos por Lafferty et al. (2001), no contexto da classificação de seqüências de dados. Kumar e Hebert (2003) estenderam o modelo para dados bidimensionais, para tratar o problema da segmentação de imagens. Modelos discriminativos que utilizam probabilidades condicionadas permitem adicionar maiores dependências sem incorrer em complicações computacionais. Uma implementação da segmentação de imagens nesse sentido permite acrescentar facilmente no mesmo modelo características locais e globais, considerando as dependências entre as variáveis observadas ( $\mathrm{He}$ et al., 2004). 


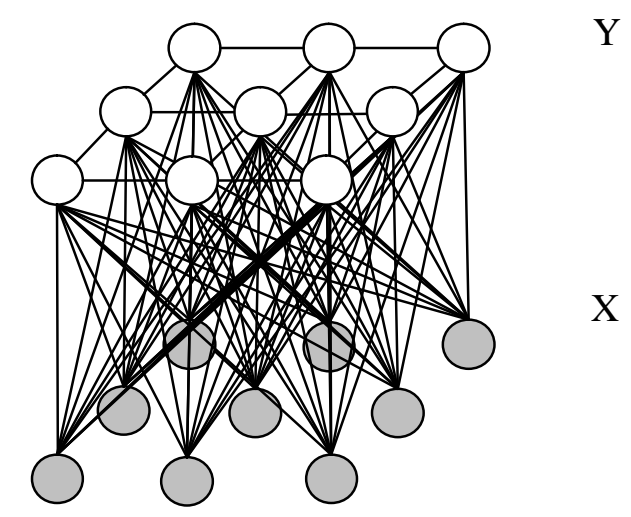

Figura 22. CRFs no contexto de processamento de imagens.

A Figura 22 mostra um CRF no contexto do processamento de imagem, onde cada variável aleatória de $\mathbf{X}$ possui um arco para cada uma das variáveis de Y. Desta maneira, é possível incluir potenciais de associação entre variáveis de $\mathbf{Y}$ que são mais elevados quando as variáveis observáveis possuem características (ou observações) semelhantes. Também é possível usar observações globais para determinar os rótulos de $\mathbf{Y}$, e assim trabalhar com diferentes escalas de observações numa imagem para o cálculo dos potenciais locais.

Definição 3.3 (Getoor e Taskar, 2007): Uma rede de Markov condicionada é uma rede de Markov $(G, \Phi)$ que define a distribuição:

$P(y \mid x)=\frac{1}{Z(x)} \prod_{c \in C(G)} \phi_{c}\left(x_{c}, y_{c}\right)$,

onde a função de partição $Z(x)$ agora depende de $\mathbf{x}$ :

$$
Z(x)=\sum_{y^{\prime}} \prod_{c \in C(G)} \phi_{c}\left(x_{c}, y_{c}^{\prime}\right) .
$$

O CRF representa uma classe de modelos probabilísticos adequados para o aprendizado relacional. Dependendo da maneira como é definido o $\mathrm{CRF}$, muitos outros modelos propostos independentemente podem ser considerados como casos especiais deste modelo (Sutton e McCallum, 2007): os campos aleatórios condicionados dinâmicos ou DCRFs (Sutton et 
al. 2007), as redes lógicas de Markov ou MLNs (Richardson e Domingos, 2006) e as RMNs. A rede de Markov relacional foi introduzida por Taskar et al. (2002) e é de particular interesse nesse trabalho. Com este modelo é possível descrever as dependências entre as variáveis aleatórias usando uma lógica relacional.

Uma rede de Markov relacional é apenas uma forma de especificar uma classe de CRFs de uma maneira compacta, ou seja, a descrição lógica utilizada permite a instanciação de um CRF proposicional, conforme definido acima.

\subsubsection{Redes de Markov relacionais (RMN)}

A descrição relacional do domínio é formada por um esquema $\varepsilon=\left\{E_{1}, E_{2}, \ldots\right.$, $\left.E_{n}\right\}$ que define um conjunto de entidades do domínio. Cada entidade possui atributos de conteúdo E.X, rótulo $E . Y$ e referência E.R. Os atributos de conteúdo são as variáveis observáveis e as de rótulo as não-observáveis. Os atributos de referência servem para associar as entidades nas tabelas relacionais e estão relacionadas aos arcos no grafo. Uma instanciação desse esquema especifica um conjunto de entidades $I(E)$ para cada tipo $E$, e os valores de todos os atributos para todas as entidades.

$I$.X, $I$.Y e $I$.R será usado para denotar os atributos de conteúdo, rótulo e referência da instanciação, respectivamente, e $I$.x, $I$.y e $I$.r os valores destes atributos. O componente $I$.r é chamado de esqueleto da instanciação ou grafo da instanciação, e especifica o conjunto de entidades ou nós e os atributos de referência ou arcos, mas não os seus valores (Taskar et al., 2007).

Uma RMN especifica os cliques e os potenciais entre os atributos das entidades relacionadas num nível de template. Assim, um único modelo proporciona uma distribuição de probabilidade coerente para qualquer coleção de instâncias do esquema. 
Definição 3.4 (Taskar et al., 2007): Um template de clique relacional $T=$ $(\mathbf{F}, \mathbf{W}, \mathbf{S})$ consiste de três componentes:

- $\mathbf{F}=\left\{F_{i}\right\}-$ um conjunto de instâncias de entidades, onde cada instância $F_{i}$ é do tipo $E\left(F_{i}\right)$.

- $\mathbf{W}(\mathbf{F} \cdot \mathbf{R})$ - uma fórmula booleana usando condições da forma $F_{\mathrm{i}} \cdot R_{\mathrm{j}}=$ $F_{k} \cdot R_{1}$.

- F.S $\subseteq$ F.X $\cup \mathbf{F} . \mathbf{Y}$ - um subconjunto selecionado de atributos de conteúdo e rótulos em $\mathbf{F}$.

Como exemplo no domínio das imagens, poderia ser definido um template de clique que considera: F, como um conjunto formado por dois pixels; $\mathbf{W}$, como uma fórmula booleana que é verdade quando o primeiro pixel pertence à vizinhança do segundo (e por definição, o segundo pertence à vizinhança do primeiro); F.S, é a seleção dos atributos de rótulo dos pixels envolvidos. Esse template seria aplicado como uma busca num banco de dados relacional a todos os pixels, para cada combinação possível de um pixel com seus vizinhos.

Definição 3.5 (Getoor e Taskar, 2007): Uma RMN M $=(T, \Phi)$ especifica um conjunto de templates de clique $T$ e os potenciais correspondentes $\Phi=\left\{\phi_{c}\right\}_{C}$ $\in T$ para definir uma distribuição condicionada:

$$
P(\mathrm{I} . y \mid \mathrm{I} . x, \mathrm{I} . r)=\frac{1}{Z(\mathrm{I} . x, \mathrm{I} . r)} \prod_{C \in T} \prod_{c \in C(\mathrm{I})} \phi_{C}\left(I . x_{C}, I . y_{C}\right),
$$

onde $Z(I . x, I . r)$ é a função de partição que normaliza a distribuição:

$$
Z(\mathrm{I} . x, \mathrm{I} . r)=\sum_{\mathrm{I} . y^{\prime}} \prod_{C \in T} \prod_{c \in C(\mathrm{I})} \phi_{C}\left(\mathrm{I} . x_{c}, \mathrm{I} . y_{c}^{\prime}\right) \text {. }
$$

O aprendizado dos parâmetros (que consiste da determinação dos pesos $w_{i}$ das características usadas na definição dos potenciais) e a inferência com os modelos de RMN e CRF usam os mesmos algoritmos. 


\subsubsection{Aprendizado dos parâmetros do modelo de CRF}

Serão apresentados dois algoritmos para o aprendizado de parâmetros: a maximização da verossimilhança condicionada, que necessita realizar inferências no modelo durante o aprendizado; e a maximização da pseudoverossimilhança, um método aproximado que não necessita realizar inferências no modelo.

\subsubsection{Maximização da verossimilhança condicionada}

O aprendizado dos parâmetros $\boldsymbol{w}$ do modelo é feito pelo estimador de máxima logaritmo da verossimilhança (MLL) dos rótulos $\mathbf{y}^{(i)}$ dadas as observações $\mathbf{x}^{(i)}$, de um conjunto de treinamento $D=\left\{\mathbf{x}^{(i)}, \mathbf{y}^{(i)}\right\}_{i=1}^{m}$, onde $\mathbf{x}^{(i)}=\{$ $\left.x_{1}{ }^{i}, \ldots, x_{n}{ }^{i}\right\}$ e $y^{(i)}=\left\{y_{1}{ }^{i}, \ldots, y_{n}{ }^{i}\right\}$.

$$
\hat{w}=\arg _{M A X} L L(w, D)=\sum_{i=1}^{m} \ln P\left(\mathbf{y}^{(i)} \mid \mathbf{x}^{(i)}, w\right)
$$

O aprendizado relacional supervisionado de um CRF é bastante similar ao caso "plano" de uma MN. A diferença está nas dependências entre os dados de treinamento: no caso "plano", a função de otimização considera a soma do logaritmo da verossimilhança em todos os exemplos do conjunto de treinamento. Já no caso relacional, todos os exemplos são uma instância apenas.

$$
\hat{w}=\arg _{M A X} L L(w, D)=\ln P(I . y \mid I . x, I . r, w)
$$

Portanto, existe uma flexibilidade na inclusão de dependências entre os exemplos do conjunto de treinamento. No caso do processamento de imagens, por exemplo, os pixels de uma mesma imagem podem apresentar as dependências espaciais, como visto acima, mas uma imagem pode ser independente das outras imagens do conjunto. Computacionalmente, ao incluir todos os exemplos numa mesma instância, a normalização envolve o cálculo do número exponencial de atribuições a todos os rótulos em todos os exemplos ao mesmo tempo, enquanto que no caso plano, essa 
normalização se decompõe no produto de probabilidades de cada exemplo (já que a função maximizada na verdade é o logaritmo da verossimilhança).

Para evitar o overfitting, pode ser empregada uma penalização na verossimilhança para valores de pesos muito altos. Conceitualmente é o mesmo que um estimador máximo a posteriori (MAP) dos pesos:

$\hat{w}=\arg _{\text {MAX }} L L(w, D)=\ln P(I . y \mid I . x, I . r, w)+\ln . P(w)$

onde $P\left(w_{i}\right)=\frac{1}{\sqrt{2 \pi \sigma^{2}}} \cdot e^{\left(-\frac{w_{i}^{2}}{2 \sigma^{2}}\right)}$, considerando os parâmetros do modelo independentes um do outro. Assim cada peso é regido por uma distribuição uniforme de média zero e desvio padrão igual à $\sigma$.

O aprendizado dos pesos das características no modelo relacional pode ser tanto com o estimador ML quanto com o MAP. A função $L(w, D)$ é côncava, por causa da convexidade de funções da forma $\mathrm{g}(\mathrm{x})=\log \Sigma_{\mathrm{i}} \exp \mathrm{x}_{\mathrm{i}}$. Essa propriedade é de extrema importância na estimação dos parâmetros, porque significa que todo ponto de ótimo local é também um ótimo global. Com o acréscimo do regulador, é assegurado que $L$ é estritamente côncava - o que implica que existe apenas um ótimo global (Sutton e McCallum, 2007).

Para a otimização dessa função, calcula-se o gradiente da verossimilhança e iguala-o a zero. O gradiente é dado por:

$\nabla L(w, D)=f(I . y, I . x, I . r)-E_{P_{w}}[f(I . Y, I . x, I . r)]-\frac{w}{\sigma^{2}}$

onde $E_{P_{W}}[f(I . Y, I . x, I . r)]=\sum_{I . y^{\prime}} f\left(I . y^{\prime}, I . x, I . r\right) P_{W}\left(I . y^{\prime} \mid I . x, I . r\right)$.

O gradiente consiste da contagem das características empíricas $f(I . y, I . x, I . r)$ menos a contagem das características esperadas $E_{P_{w}}[f(I . Y, I . x, I . r)]$ e o termo de uniformidade devido à distribuição a priori. Para calcular a contagem esperada é necessário realizar inferências sobre a rede de Markov instanciada. 
O método mais simples de otimização de $L$ é pela escolha da direção mais inclinada do gradiente, mas são necessárias muitas iterações para ser um algoritmo prático. Usando o método de Newton, a convergência é muito mais rápida por considerar a curvatura, ou melhor, a derivada de segunda ordem da verossimilhança. No entanto, nestes casos é necessário calcular a matriz de todas as derivadas de segunda ordem, cujo tamanho é quadrático segundo o número de parâmetros (Sutton e McCallum, 2007).

Técnicas recentes de otimização fazem uso de informações de segunda ordem aproximadas. Podem ser exemplificados o método quasi-Newton chamado de BFGS (Broyden-Fletcher-Goldfarb-Shanno), que calcula uma aproximação do Hessiano apenas da primeira derivada da função objetivo; L-BFGS (limited-memory BFGS) e o gradiente conjugado.

\subsubsection{Pseudo-verossimilhança}

Uma alternativa para evitar o emprego de inferências sobre o modelo durante $\mathrm{O}$ aprendizado é chamada de pseudo-verossimilhança. É uma técnica que aproxima o cálculo da verossimilhança segundo a seguinte equação (Besag, 1977):

$L(w, D)=P(y \mid x, w) \approx \prod_{i \in S} P\left(y_{i} \mid y_{N_{i}}, x, w\right)$

ou $L L(w, D)=\ln P(y \mid x, w) \approx \sum_{i \in S} P\left(y_{i} \mid y_{N_{i}}, x, w\right)$

Estudos empíricos apontam para os bons resultados alcançados com essa técnica aproximada (Korč e Förstner, 2008), já que é computacionalmente custoso o cálculo exato da verossimilhança. Devido à aproximação, a função deixa de ser côncava e são necessários parâmetros iniciais próximos do máximo global para que o resultado final seja satisfatório.

\subsubsection{Inferência}

Existem algoritmos para inferências exatas em modelos de grafos de probabilidade que consideram uma estrutura em árvore. Inferência em 
grafos densamente conectados - o caso de muitos modelos relacionais exige algoritmos de inferência aproximada. No entanto, esses algoritmos servem tanto para grafos de modelos planos quanto relacionais. Taskar et al. (2002) propõe a utilização do belief propagation (Pearl, 1988; Yedidia et al., 2000) para inferência em RMNs.

\subsubsection{Loopy belief propagation}

O algoritmo belief propagation (Pearl, 1988) é equivalente a um caso especial do algoritmo sum-product, que será descrito a seguir (Bishop, 2007).

A probabilidade marginal da variável $Y_{i}$ é obtida pela somatória da distribuição conjunta sobre todas as variáveis exceto $Y_{i}$

$$
P\left(Y_{i}\right)=\sum_{\mathbf{Y} \backslash Y_{i}} P(\mathbf{Y})
$$

onde $Y Y_{i}$ denota o conjunto de variáveis $Y$ omitindo-se a variável $Y_{i}$.

Considerando a estrutura de um grafo de fatores ${ }^{14}$, a probabilidade conjunta pode ser escrita por

$$
P(\mathbf{Y})=\prod_{s \in n e\left(Y_{i}\right)} F_{s}\left(Y_{i}, Y_{s}\right)
$$

onde ne $\left(\mathrm{Y}_{\mathrm{i}}\right)$ denota o conjunto de nós de fatores vizinhos a $\mathrm{Y}_{\mathrm{i}} ; \mathbf{Y}_{\mathrm{s}}$ denota o conjunto de todas as variáveis na sub-árvore conectada ao nó de variável $Y_{i}$ por meio do fator $f_{s}$; e $F_{s}\left(Y_{i}, Y_{s}\right)$ representa o produto de todos os fatores no grupo associado com o fator $f_{s}$ (Figura 23).

Substituindo 3.27 na 3.26 , tem-se

$$
P\left(Y_{i}\right)=\prod_{s \in n e\left(Y_{i}\right)}\left[\sum_{\mathbf{Y}_{\mathbf{s}}} F_{s}\left(Y_{i}, \mathbf{Y}_{\mathbf{s}}\right)\right]=\prod_{s \in n e\left(Y_{i}\right)} \mu_{f_{s} \rightarrow Y_{i}}\left(Y_{i}\right)
$$

\footnotetext{
${ }^{14}$ Tanto um grafo direcionado quanto um não-direcionado podem ser transformados num grafo de fatores, sobre os quais é mais simples definir algoritmos. Maiores informações sobre o grafo de fatores podem ser encontrados em Bishop (2007).
} 
onde $\mu_{f_{s} \rightarrow Y_{i}}$ pode ser visto como uma mensagem do fator $f_{s}$ para a variável $Y_{i}$.

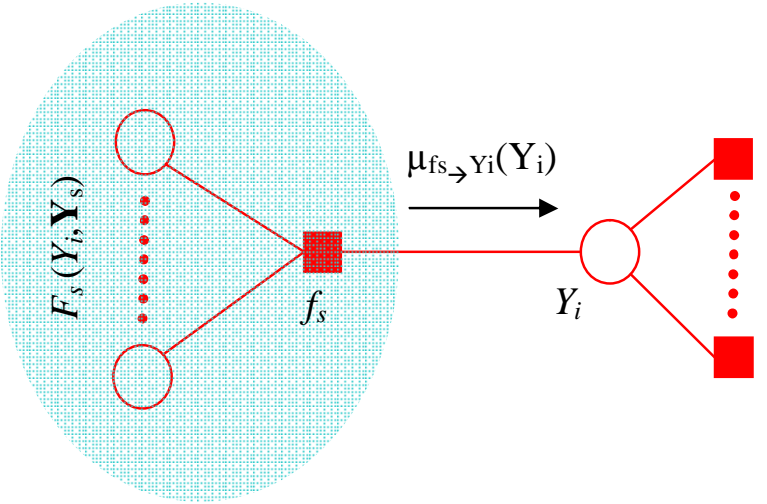

Figura 23. Um fragmento de um grafo de fatores para ilustrar o cálculo da distribuição marginal $P\left(Y_{i}\right)$ (reproduzido de Bishop, 2007).

Para calcular essa mensagem, perceba que $F_{s}\left(Y_{i}, Y_{s}\right)$ é descrito por um subgrafo de fatores e portanto pode ser fatorizado

$$
F_{s}\left(Y_{i}, \mathbf{Y}_{\mathbf{s}}\right)=f_{s}\left(Y_{i}, Y_{1}, \ldots, Y_{M}\right) \prod_{m \in n e\left(f_{s}\right) \backslash Y_{i}}\left[\sum_{Y_{s m}} G_{m}\left(Y_{m}, \mathbf{Y}_{\mathbf{s m}}\right)\right]
$$

onde $\mathrm{Y}_{1}, \ldots, \mathrm{Y}_{\mathrm{M}}$ denotam as variáveis associadas ao fator $f_{s}$. Então

$$
\begin{aligned}
& \mu_{f_{s} \rightarrow Y_{i}}\left(Y_{i}\right)=\sum_{Y_{1}} \ldots \sum_{Y_{M}} f_{s}\left(Y_{i}, Y_{1}, \ldots, Y_{M}\right) \prod_{m \in n e\left(f_{s}\right) \backslash Y_{i}}\left[\sum_{Y_{s m}} G_{m}\left(Y_{m}, \mathbf{Y}_{\mathbf{s m}}\right)\right] \\
& \text { e } \mu_{Y_{m} \rightarrow f_{s}}\left(Y_{m}\right) \equiv \sum_{Y_{s m}} G_{m}\left(Y_{m}, \mathbf{Y}_{\mathbf{s m}}\right)
\end{aligned}
$$

onde $\mu_{Y_{m} \rightarrow f_{s}}\left(Y_{m}\right)$ é definido como uma mensagem de nós de variável para nós de fatores.

A Figura 24 ilustra o processo de cálculo da uma mensagem vindo de um nó de fator para um nó de variável. 


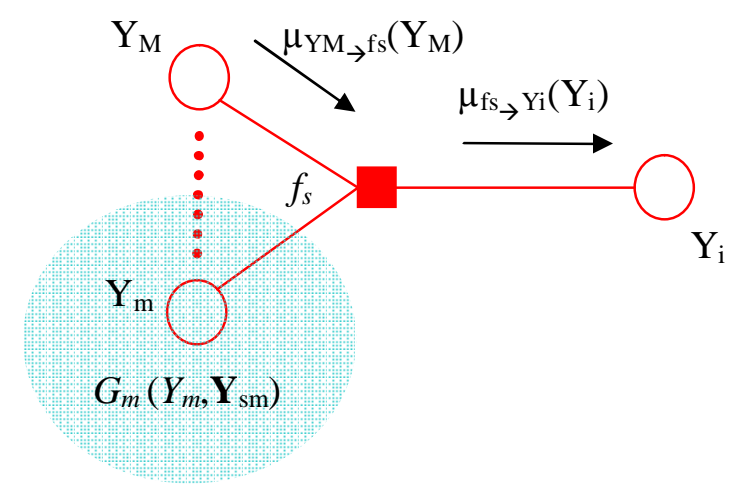

Figura 24. Ilustração da fatoração de um subgrafo associado com o nó - fator $f_{s}$ (reproduzido de Bishop, 2007).

Assim, foram definidos dois tipos de mensagens: aquelas que vão de nós de fatores para nós de variáveis $\mu_{f_{s} \rightarrow Y_{i}}$, e aquelas que vão de nós de variáveis para nós de fatores $\mu_{Y_{m} \rightarrow f_{s}}\left(Y_{m}\right)$. As mensagens passadas por meio de um arco são sempre função da variável associada com o nó da variável que o arco conecta.

A equação 3.27 diz que, para calcular a mensagem enviada por um nó de fator para um nó de variável pelo arco que os conecta, basta considerar o produto das mensagens que chegam pelos arcos que alcançam o nó de fator e multiplicar pelo fator associado ao nó, e então marginalizar sobre todas as variáveis associadas às mensagens provenientes. Assim, um nó de fator pode mandar uma mensagem para um nó de variável quando ele tiver recebido as mensagens de todos os nós de variáveis da vizinhança.

Por fim, é derivada uma expressão para calcular as mensagens dos nós de variáveis para os nós de fatores, novamente usando a fatorização do subgrafo

$$
G_{m}\left(Y_{m}, \mathbf{Y}_{s m}\right)=\prod_{l \in n e\left(Y_{m}\right) \backslash f_{s}} F_{l}\left(Y_{m}, \mathbf{Y}_{m l}\right)
$$


onde ne $\left(Y_{m}\right) \backslash f_{s}$ representa todos os vizinhos do nó $Y_{m}$ exceto o nó $f_{s}$. Cada $F_{(}\left(Y_{i}, \mathbf{Y}_{m l}\right)$ representa uma sub-árvore do grafo original. Substituindo a equação 3.28 na 3.27 tem-se

$\mu_{Y_{m i} \rightarrow f_{s}}\left(Y_{m}\right)=\prod_{l \in n e\left(Y_{m}\right) \backslash f_{s}} \mu_{f_{l} \rightarrow Y_{m}}\left(Y_{m}\right)$

Cada um dos dois tipos de mensagens pode ser calculada recursivamente em termos das outras mensagens. Para iniciar a recursão, pode-se considerar o nó $Y_{i}$ como a raiz da árvore e começar o envio de mensagens pelos nós das folhas. Da definição 3.29, se o nó da folha for um nó de variável, a mensagem enviada ao longo do seu único arco será

$$
\mu_{Y_{i} \rightarrow f}\left(Y_{i}\right)=1
$$

Da mesma forma, se o nó da folha for um nó de fator, a mensagem enviada terá a forma

$$
\mu_{f \rightarrow Y_{i}}\left(Y_{i}\right)=f\left(Y_{i}\right)
$$

O algoritmo sum-product pode ser obtido da seguinte maneira: escolhe-se arbitrariamente um nó qualquer como raiz. As mensagens são propagadas das folhas para a raiz, como especificado anteriormente. Neste ponto, o nó raiz terá recebido mensagens de todos os seus vizinhos, e portanto poderá enviar mensagens a todos eles. Cada um deles, por sua vez, terá recebido mensagens de cada um dos seus vizinhos também e poderão mandar mensagens para todos os seus vizinhos para além da raiz e assim por diante. Dessa maneira, as mensagens são passadas da raiz para as folhas, e terão passado por todos os arcos, nas duas direções, e todos os nós terão recebido mensagens de seus vizinhos.

O algoritmo loopy belief propagation é simplesmente a aplicação do algoritmo sum-product para um grafo contendo ciclos, por meio da definição de um agendamento (schedule) do envio de mensagens. Isso é possível porque as regras de envio de mensagens são locais. 
Apesar de não haver garantias de convergência, na prática, esse algoritmo é amplamente utilizado e produz bons resultados.

\subsection{Considerações finais}

Neste capítulo, foi introduzido o modelo de campos aleatórios condicionados ou CRFs, que será empregado na implementação do mapeamento semântico. O CRF é utilizado no mapeamento para a segmentação das imagens do sistema de visão que o robô adquire. A semântica envolvida no mapeamento é a classificação ou atribuição de rótulos aos pixels da imagem.

Foram apresentados também os algoritmos para aprendizado de parâmetros do modelo (pseudo-verossimilhança) e inferência aproximada (loopy belief propagation) que serão aplicados para construir a representação de mapa semântico. Foram definidos também os critérios de cobertura, precisão e exatidão para avaliar o desempenho do classificador.

Ao apresentar o problema do mapeamento semântico como uma tarefa de classificação (mesmo que num escopo reduzido onde a semântica é apenas uma atribuição de rótulos), foi possível abordar a questão dentro da teoria de aprendizado estatístico e aprendizado estatístico relacional. $O$ intuito ao longo do capítulo foi contrastar, neste contexto, as vantagens e desvantagens da utilização de um modelo mais expressivo para a classificação dos dados espaciais. 
Capítulo 4

\section{MAPEAMENTO SEMÂNTICO COM SEGMENTAÇÃO DE IMAGENS}

Mapas semânticos podem ser definidos como representações hierárquicas que estruturam o nível de informações espaciais num nível semântico. A estruturação pode ser obtida por meio da classificação ou agrupamento dos dados espaciais. Com o nível semântico, estas representações acrescentam conhecimento ao sistema para melhorar o desempenho e aumentar a autonomia dos robôs móveis.

Tanto o processo de classificação quanto o de agrupamento produzem resultados proporcionais à qualidade e precisão da descrição dos dados empregada no modelo. Portanto, uma representação de mapa semântico deve beneficiar-se da expressividade de modelos que combinam probabilidade e lógica de primeira ordem, propostos recentemente pela comunidade de aprendizado estatístico relacional (SRL).

\subsection{SRL no problema do mapeamento semântico}

A representação proposta para o mapeamento semântico neste trabalho possui dois níveis hierárquicos: um nível espacial que corresponde a uma grade de ocupação construída com um sensor de varredura laser, e um nível semântico que corresponde a imagens segmentadas. As células da grade de ocupação com alta probabilidade de estarem ocupadas são agrupadas para representar os diferentes obstáculos encontrados pelo laser. Por sua vez, cada obstáculo está associado a uma descrição visual na forma de uma imagem segmentada.

Como ambos os níveis da representação são implementados como redes de Markov, a junção dos dois níveis em um único grafo não-direcionado representa um vínculo entre a informação sensorial obtida do sistema de 
visão e o conhecimento simbólico presente nas grade de ocupação. Os vínculos podem ser definidos em uma descrição relacional do domínio. Desse modo, o mapa semântico pode ser interpretado como o conjunto de vínculos obtidos durante o mapeamento.

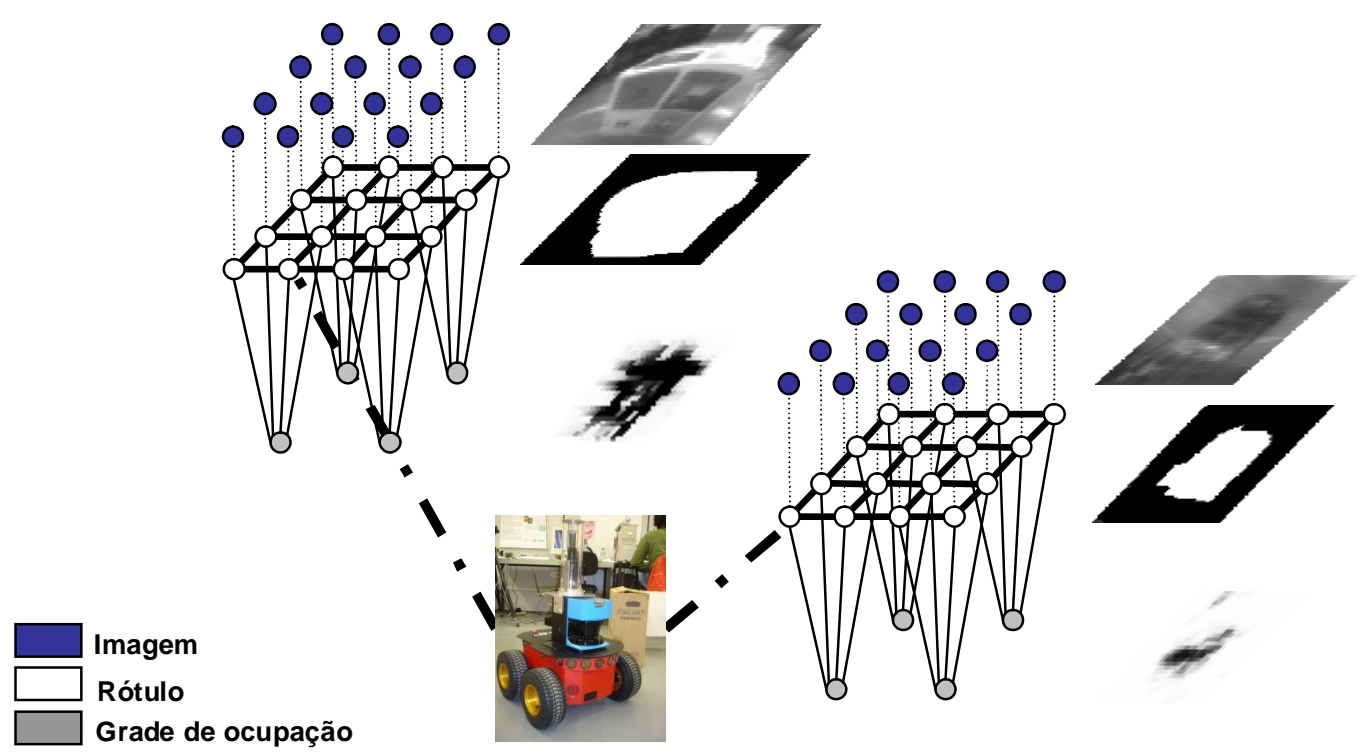

Figura 25. llustração do vínculo.

A Figura $25^{15}$ ilustra dois vínculos representados por grafos desconectados. Considere que cada grafo é formado por três planos, onde na esquerda são apresentados os nós e na direita uma visualização dos dados relacionados à observações nestes nós: o plano inferior corresponde às variáveis nãoobserváveis (células) da grade de ocupação, referentes à área atualizada por uma leitura instantânea do sensor laser; o plano intermediário representa uma região de interesse na imagem, onde estão as variáveis nãoobserváveis dos rótulos dos pixels; e o plano superior corresponde às variáveis observáveis que formam a imagem propriamente dita. No plano intermediário são consideradas dependências espaciais de primeira ordem.

\footnotetext{
15 Nesta representação foram omitidas as variáveis observáveis correspondentes ao laser, e os múltiplos arcos que conectam cada pixel observado com todas as variáveis não-observadas da imagem, para facilitar a visualização.
} 
No plano inferior a dependência é de ordem zero, o que significa que as variáveis são independentes umas das outras.

A criação do vínculo entre o processo de atualização da grade de ocupação e a segmentação da imagem determina dois tipos de entidade, células e pixels, que se relacionam. Usando um modelo de CRF para dados relacionais, é possível modelar o problema de mapeamento semântico segundo os algoritmos desenvolvidos pela comunidade de SRL.

\subsubsection{Descrição relacional do domínio}

A estrutura relacional entre as duas entidades corresponde aos arcos que ligam as células da grade aos pixels da imagem, definindo o vínculo.

As Tabela 3 e Tabela 4 apresentadas no Capítulo 3 representam a entidade pixel. A Tabela 5 representa a entidade célula. As colunas chamadas variáveis não-observáveis são os atributos de rótulo de cada uma das entidades, e as colunas características, são os atributos de conteúdo, que são as variáveis observáveis.

Tabela 5. Entidade célula da grade.

\begin{tabular}{|c|c|}
\hline Variáveis não-observáveis & Característica \\
\hline célula 1 & $\mathrm{x}_{1}$ \\
\hline$\ldots$ & $\ldots$ \\
\hline célula $\mathrm{n}$ & $\mathrm{x}_{\mathrm{n}}$ \\
\hline
\end{tabular}

A única variável observável de cada célula é a leitura do laser. Na imagem, a variável observável refere-se ao descritor aplicado sobre a imagem.

A Tabela 6 relaciona cada célula da grade com um pixel da imagem. Pode acontecer de mais de uma célula estar associada a um mesmo pixel, o que depende de vários fatores, como a forma do espelho e as resoluções da imagem e da grade. 
Tabela 6. Vínculo.

\begin{tabular}{|c|c|}
\hline Variáveis não-observáveis & Vínculo \\
\hline célula 1 & pixel 1 \\
\hline célula 2 & pixel 1 \\
\hline$\ldots$ & $\ldots$ \\
\hline célula n & pixel $\mathrm{i}$ \\
\hline
\end{tabular}

\subsubsection{Grafo da instanciação}

O grafo da instanciação refere-se à junção do grafo relacionado à imagem e ao grafo relacionado à grade. Esses arcos que conectam os dois níveis do modelo são especificados por meio da projeção das células da grade nos pixels da imagem. Nesse ponto é necessário levar em consideração o aspecto da resolução tanto da imagem quanto da grade.

Por causa da geometria do espelho, as células da grade mais próximas do robô correspondem a um conjunto de pixels maior que as células mais afastadas do robô, onde um conjunto de pixels representa mais que uma célula.

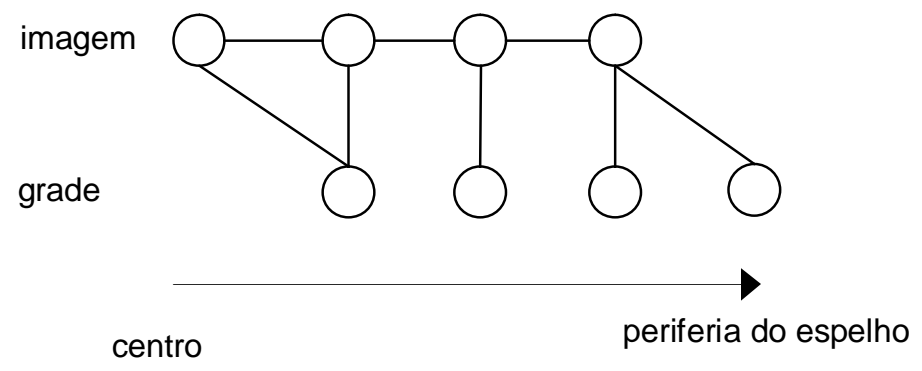

Figura 26. Vínculo entre a grade e a imagem.

Uma simplificação desse modelo consiste em utilizar variáveis aleatórias representando tanto áreas variáveis da grade de ocupação quanto conjuntos de pixels diferentes. 


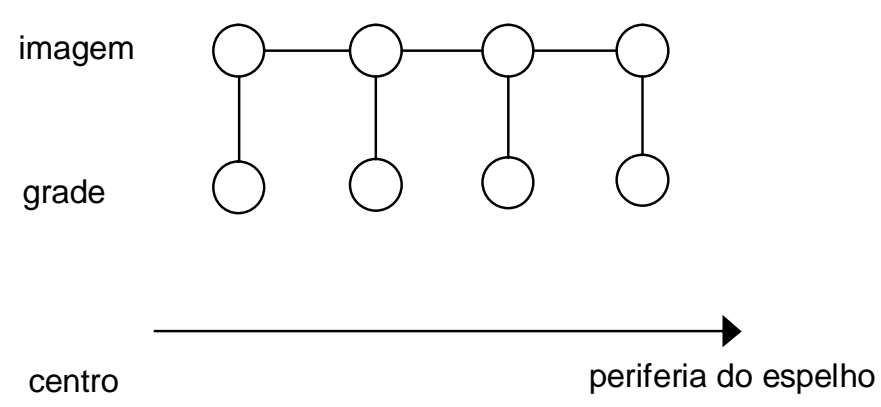

Figura 27. Modelo simplificado do vínculo.

Dessa maneira, o modelo do vínculo corresponde a um CRF em duas camadas, uma referente ao mapa e outra à imagem. Com esse modelo é possível manter os modelos de atualização da grade e de segmentação de imagens convencional, e acrescentar um potencial entre uma variável da grade e outra da imagem.

\subsubsection{Templates de cliques}

Existem quatro templates de cliques para esse modelo: dois potencias de nó, um para a imagem e outro para a grade; e dois potenciais de arco, um entre os nós da imagem e outro entre o a imagem e a grade.

Os potenciais relacionados à imagem serão definidos na seção 4.2 .5 relativa à segmentação de imagem. $O$ potencial de nó para a grade corresponde ao processo de estimação bayesiana para atualização da grade de ocupação. O potencial que une imagem e grade deve atribuir a classe obstáculo para a descrição da imagem quando a variável observável da grade indicar uma alta probabilidade de ocupação.

\subsection{Algoritmo para o mapeamento semântico}

$\mathrm{Na}$ seqüência é apresentado o algoritmo de mapeamento semântico implementado neste trabalho, onde a segmentação da imagem e a estimação da grade de ocupação são resultados de processos de inferência 
distintos. A descrição relacional nesse caso está presente apenas na construção do CRF para a segmentação da imagem, na forma de dependências espaciais entre os pixels. Na seção seguinte, são enumeradas algumas aplicações para a representação proposta de mapa semântico.

O algoritmo tem como entrada uma imagem omnidirecional, parâmetros do modelo de CRF para segmentação, os dados referentes à postura do robô $\mathrm{e}$ as distâncias obtidas com o sensor de varredura laser. A saída do algoritmo são agrupamentos das distâncias obtidas com o laser, referentes aos obstáculos encontrados, e os rótulos atribuídos aos pixels das regiões da imagem referentes aos agrupamentos calculados. O mapa semântico é construído em cinco etapas:

- Construção da grade de ocupação: as informações de distância obtidas das leituras do laser são usadas para determinar o estado de ocupação de cada célula;

- Projeção dos pontos do laser na imagem: uma transformação geométrica é aplicada para projetar a informação do laser sobre a imagem, para que se possa obter uma descrição visual dos obstáculos detectados;

- Agrupamento dos pontos do laser: um algoritmo de agrupamento de dados é aplicado sobre os pontos do laser para agrupar os pontos referentes a um mesmo obstáculo;

- Extração das descrições visuais: os resultados do agrupamento e da projeção dos pontos sobre a imagem são combinados para produzir as descrições visuais dos obstáculos;

- Segmentação da imagem: por último, cada descrição visual é segmentada para a obtenção dos pixels que representam o obstáculo dentro da região de interesse obtida;

Cada uma dessas etapas será descrita em maior detalhe nas sub-seções a seguir. 


\subsubsection{Construção da grade de ocupação}

As grades de ocupação foram propostas por Moravec e Elfes (1985) usando técnicas ad hoc, para juntar as informações de vários sensores ruidosos adquiridas em instantes de tempo diferentes. Posteriormente deram às grades um embasamento teórico a partir da teoria de probabilidade. A idéia era atualizar constantemente as estimativas de distância para eliminar a incerteza que existe nas leituras dos sensores, principalmente dos sensores de ultra-som de baixo custo utilizados na época. Com o emprego de sensores de varredura laser, as grades de ocupação ganharam muita popularidade. Modelos para atualizar as grades com dados de visão estéreo foram propostos posteriormente (Moravec, 1996; Corrêa, 2005).

O modelo de uma grade de ocupação consiste num reticulado composto por variáveis aleatórias binárias para representar o espaço físico, indicando a probabilidade de ocupação daquela área. Formalmente, as grades são um campo aleatório markoviano de ordem zero. Isso significa que cada célula do reticulado é uma variável aleatória independente das demais. Essa hipótese é adotada para facilitar a estimação do campo, mas impede a representação da interação entre células vizinhas.

A Figura 28 mostra o grafo relacionado à grade de ocupação. À esquerda está representada parte de uma grade de ocupação, onde os nós do grafo não estão conectados. As cores dos nós são para ilustrar a probabilidade quanto ao estado de ocupação dos mesmos. A cor branca indica que o nó ou célula está vazio; a cor preta, que a célula está ocupada; e a cor cinza indica incerteza. À direita está representada uma seqüência destas células, conectadas com o nó pontilhado que representa um dos pontos do laser, que é a variável observável. Calculando a direção de cada leitura, e o alcance em cada direção é possível montar o grafo corresponde a cada ponto, segundo a postura do robô. 

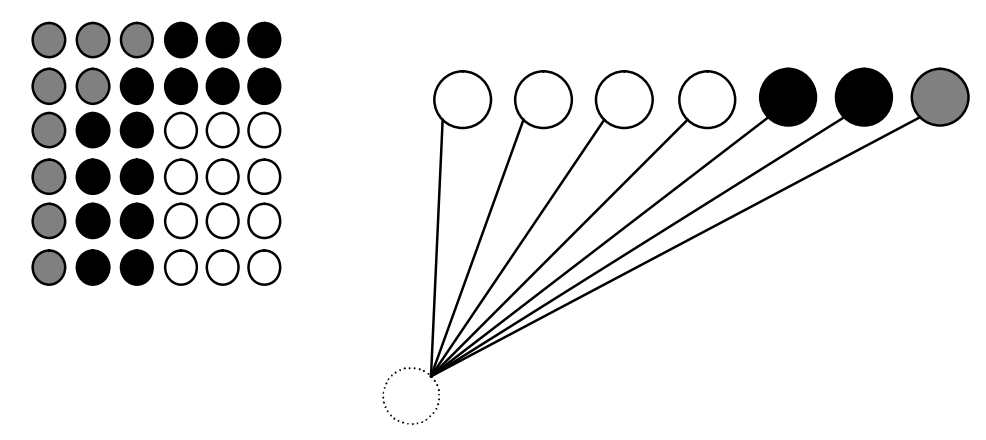

Figura 28. Grafo completo referente à grade de ocupação.

A intenção ao apresentar uma grade de ocupação dessa maneira é facilitar posteriormente a integração com a segmentação da imagem, num grafo único.

A configuração da grade é obtida por estimação bayesiana. Assim, estimase o valor da probabilidade a posteriori de uma célula condicionada às leituras sensoriais a partir de uma função densidade de probabilidade. Esta probabilidade é obtida através do teorema de Bayes na sua formulação iterativa:

$$
p\left(O C C \mid\left\{S_{t+1}\right\}\right)=\frac{p\left(\left\{S_{t+1}\right\} \mid O C C\right) \cdot P\left(O C C \mid\left\{S_{t}\right\}\right)}{p\left(\left\{S_{t+1}\right\} \mid O C C\right) \cdot P\left(O C C \mid\left\{S_{t}\right\}\right)+p\left(\left\{S_{t+1}\right\} \mid E M P\right) \cdot P\left(E M P \mid\left\{S_{t}\right\}\right)}
$$

onde OCC é mais precisamente $\mathrm{s}\left(\mathrm{C}_{\mathrm{i}}\right)=\mathrm{OCC}, \mathrm{C}_{\mathrm{i}}$ representa as células do reticulado e $\mathrm{s}\left(\mathrm{C}_{\mathrm{i}}\right)$ é a variável aleatória binária que assume os valores OCC (ocupado) ou EMP (livre).

O termo $\mathrm{P}\left(\mathrm{OCC} \mid\left\{\mathrm{S}_{\mathrm{t}}\right\}\right)$ representa a probabilidade das configurações espaciais a priori, que é o conhecimento do ambiente antes de uma nova leitura do sensor. Como a intenção é trabalhar com ambientes desconhecidos, inicialmente não se tem conhecimento algum sobre o meio, estabelecendose que $P\left(s\left(C_{i}\right)=O C C\right)=P\left(s\left(C_{i}\right)=E M P\right)=0,5$, o que significa utilizar a probabilidade de máxima entropia. A informação a priori no caso iterativo vem da grade de ocupação mais atual antes da obtenção de nova 
informação sensorial, mostrando que o resultado não depende diretamente de todo o histórico das leituras obtidos pelo sensor.

O termo $\mathrm{P}\left(\left\{\mathrm{S}_{\mathrm{t}+1}\right\} \mid \mathrm{OCC}\right)$ é chamado de modelo do sensor. $\mathrm{O}$ modelo do sensor consiste de uma função densidade de probabilidade que melhor caracterize o sistema, ou seja, uma probabilidade condicionada de como são as leituras do sensor dada uma configuração espacial do ambiente, $p(S \mid M)$ onde "S" indica uma leitura do sensor e "M", uma configuração de mundo.

\subsubsection{Projeção dos pontos do laser na imagem}

A formulação da transformação geométrica de um ponto no espaço para o plano da imagem é apresentada para o caso de um sistema de visão omnidirecional, como o que existe no robô empregado nesse trabalho.

Um sistema de visão omnidirecional, montado com uma câmera convencional e um espelho hiperbólico, possui a propriedade de centro único de projeção coincidente com o foco virtual da hipérbole (Figura 29). Esta propriedade garante que os raios incidentes no espelho passam pelo mesmo ponto $F$, onde é fixo o sistema de coordenadas. $O$ centro $C$ da câmera coincide com o foco da câmera $F$. A distância entre $F$ e $F^{\prime}$ é de $2^{*} e$, onde $e=\sqrt{a^{2}+b^{2}}$, com $a$ e $b$, parâmetros de forma do espelho hiperbólico. 


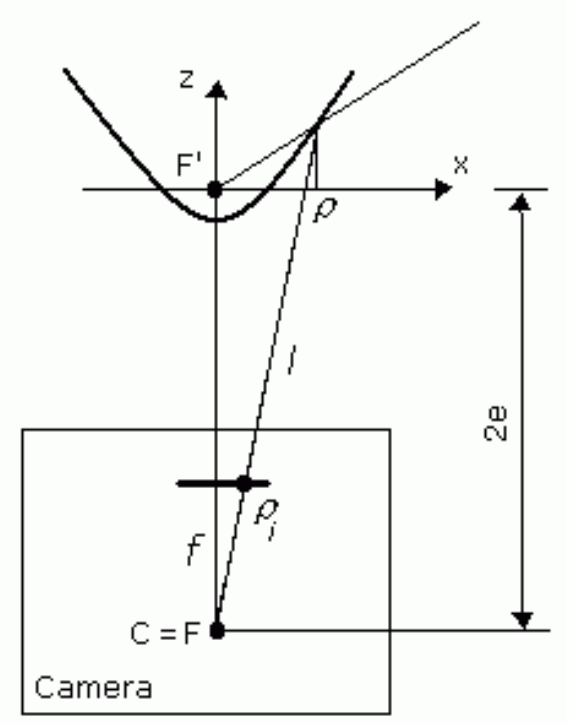

Figura 29. Sistema de projeção geométrica (extraído de Svoboda et al., 1998).

A equação que relaciona pontos na imagem com pontos no espaço é dado por (Svoboda et al., 1998):

$\rho_{j}=K \frac{1}{z_{C}} R_{C}\left(\mathfrak{J}^{-}\left(R_{M}\left(X-t_{M}\right)\right) R_{M}\left(X-t_{M}\right)-t_{C}\right)$

onde $\rho_{j}$ é um ponto na imagem; $X$ é um ponto no espaço; $R_{M}$ e $t_{M}$ são respectivamente as matrizes de rotação e o vetor de translação entre os sistemas de coordenadas global e do espelho do sistema de visão omnidirecional; $R_{C}$ e $t_{C}$ são respectivamente as matrizes de rotação e o vetor de translação entre os sistemas de coordenadas do espelho e da câmera; $K$ é a matriz com os parâmetros intrínsecos da câmera do sistema de visão; $z_{C}$ é um fator de escala; e $\mathfrak{I}^{-}($) é uma função não-linear de um vetor $v=$ $\left[\mathrm{v}_{1}, \mathrm{v}_{2}, \mathrm{v}_{3}\right]^{\top}$ :

$\mathfrak{J}^{ \pm}(v)=\frac{b^{2}\left( \pm e \cdot v_{3}+a\|v\|\right)}{b^{2} \cdot v_{3}^{2}-a^{2} \cdot v_{1}^{2}-a^{2} \cdot v_{2}^{2}}$

A equação 4.2 é aplicada para cada ponto $X$ do laser para obtenção do ponto $\rho_{j}$ na imagem omnidirecional. 
No entanto, como o mapa semântico conterá descrições visuais dos obstáculos, é mais interessante trabalhar com imagens sem as distorções provocadas pelo espelho hiperbólico. A partir das imagens omnidirecionais podem ser obtidas imagens perspectivas, por meio da definição de uma câmera virtual apontada para uma determinada região do espaço.

A Figura 30 mostra o plano de projeção perspectiva, que é ortogonal a direção escolhida. O plano é definido pelas coordenadas $f_{p}$ que pode ser vista como a distância focal da câmera virtual, $\theta$ que pode ser interpretado como o ângulo de pan e $\varphi$ que seria o ângulo de tilt.

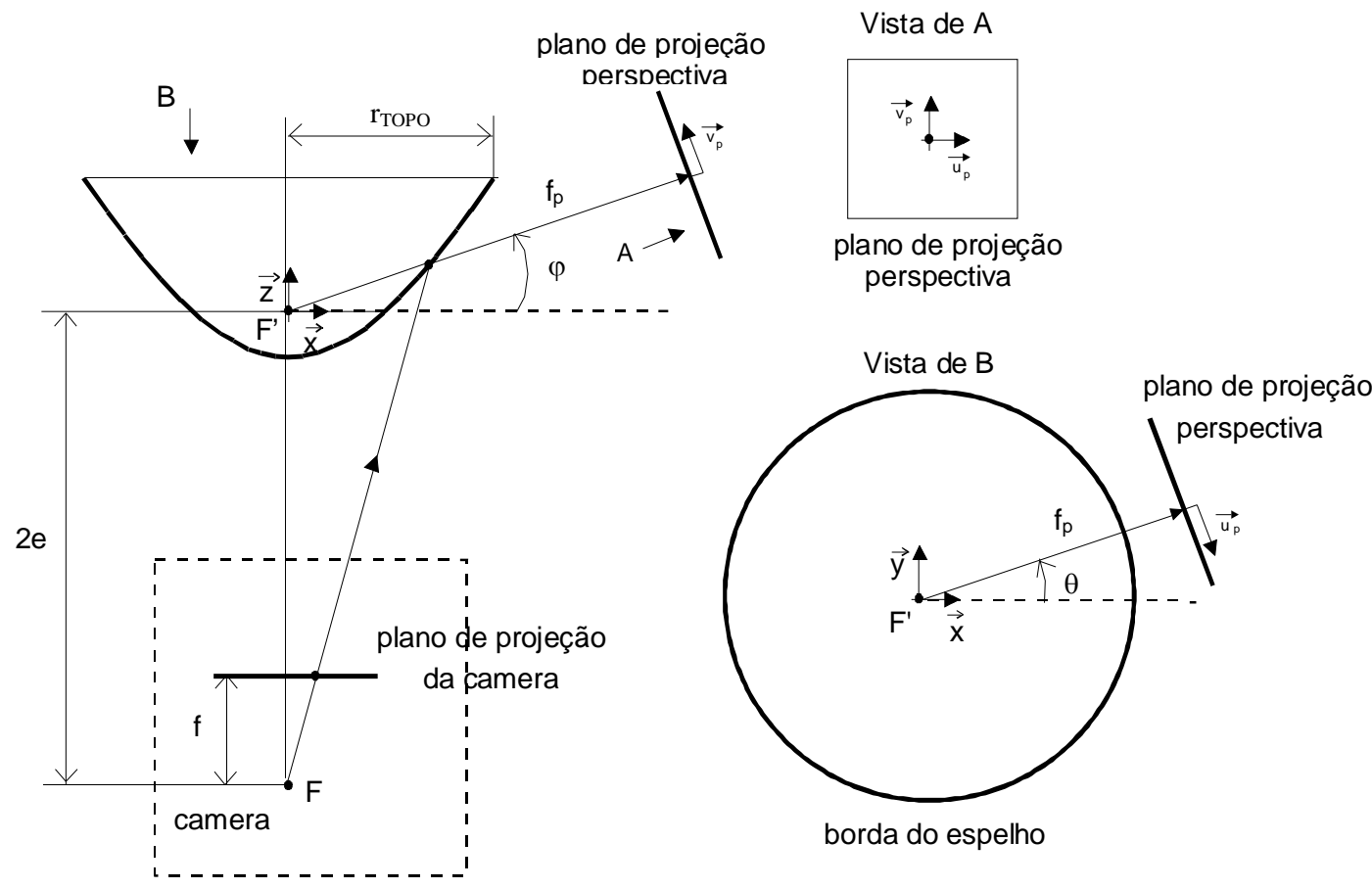

Figura 30. Construção do plano da perspectiva (extraído de Grassi Jr, 2002).

Na Figura 30 são mostradas ainda duas vistas, ao lado direito. A vista $A$ mostra o sistema de coordenadas no plano da imagem perspectiva. A vista $\mathrm{B}$ mostra uma visão de topo do espelho para indicar o ângulo $\theta$.

O ângulo $\theta$ da direção do plano é determinado a partir da direção dos obstáculos detectados pelo laser. Além dele, é necessário determinar a distância focal $f_{p}$ e o ângulo $\varphi$. Ambos são considerados fixos nesse 
trabalho: adota-se o valor de $f_{p}=170$ e $\varphi=90^{\circ}$ o que significa que a direção normal ao plano de projeção é sempre paralela ao solo e ao plano de leitura do laser.

A formulação detalhada do cálculo dos pontos da imagem perspectiva a partir de pontos da imagem omnidirecional é encontrada em Grassi Jr. (2002).

\subsubsection{Agrupamento dos pontos do laser}

O agrupamento dos pontos do laser é feito com o algoritmo K-means, detalhado no Capítulo 3. Esse algoritmo é aplicado aos pontos do laser nas coordenadas espaciais e no espaço de cores de suas projeções na imagem. $O$ número $K$ de obstáculos existentes deve ser especificado para cada ambiente.

No agrupamento, cada ponto é descrito por 5 variáveis: $\left(x_{\text {laser }}, y_{\text {laser }}\right)$ que são coordenadas segundo o sistema fixo na grade de ocupação e $\left(r_{\text {laser, }}, g_{\text {laser }}, b_{\text {laser }}\right)$ que são as cores referentes ao pixels da imagem perspectiva onde os pontos foram projetados. Caracterizando os pontos espacialmente com as coordenadas da grade e visualmente com as cores dos obstáculos a que correspondem, a descrição fica mais precisa.

\subsubsection{Descrições visuais}

Para que se possa obter uma descrição visual dos obstáculos formados pelo agrupamento descrito acima, é preciso determinar a direção do plano de projeção da imagem perspectiva que contém cada um dos obstáculos formados.

A direção do plano é função dos pontos extremos de cada conjunto. Para encontrar estes pontos é preciso calcular o ângulo $\theta_{\mathrm{i}}$ que cada ponto dentro de um mesmo conjunto forma com o robô, e armazenar o maior e o menor valor. A Figura 31 ilustra o robô numa determinada postura e os pontos do laser em verde que correspondem à posição de um obstáculo em particular. 


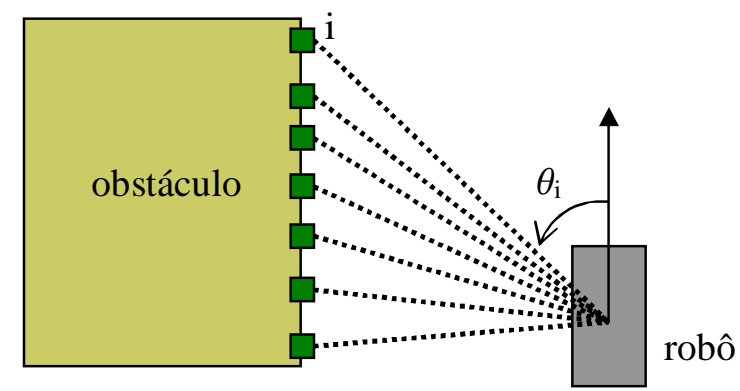

Figura 31. Cálculo da direção do plano de projeção perspectiva.

A partir destes pontos extremos, calcula-se a bissetriz do ângulo formado pela reta que une cada um deles ao robô. A bissetriz, nas coordenadas do sistema de visão, é usada como direção para criar uma imagem perspectiva a partir da imagem omnidirecional.

Então, os pontos extremos são projetados sobre a imagem perspectiva para determinar as colunas que delimitam o obstáculo. Essa região da imagem é extraída para criação da descrição visual.

Para a obtenção de uma descrição visual mais robusta, pode-se repetir esse mesmo procedimento para calcular imagens perspectivas de um mesmo obstáculo referentes às várias imagens omnidirecionais adquiridas em instantes de tempo distintos durante a navegação. As descrições visuais obtidas podem ser tanto ligeiramente diferentes umas das outras quanto representar um ponto de vista do obstáculo completamente diferente, dependendo das posições relativas entre robô e obstáculo.

A última etapa do mapeamento semântico consiste na segmentação das descrições visuais.

\subsubsection{Segmentação da imagem}

O processo de segmentação da imagem é modelado como um CRF, com dependência espacial de primeira ordem entre as variáveis nãoobserváveis. A equação 3.16 de um CRF geral é reproduzida abaixo para que a partir dela seja possível definir o modelo adotado para a segmentação: 
$P(y \mid x)=\frac{1}{Z(x)} \prod_{c \in C(G)} \phi_{c}\left(x_{c}, y_{c}\right)$

São usados no modelo dois tipos de potenciais, um para os nós e outro para os arcos do grafo. Identificando o potencial dos nós por $\phi_{c_{n}}$ e o potencial dos arcos por $\phi_{c_{e}}$, onde os sub-índices $n$ referem-se aos nós e e aos arcos.

Manipulando a equação 4.4, tem-se:

$$
P(y \mid x)=\frac{1}{Z(x)} \prod_{c_{n} \in C_{n}(G)} \phi_{c_{n}}\left(x_{c}, y_{c}\right) \prod_{c_{e} \in C_{e}(G)} \phi_{c_{e}}\left(x_{c}, y_{c_{k}}, y_{c_{j}}\right)
$$

O potencial dos nós define como as propriedades locais da imagem influenciam na determinação da classe de um pixel. O potencial dos arcos define como a classe de um pixel influencia a classe dos seus vizinhos.

Ainda, os potenciais podem ser escritos como

$$
\begin{aligned}
& \phi_{c_{n}}\left(x_{c}, y_{c}\right)=\exp \left(\sum_{i} w_{n_{i}} f_{n_{i}}\left(x_{c}, y_{c}\right)\right) \\
& \phi_{c_{e}}\left(x_{c}, y_{c_{k}}, y_{c_{j}}\right)=\exp \left(\sum_{i} w_{e_{i}} f_{e_{i}}\left(x_{c}, y_{c_{k}}, y_{c_{j}}\right)\right)
\end{aligned}
$$

onde $w_{n}$ e $w_{e}$ são os pesos associados às características $f_{n}$ e $f_{e}$, que correspondem respectivamente aos nós e arcos.

Como o modelo é um CRF, é possível acrescentar no potencial dos arcos os valores das variáveis observáveis $x_{c}$, e dessa maneira atribuir apenas classes iguais a pixels que são visualmente semelhantes.

As características dos nós e dos arcos são consideradas iguais no modelo de segmentação adotado nesse trabalho e correspondem a um vetor descritor da imagem. No entanto, para a composição dos potenciais de arco são consideradas as diferenças entre os descritores dos dois pixels envolvidos no cálculo do potencial. 
Como exemplo de descritores que podem ser usados para representar os obstáculos na imagem, foram considerados três descritores locais baseados em histogramas (Mikolajczyk e Schmid, 2005): o primeiro calcula a magnitude e a orientação do gradiente na imagem e monta um histograma da distribuição das orientações ponderadas pela magnitude (Kumar e Herbert, 2003); o segundo consiste num histograma das intensidades dos pixels, considerando o espaço RGB; e o último consiste no histograma bidimensional chamado spin images (Lazebnik et al., 2003).

O primeiro histograma das orientações do gradiente considera 14 características. O histograma é montado considerando escalas distintas na imagem: 8x8, 16×16 e 32×32 pixels. Para cada escala, são calculadas cinco características. Os três primeiros momentos do histograma criado para cada escala representa as três primeiras características. As duas últimas características são as duas orientações preponderantes no histograma. A quantidade 14 surge porque a última característica é considerando como uma subtração entre escalas diferentes, gerando apenas dois valores.

O histograma de intensidade RGB é composto por dez intervalos de intensidade para cada uma das três cores, gerando assim 30 características para descrever um conjunto de pixels.

O descritor spin image considera distribuições da intensidade dos pixels localizados à distâncias fixas do centro da janela utilizada. Portanto, é um histograma bi-dimensional composto por intervalos na intensidade e no raio dos círculos considerados. A Figura 32 mostra uma janela de $8 \times 8$ sobre a imagem. Cada cor diferente representa um raio diferente, ou seja, o lugar geométrico dos pixels que serão considerados para esta distância no histograma. A dimensão relacionada à distância busca capturar a forma dos objetos num descritor local. Para a Figura 32 existem quatro raios contendo: 4 pixels (em branco), 12 pixels (em cinza claro), 20 pixels (em cinza escuro), e 28 pixels (em preto). Considerando cada um destes conjuntos de pixels, é montado um histograma diferente da intensidade dos pixels, onde a intensidade é normalizada. 


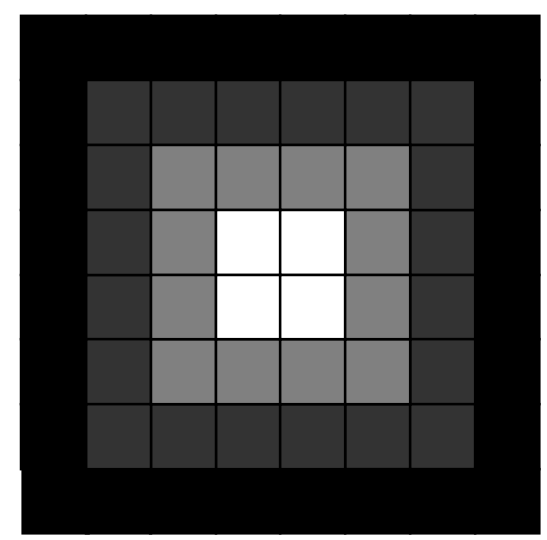

Figura 32. Os quatro intervalos na dimensão da distância a partir do centro do conjunto de pixels.

Existe também a possibilidade de usar uma expansão do descritor local, para produzir características que são combinações umas das outras. Essa expansão é calculada da seguinte forma:

$$
n=1+\left|f_{i}\right|+\frac{\left|f_{i}\right| .\left(\left|f_{i}\right|+1\right)}{2}
$$

onde $n$ é a quantidade final de características e $\left|f_{i}\right|$ a quantidade inicial.

Os parâmetros do modelo $w_{n}$ e $w_{e}$ são encontrados usando o algoritmo de aprendizado aproximado pseudo-likelihood, sobre um conjunto de treinamento, com uma atribuição aleatória de pesos iniciais para as características. Na fase de teste e durante a segmentação das descrições visuais, é empregado o loopy belief propagation.

Desse modo, o modelo de mapa semântico que considera dois processos de inferências está concluído.

\subsection{Aplicações para o mapa semântico}

A proposta do mapa semântico representando vínculo entre os obstáculos do mapa e suas descrições visuais têm como objetivo ser o bloco a partir do qual uma arquitetura possa ser construída para facilitar a realização de outras tarefas, pelo emprego das restrições que a informação semântica 
impõem sobre as informações espaciais. Abaixo são apresentados quatro problemas que poderiam ser abordados com essa proposta:

- SLAM: Nesse exemplo, a localização do robô pode contar com a informação dos vínculos estabelecidos entre os obstáculos no mapa e seus correspondentes sensoriais nas imagens, como marcos naturais no ambiente. Seria possível obter tanto uma estimativa mais qualitativa para determinar se o robô está entre ou perto de alguns obstáculos, quanto o cálculo mais preciso da sua posição considerando os centros de massa das representações na imagem e na grade. E essa localização é simultânea ao mapeamento. Estabelecido o vínculo dinâmico, o resultado é o rastreamento de objetos ou obstáculos utilizando informação visual e espacial advinda do mapa. A construção do mapa também é melhorada a partir do momento em que seja possível estimar a posição do robô, abordando assim o problema do SLAM.

- Objetos dinâmicos: É possível também lidar com a dinâmica dos obstáculos detectados e enriquecer a representação com modelos da dinâmica dessas entidades por meio de filtros de Kalman. Dessa maneira seria possível prever as suas trajetórias, bem como a movimentação no plano da imagem omnidirecional. Para isso seria necessário acrescentar atributos de posição para os obstáculos no mapa, e parâmetros associados à sua dinâmica, vinculados ao filtro de Kalman.

- Reconhecimento visual: O modelo para segmentação de imagens proposto identifica obstáculos quaisquer e não distingue uma porta de uma caixa, por exemplo. Isso acontece em primeiro lugar pela escolha do vetor de características escolhido para representar os pixels pertencentes à classe Obstáculo. Mas o modelo pode ser treinado para reconhecer e distinguir um grande número de obstáculos diferentes.

- Interface homem-máquina: Com a informação semântica disponível na representação pode-se construir uma interface de comunicação entre 
operador e robô para determinar planos ou tarefas por meio de comandos e variáveis com significados abstratos baseados nos obstáculos criados, como por exemplo: Aproxime-se da caixa1, ou passe pela porta3. Isso exigiria a criação de distinções também na grade de ocupação, que pode ser realizada como foi demonstrado por Anguelov et al. (2002), que segmentava objetos de formas primárias das grades de ocupação. A informação semântica também poderia ser empregada para restringir algoritmos de busca ou planejamento, fazendo uma busca específica entre elementos da mesma entidade.

O capítulo seguinte contém os detalhes da implementação do algoritmo para o mapeamento semântico, os testes realizados e uma análise dos resultados obtidos. 


\section{IMPLEMENTAÇÕES E RESULTADOS}

\subsection{Implementações}

A implementação do processo de mapeamento semântico envolveu o desenvolvimento de código em MATLAB, para a segmentação da imagem e para o agrupamento de pontos do laser e células da grade de ocupação; e em $\mathrm{C}_{++}$, para o controle do robô, para a construção da grade de ocupação, e para a visualização e a calibração do vínculo entre pontos do laser e células da grade com as imagens omnidirecionais e perspectivas.

\subsubsection{Grades de ocupação}

As grades de ocupação construídas para compor o mapa semântico usam apenas os dados do sensor de varredura laser, presentes no robô Pioneer P3-AT da ActivMedia Robotics, mostrado na Figura 33.

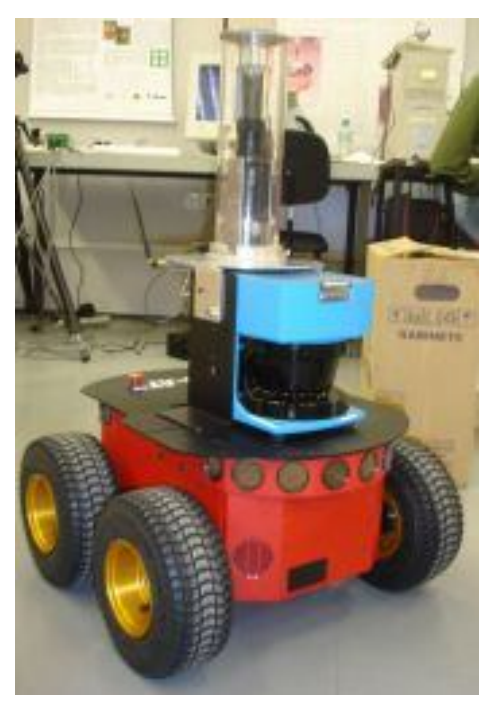

Figura 33. Robô Pioneer P3-AT. 
Utilizando o software Aria ${ }^{16}$ (Advanced Robotics Interface for Applications) numa arquitetura cliente-servidor para controlar o robô remotamente, são obtidas leituras do laser com relação a um sistema de coordenadas global, coincidente com o sistema de coordenadas do robô em sua posição inicial, no centro da grade de ocupação.

A quantidade de pontos do laser em cada leitura é variável e portanto os pontos não correspondem a ângulos fixos. As leituras produzidas em instantes de tempo consecutivos são correspondidas entre si, usando um algoritmo de localização de Markov para produzir um mapa bastante preciso. Esse algoritmo é implementado pelo software do robô.

A Figura 34 mostra um mapa do laboratório construído diretamente com as coordenadas $\left(x_{\text {laser }}, y_{\text {laser }}\right)_{G}$ dos pontos do laser, durante uma navegação do robô pelo meio. Alguns pontos presentes no interior do mapa referem-se a pessoas em movimento durante a aquisição, algumas leituras imprecisas, e objetos esbeltos, como pés de cadeiras e mesas presentes no ambiente.

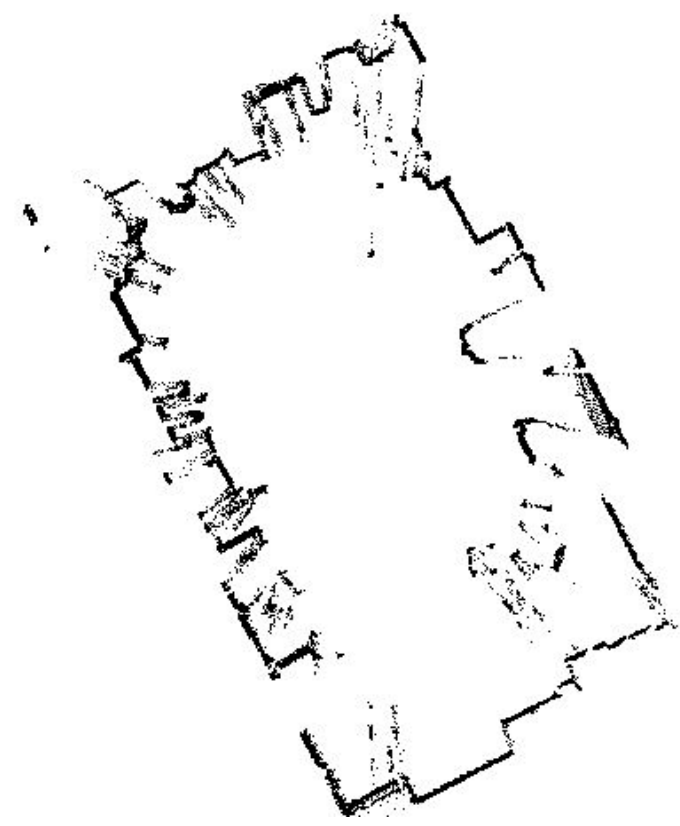

Figura 34. Mapa local construído com dados do sensor laser.

\footnotetext{
${ }^{16}$ Esse software de desenvolvimento foi adquirido com o robô.
} 
O algoritmo utilizado para a construção das grade foi implementado segundo Thrun et al. (2005). As coordenadas dos pontos obtidas pelo laser são transformadas em coordenadas relativas ao sistema de referência do robô. A postura do robô obtida do software corresponde aos valores da odometria corrigidos com as informações de um giroscópio interno. Fora esta correção, não é utilizado nenhum algoritmo para a localização do robô. A Figura 35 mostra uma grade de ocupação construída com os dados obtidos em outra navegação pelo mesmo ambiente. A qualidade do resultado obtido é adequada para a construção do nível semântico.

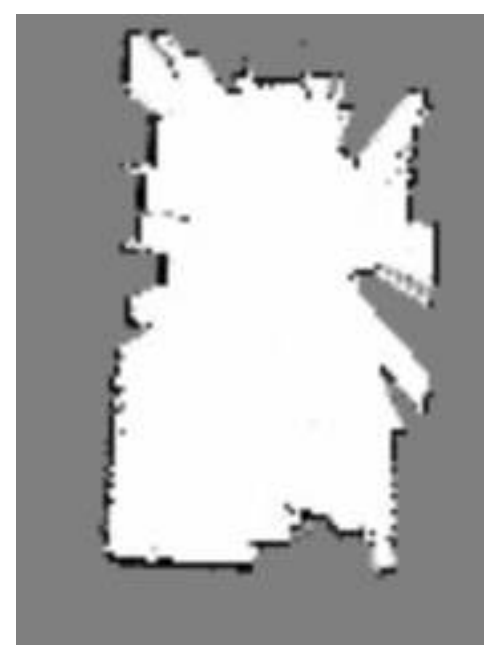

Figura 35. Grade de ocupação obtida com o laser do Pioneer.

As dimensões aproximadas do ambiente são $11 \mathrm{~m}$ de comprimento por $6 \mathrm{~m}$ de largura. A resolução da grade de ocupação é de $0,05 \mathrm{~m} /$ célula, ou seja, cada célula tem dimensões de $5 \times 5 \mathrm{~cm}$. O reticulado tem dimensões de 250 $x 250$ células.

\subsubsection{Sistema de visão omnidirecional}

Foi montado um sistema de visão omnidirecional sobre o Pioneer, formado por um espelho hiperbólico de $20 \mathrm{~mm}$ de raio e uma câmera firewire colorida. As imagens omnidirecionais adquiridas pelo sistema têm dimensão de aproximadamente $768 \times 768$ pixels. Estas imagens são enviadas ao 
computador remoto que processa os dados e controla o robô. A comunicação é feita numa arquitetura de software segundo especificação CORBA (Common Object Request Broker Architecture). Todo o processamento de imagem remoto utiliza a biblioteca OpenCV da Intel.

\subsubsection{Calibração do sistema de visão}

Para trabalhar com projeções de pontos no espaço tridimensional sobre a imagem omnidirecional é necessário calibrar o sistema de visão e o arranjo câmera-laser. O método de calibração adotado foi a projeção sobre a imagem de dois círculos de raios conhecidos: a base do suporte do sistema de visão e o diâmetro externo do espelho hiperbólico. Como o sistema de visão permite um ajuste mecânico para centralizar a imagem e alinhar o espelho com o plano da imagem, o método de calibração adotado é adequado para obter a precisão necessária para as projeções na imagem de pontos quaisquer no espaço.

$\mathrm{Na}$ Figura 36, a circunferência maior representa o espelho, e a circunferência menor representa a base do sistema, com de raio $200 \mathrm{~mm}$. Ambas estão em amarelo, assim como as duas retas que passam pelo centro da imagem. 


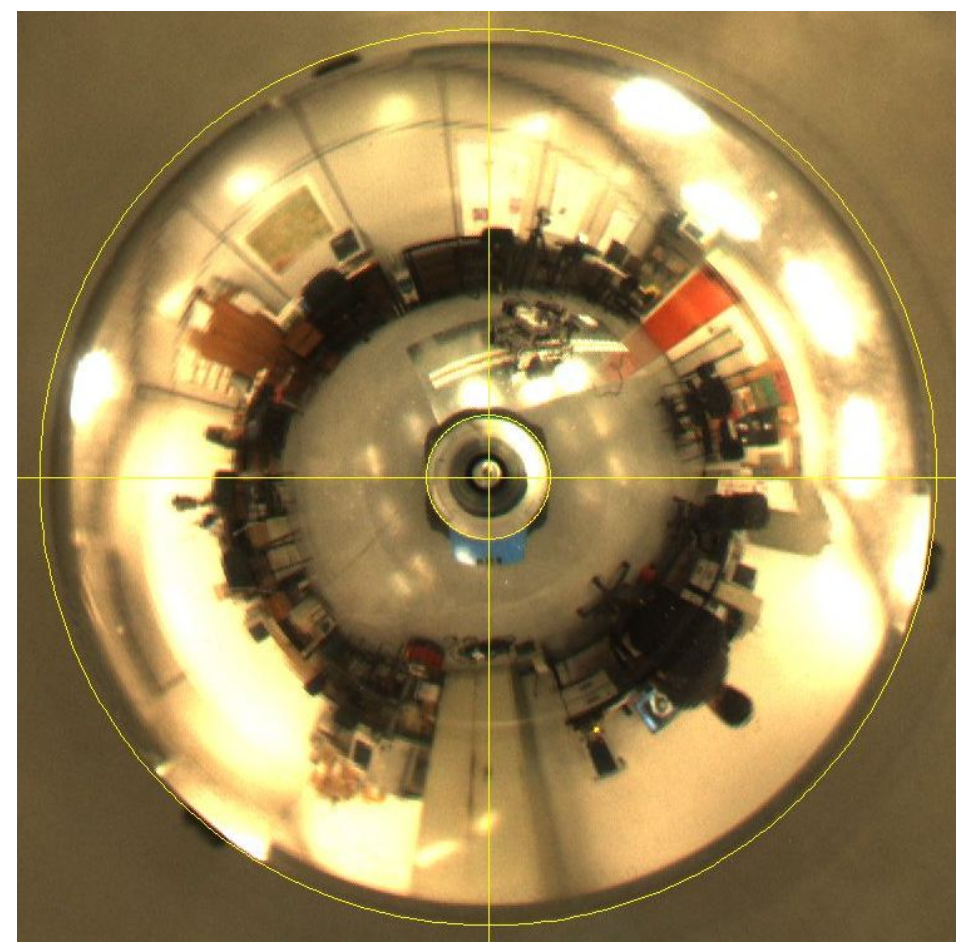

Figura 36. Padrão de calibração do sistema de visão omnidirecional.

Os parâmetros considerados na calibração foram: as coordenadas do centro da imagem, a distância focal, o tamanho dos pixels no CCD da câmera, e as alturas com relação ao solo do sistema de visão e do laser. Esses parâmetros são estimados empiricamente, partindo-se de valores iniciais próximos dos reais e analisando o resultado produzido na imagem.

O resultado da calibração pode ser melhor avaliado com a projeção de outros pontos sobre a imagem. A Figura 37 mostra a projeção de uma leitura do laser, correspondente aos pontos em branco na imagem. O perfil projetado alinha-se com boa precisão aos objetos presentes na imagem. 


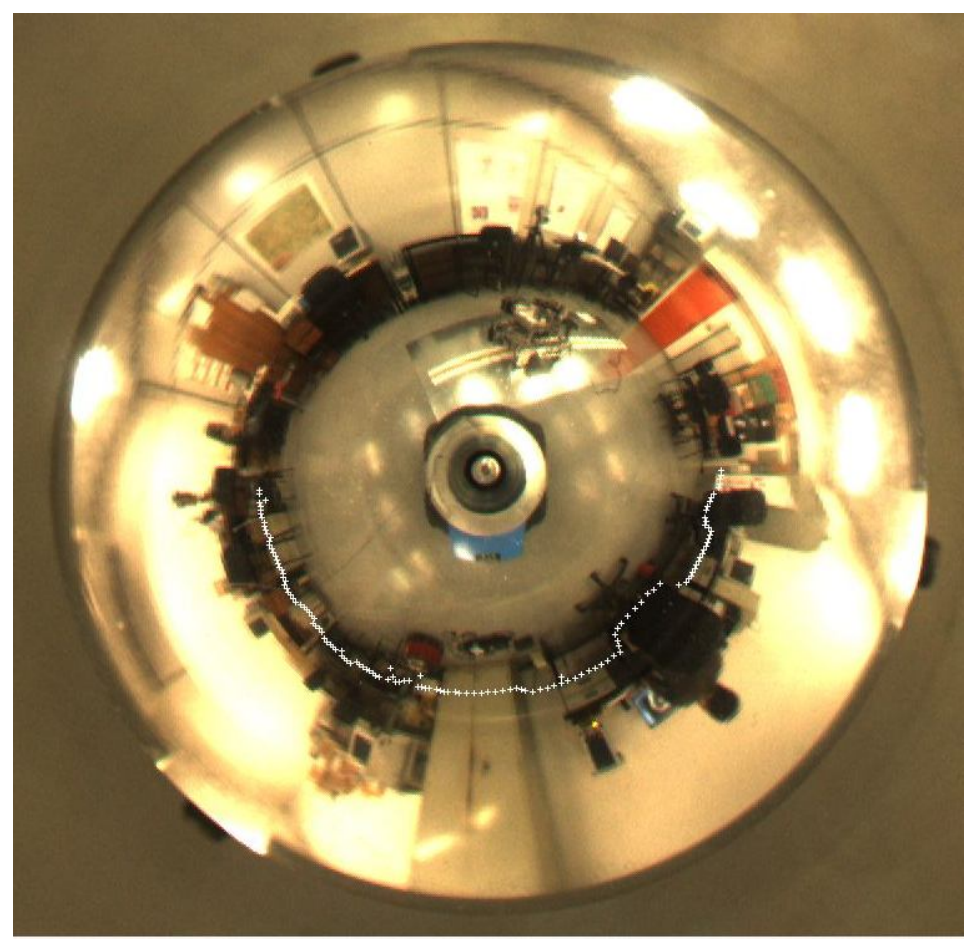

Figura 37. Uma leitura do sensor laser projetada sobre a imagem omnidirecional.

A Figura 38 mostra a projeção dos centros das células da grade de ocupação sobre a imagem omnidirecional. As células com baixa probabilidade de ocupação são projetadas considerando a altura do solo (pontos em branco) e as com alta probabilidade, com a altura do laser (pontos em preto). O resultado também é bastante satisfatório. 


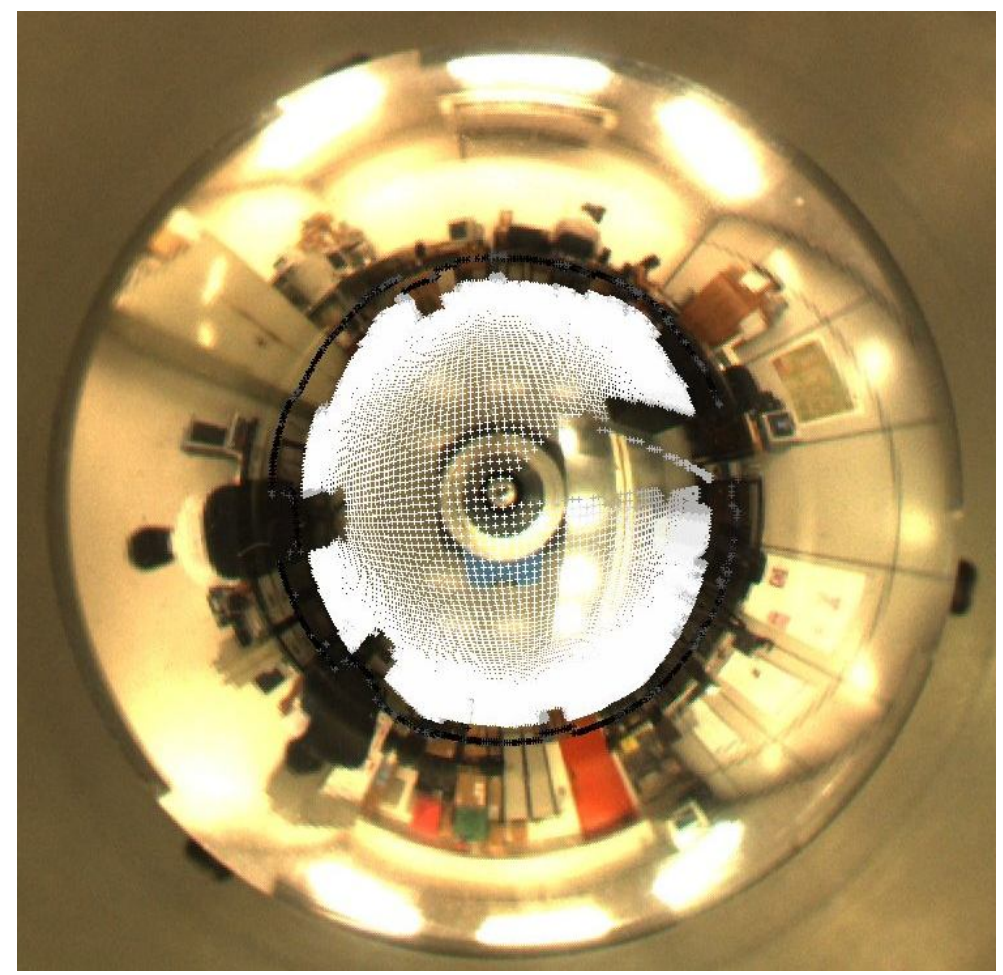

Figura 38. Grade de ocupação de 250 × 250 células projetas sobre a imagem omnidirecional.

\subsubsection{Imagens perspectivas}

Para a obtenção de imagens perspectivas, foi utilizado o software desenvolvido em Grassi Jr. (2002). Pequenas alterações foram feitas para adaptá-lo à câmera colorida e para obtenção dos pontos da imagem perspectiva correspondentes às leituras do laser. A projeção é feita sempre sobre a imagem omnidirecional, e a partir destas coordenadas na imagem são obtidas as coordenadas na imagem perspectiva usando lookup tables construídas pelo software. Cada imagem perspectiva tem dimensão $192 \mathrm{x}$ 192 pixels.

\subsubsection{Agrupamento dos pontos do laser}

Para a implementação do agrupamento dos pontos do laser foi utilizada a função kmeans do MATLAB. Ela permite a escolha de medidas diferentes de 
distância entre pontos, tais como a distância euclideana ao quadrado e a soma das diferenças absolutas (distância L1).

\subsubsection{Segmentação de imagens com CRF}

Na segmentação da imagem com CRF foi empregada a toolbox CRF2D para MATLAB desenvolvida por Kevin Murphy (Murphy et al., 1999). Ela funciona apenas para problemas de classificação binária. Nela estão implementadas inferências aproximadas com loopy belief propagation e mean-field para um grafo não-direcionado geral, com potenciais envolvendo no máximo dois nós (pairwise potentials). Para o aprendizado dos parâmetros do CRF, existem duas possibilidades de funções a serem otimizadas: verossimilhança condicionada e pseudo-verossimilhança. Para a otimização destas funções estão disponíveis (annealed) stochastic gradient ascent e stochastic meta descent. Outras opções são a utilização do método BFGS, presente na toolbox de otimização do MATLAB, com a função fminunc; ou conjugate gradient, com código de terceiros disponível na página da CRF2D toolbox.

No entanto, a toolbox implementa apenas a estrutura para montagem e aprendizado por pseudo-verossimilhança de CRFs em 2D (latticeFeatures). Dessa maneira, para o modelo com inferências conjuntas entre grade e imagem, a estrutura de montagem e o aprendizado da toolbox foram adaptados para lidar com CRFs formados por dois planos conectados, num modelo em 3D. O loopy belief propagation convergiu para o grafo em 3D, quando usados dados simplificados correspondentes à grade de ocupação.

\subsubsection{Aprendizado dos parâmetros do modelo}

Durante testes preliminares, determinou-se que a escala $8 \times 8$ pixels era a mais adequada para representar uma variável aleatória do campo sobre a imagem. Assim, cada imagem perspectiva produz um reticulado de dimensões $24 \times 24$.

O conjunto de treinamento contém 114 imagens perspectivas e seus respectivos rótulos. O conjunto de testes usado na validação dos parâmetros 
aprendidos contém 66 imagens e seus respectivos rótulos. A partir dos rótulos é que são atribuídas as medidas de desempenho da segmentação.
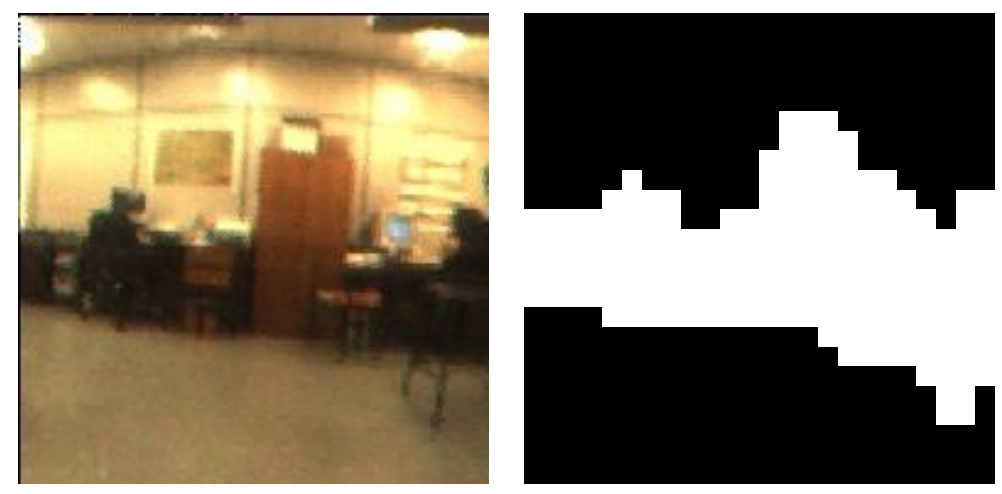

Figura 39. Imagem perspectiva de treinamento e respectivos rótulos.

A Figura 39 mostra uma imagem do conjunto de treinamento à esquerda e o respectivo rótulo à direita. $\mathrm{O}$ procedimento para atribuição de rótulo às imagens é manual. A metodologia consiste na redução da resolução da imagem perspectiva original de 192×192 para 24x24 pixels. Em seguida, cada pixel é marcado com a cor preta se pertencer ao solo ou à parede, e com a cor branca se for um obstáculo. A marcação não necessita de muita precisão, já que o algoritmo de aprendizado lida com inconsistências e ruídos nos dados.

Em algumas configurações para a descrição dos pixels da imagem, foi empregada uma característica relacionada à projeção do laser sobre a imagem (Figura 40).
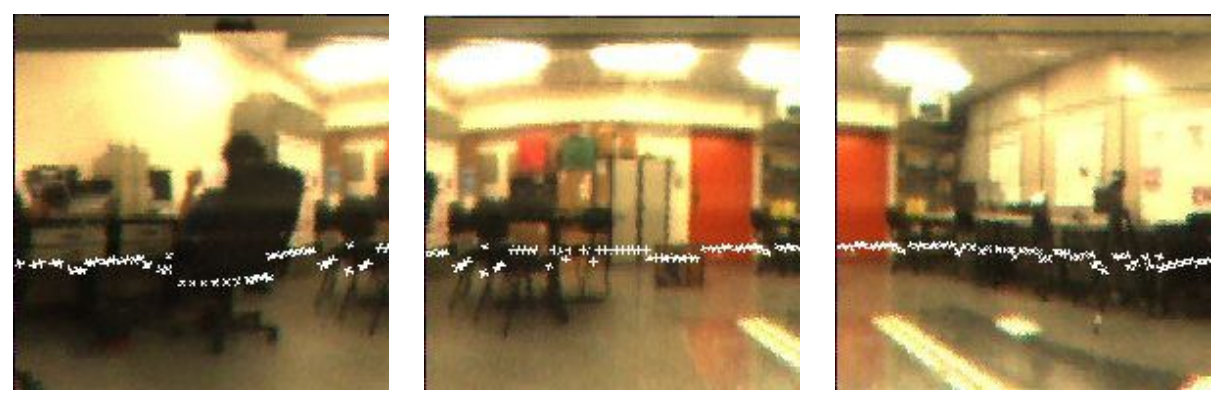

Figura 40. Projeção das leituras do laser na imagens perspectivas. 
Para construir essa característica é necessário projetar também nas imagens os mesmos valores de distância só que considerando a altura do solo. Isso é feito adotando-se como hipótese que a superfície detectada corresponde a um obstáculo que pode ser decomposto em várias faces planas, normais ao raio de detecção. A Figura 41 mostra na esquerda a projeção dos pontos do laser (leituras mais altas) e a projeção das mesmas distâncias considerando a altura do solo. Repare que a projeção é precisa sobre o pé dos obstáculos detectados. À direita é representada uma matriz com as mesmas dimensões do reticulado, onde cada elemento é uma variável booleana que recebe o valor 1 quando o pixel correspondente está entre as leituras projetadas, e 0 quando está acima ou abaixo dessa área.
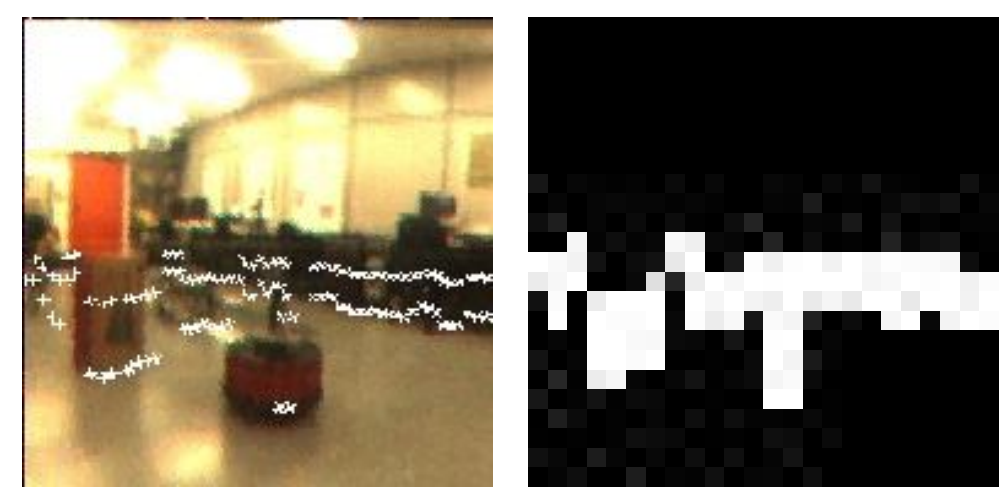

Figura 41. Imagem perspectiva com o laser projetado e a respectiva característica associada.

O descritor final escolhido para a segmentação foi uma combinação dos histogramas de orientações do gradiente e de cores da imagem, adicionando a característica relacionada ao laser descrita acima.

Um exemplo da segmentação obtida é mostrada na Figura 42. A primeira linha mostra três imagens diferentes do conjunto de teste; a segunda linha, o resultado da segmentação; e a terceira linha, os rótulos usados para validar o resultado. 

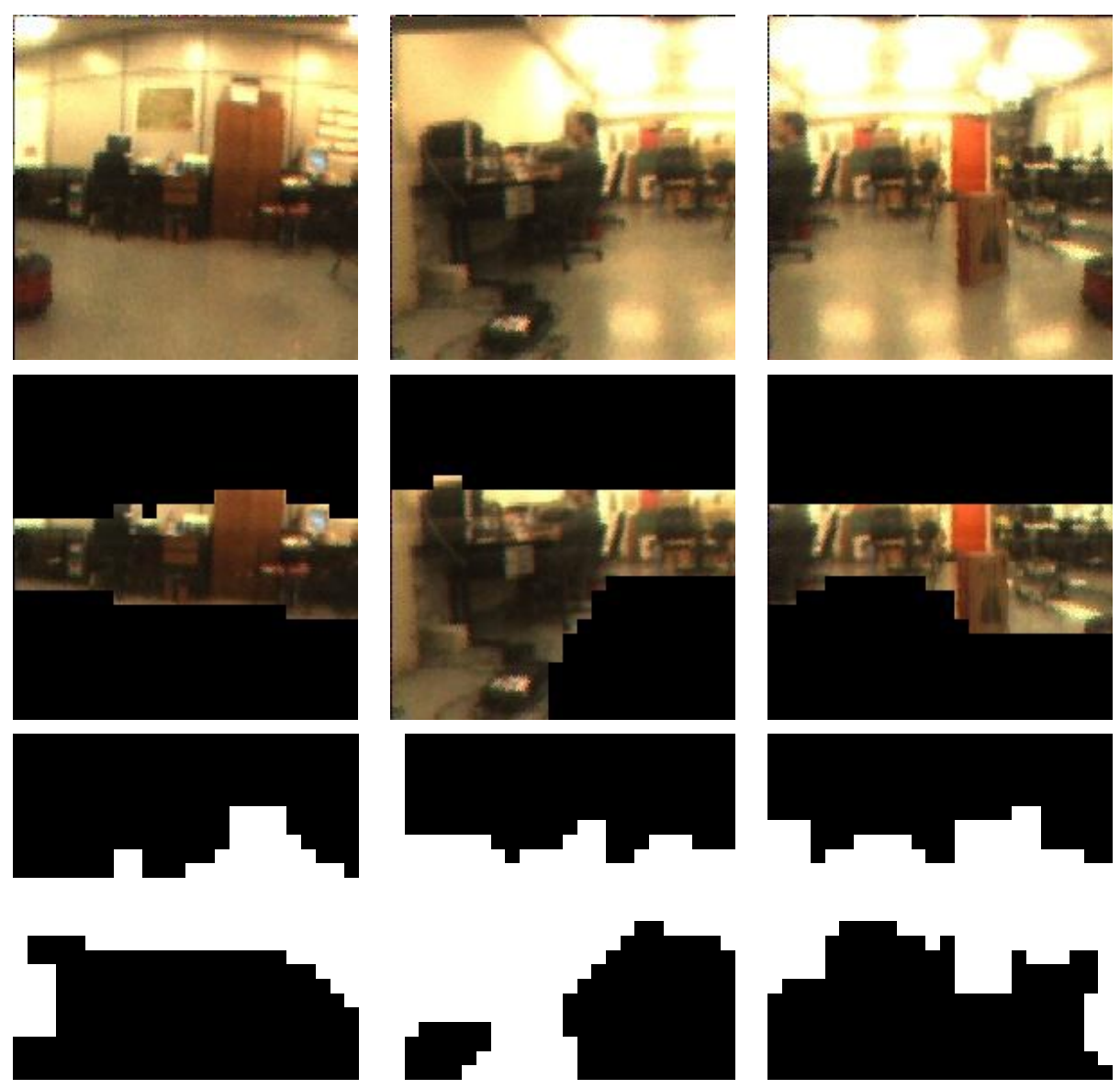

Figura 42. Imagens perspectivas segmentadas.

\subsection{Experimentos}

O processo de mapeamento semântico envolve basicamente dois algoritmos que precisam ser testados: a segmentação da imagem e o agrupamento de pontos do laser.

A segmentação da imagem é o algoritmo que emprega o modelo de grafo de probabilidade com descrição relacional. Muitos testes foram realizados com o modelo, procurando encontrar os descritores mais adequados para identificar obstáculos quaisquer na imagem.

$\mathrm{O}$ agrupamento dos pontos do laser é feito com o algoritmo $K$-means que necessita da determinação inicial de um número $K$ de obstáculos presentes 
no ambiente. Associado às projeções dos pontos nas imagens, o agrupamento produz o mapa semântico com descrições visuais dos obstáculos detectados pelo laser. O resultado da segmentação é usado nestas descrições para encontrar os pixels que se referem ao obstáculo.

\subsubsection{Testes com a segmentação de imagens}

Os resultados dos testes realizados foram arranjados em tabelas para facilitar a visualização das diferentes configurações do problema da segmentação. As configurações dependem dos seguintes elementos:

- o descritor local considerado na função potencial aplicada aos nós do grafo (características: nó);

- o descritor local considerado na função potencial aplicada aos arcos do grafo (características: arco);

- a intensidade dos pixels no espaço de cores RGB: todas os três planos (cores: RGB) ou uma cor apenas (cores: azul, por exemplo);

- a quantidade de escalas de observação dos pixels consideradas: 8x8

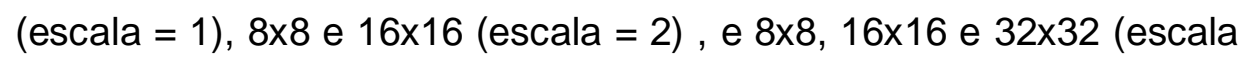
$=3$;

- a utilização da expansão do descritor local, tanto para os nós quanto para os arcos: com expansão (kernel: nó = 1 ou arco =1) ou sem expansão (kernel: nó = 0 ou arco $=0$ );

- o número de variáveis (pesos a serem encontrados) ou a dimensionalidade do vetor correspondente à junção dos potenciais de nós e arcos: (no. de variáveis: 527, por exemplo);

- o tempo gasto no treinamento e a respectiva unidade utilizada: (tempo de treinamento $=\sim 1 \mathrm{~h} 3 \mathrm{~min})$; 
- o número de iterações necessários para a convergência do algoritmo, com base no valor da tolerância da derivada primeira que deve se aproximar de zero: (iterações $=309$ );

- os valores de cobertura, precisão e exatidão;

- o valor do lambda, que é uma penalização pela escolha de pesos muito grandes, usado para evitar o overfitting: lambda $=1$;

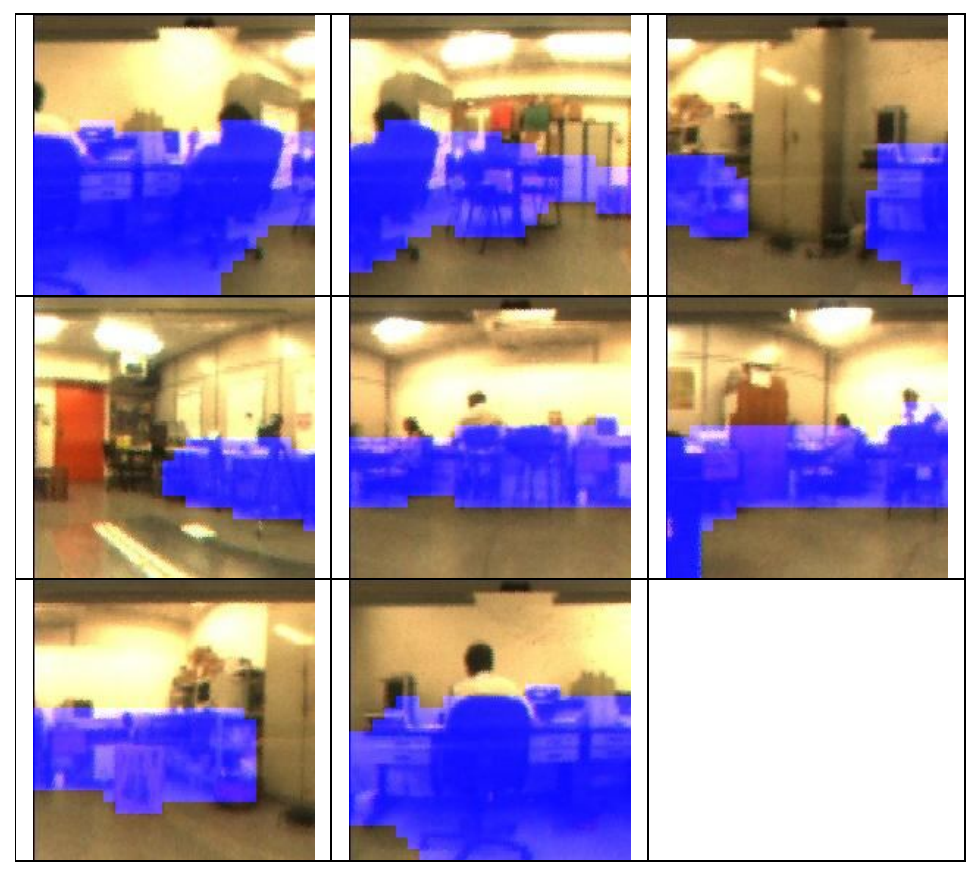

Figura 43. Alguns resultados da segmentação.

A Figura 43 exibe alguns resultados visuais da segmentação, de imagens fora do conjunto de treinamento e testes. Os pixels classificados como obstáculo são representados em azul. A média de tempo de classificação dos exemplos é de aproximadamente $0.2 \mathrm{~s}$, lembrando que o algoritmo roda em MATLAB.

Os resultados da segmentação apresentados a seguir serão na forma dos valores das medidas de cobertura, precisão e exatidão.

Uma primeira comparação de resultados considera imagens descritas por um histograma da intensidade dos pixels na imagem com dez intervalos, 
correspondendo à intensidade normalizada de 0.1 a 1 , para cada uma das três cores RGB. O teste de número 2 usa apenas uma escala de $8 \times 8$ pixels para descrever os potenciais dos nós e dos arcos. O teste 3 usa três

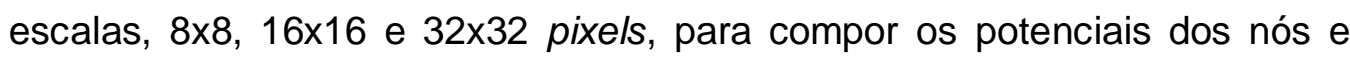
dos arcos. Já o teste 4 utiliza uma escala $8 \times 8$ para descrever os potenciais dos nós e as três escalas mencionadas acima para os potenciais dos arcos. A Tabela 7 mostra os resultados.

Tabela 7. Diferenças relativas ao número de escalas empregadas.

\begin{tabular}{|c|c|c|c|}
\hline & $\mathbf{2}$ & $\mathbf{3}$ & $\mathbf{4}$ \\
\hline características: nó & colorHist $(10 \times 3)$ & colorHist $(30 \times 3)$ & colorHist $(10 \times 3)$ \\
\hline características: arco & colorHist $(10 \times 3)$ & colorHist $(30 \times 3)$ & colorHist $(30 \times 3)$ \\
\hline cores & $\mathrm{RGB}$ & $\mathrm{RGB}$ & $\mathrm{RGB}$ \\
\hline escalas & 1 & 3 & 3 \\
\hline kernel: nó & 0 & 0 & 0 \\
\hline kernel: arco & 0 & 0 & 0 \\
\hline no. de variáveis & 62 & 182 & 122 \\
\hline $\begin{array}{c}\text { tempo de } \\
\text { treinamento }\end{array}$ & $\sim 41 \mathrm{~min}$ & $\sim 54 \mathrm{~min}$ & $\sim 43 \mathrm{~min}$ \\
\hline iterações & 316 & 388 & 310 \\
\hline cobertura (\%) & 82,01 & 50,28 & 93,68 \\
\hline precisão (\%) & 58,47 & 39,73 & 46,87 \\
\hline exatidão (\%) & 64,69 & 41,65 & 47,90 \\
\hline lambda & 1 & 1 & 1 \\
\hline
\end{tabular}

O número de escalas consideradas afeta a quantidade de parâmetros a serem estimados: 62 no teste 2, 182 no teste 3 e 122 no teste 4 . Como a implementação em MATLAB apresentou uma limitação quanto à alocação de memória, não foi possível usar modelos com milhares de parâmetros havendo a necessidade de escolher cuidadosamente o tipo de descrição mais adequado para a tarefa de segmentação.

Na segunda comparação é mais aparente o efeito do número de variáveis escolhidas para descrever os pixels. Aqui foram testados os efeitos da utilização da expansão para os descritores da imagem.

A Tabela 8 mostra os resultados para quatro testes realizados. Os testes $1 \mathrm{e}$ 2 usam o mesmo descritor. No teste 1, é feita a expansão para os 
parâmetros do nó apenas. No teste 2, não foi feita nenhuma expansão. 0 teste 5 utiliza a expansão nos parâmetros do nó, mas emprega também três escalas nos parâmetros dos arcos. $O$ teste 6 usa expansão nos parâmetros dos nós e dos arcos. Para isso, foi preciso reduzir o número de parâmetros iniciais. Assim, no teste 6 foi empregado um histograma com 5 intervalos apenas, correspondentes às intensidades $[0,1 ; 0,2 ; 0,3 ; 0,5 ; 1,0]$. Os resultados de se empregar esta expansão são bastante significativos, mesmo com a redução do número de parâmetros iniciais.

Tabela 8. Comparação entre descritores expandidos.

\begin{tabular}{|c|c|c|c|c|}
\hline & $\mathbf{1}$ & $\mathbf{2}$ & $\mathbf{5}$ & $\mathbf{6}$ \\
\hline $\begin{array}{c}\text { características: } \\
\text { nó }\end{array}$ & colorHist $(10 \times 3)$ & colorHist $(10 \times 3)$ & colorHist $(10 \times 3)$ & colorHist $(5 \times 3)$ \\
\hline $\begin{array}{c}\text { características: } \\
\text { arco }\end{array}$ & colorHist $(10 \times 3)$ & colorHist $(10 \times 3)$ & colorHist $(30 \times 3)$ & colorHist $(5 \times 3)$ \\
\hline cores & RGB & RGB & RGB & RGB \\
\hline escalas & 1 & 1 & 3 & 1 \\
\hline kernel: nó & 1 & 0 & 1 & 1 \\
\hline kernel: arco & 0 & 0 & 0 & 1 \\
\hline no. de variáveis & 527 & 62 & $\sim 1 \mathrm{~h} 1 \mathrm{~min}$ & $\sim 56 \mathrm{~min}$ \\
\hline $\begin{array}{c}\text { tempo de } \\
\text { treinamento }\end{array}$ & $\sim 1 \mathrm{~h} 3 \mathrm{~min}$ & $\sim 41 \mathrm{~min}$ & 402 & 376 \\
\hline iterações & 438 & 316 & 72,84 & 73,55 \\
\hline cobertura (\%) & 71,29 & 82,01 & 90,28 & 90,69 \\
\hline precisão (\%) & 91,30 & 58,47 & 83,79 & 84,25 \\
\hline exatidão (\%) & 83,56 & 64,69 & 1 & 1 \\
\hline lambda & 1 & 1 & & \\
\hline
\end{tabular}

Foram comparados também descritores diferentes para representar obstáculos quaisquer na imagem. Além do descritor de histograma com cores, foi utilizada também o descritor spin Images, com um histograma em duas dimensões, numa representada pela intensidade com 5 intervalos e noutra pela distância com relação ao centro.

A Tabela 9 mostra os resultados dessa comparação. A medida precisão é maior para o histograma de cores. No entanto, as duas outras medidas são melhores com o spin Images. 
Outra comparação foi feita para avaliar o valor da regulação aplicado ao treinamento. Foram testados os valores de 10; 1; 0,1; e 0,01. Quanto menor o valor escolhido pra lambda, maior o tempo de treinamento. Normalmente, quanto menor o valor, melhor o resultado. Mas a melhoria para a partir do valor de 0,1 .

Tabela 9. Comparação entre descritores diferentes.

\begin{tabular}{|c|c|c|}
\hline & $\mathbf{1}$ & $\mathbf{8}$ \\
\hline características: nó & colorHist $(10 \times 3)$ & spinlmages $(20 \times 1)$ \\
\hline características: arco & colorHist $(10 \times 3)$ & spinlmages $(20 \times 1)$ \\
\hline cores & RGB & azul \\
\hline escalas & 1 & 1 \\
\hline kernel: nó & 1 & 1 \\
\hline kernel: arco & 0 & 252 \\
\hline no. de variáveis & 527 & $\sim 48 \mathrm{~min}$ \\
\hline tempo de & $\sim 1 \mathrm{~h} 3 \mathrm{~min}$ & 358 \\
\hline treinamento & 438 & 78,58 \\
\hline iterações & 71,29 & 86,47 \\
\hline cobertura (\%) & 91,30 & 84,39 \\
\hline precisão (\%) & 83,56 & 1 \\
\hline exatidão (\%) & 1 & \\
\hline lambda & & \\
\hline
\end{tabular}

Para efeito de comparação entre modelos discriminativos, foram realizados testes também com o algoritmo de SVM (Vapnik, 1995; Cristianini e ShaweTaylor, 2000). O SVM é treinado para maximizar a margem de classificação, mas não considera nenhuma dependência entre as variáveis nãoobserváveis que representam uma mesma imagem. A implementação foi feita com o pacote de software svm_light (Joachims, 1999).

A Figura 44 mostra o efeito do aumento do número de exemplos no tempo gasto para o aprendizado dos parâmetros do modelo. O tempo cresce linearmente com o acréscimo de exemplos no modelo de CRF. Cada exemplo de treinamento consiste de $24{ }^{*} 24=576$ variáveis. No último teste foram classificadas 120.960 variáveis.

Por fim, são comparados os resultados quanto às medidas de cobertura, precisão e exatidão nos modelos de SVM e CRF (Tabela 11). Apesar de ser 
esperado que o CRF, por modelar as dependências espaciais, fosse mais lento no treinamento, o desempenho deveria ser melhor. A descrição relacional teria de ser melhor explorada nesse problema para gerar resultados mais satisfatórios.

Tabela 10. Comparação do resultado considerando o valor do lambda na regulação.

\begin{tabular}{|c|c|c|c|c|}
\hline $\begin{array}{c}12 \\
\text { características: } \\
\text { nó }\end{array}$ & $\begin{array}{c}\text { colorHist } \\
(10 \times 3)\end{array}$ & $\begin{array}{c}\text { colorHist } \\
(10 \times 3)\end{array}$ & $\begin{array}{c}\text { colorHist } \\
(10 \times 3)\end{array}$ & $\begin{array}{c}\text { colorHist } \\
(10 \times 3)\end{array}$ \\
\hline $\begin{array}{c}\text { características: } \\
\text { arco }\end{array}$ & $\begin{array}{c}\text { colorHist } \\
(10 \times 3)\end{array}$ & $\begin{array}{c}\text { colorHist } \\
(10 \times 3)\end{array}$ & $\begin{array}{c}\text { colorHist } \\
(10 \times 3)\end{array}$ & $\begin{array}{c}\text { colorHist } \\
(10 \times 3)\end{array}$ \\
\hline cores & RGB & RGB & RGB & RGB \\
\hline escalas & 1 & 1 & 1 & 1 \\
\hline kernel: nó & 1 & 1 & 1 & 1 \\
\hline kernel: arco & 0 & 0 & 0 & 0 \\
\hline no. de variáveis & 527 & 527 & 527 & 527 \\
\hline treino & 114 & 114 & 114 & 114 \\
\hline teste & 66 & 66 & 66 & 66 \\
\hline $\begin{array}{c}\text { tempo de } \\
\text { treinamento }\end{array}$ & $\sim 33 \mathrm{~min}$ & $\sim 1 \mathrm{~h} 3 \mathrm{~min}$ & $\sim 1 \mathrm{~h} 30 \mathrm{~min}$ & $\sim 2 \mathrm{~h} 8 \mathrm{~min}$ \\
\hline iterações & & 438 & 601 & 891 \\
\hline cobertura (\%) & 65.60 & 71,29 & 75.60 & 76.46 \\
\hline precisão (\%) & 89.61 & 91,30 & 91.14 & 91.09 \\
\hline exatidão (\%) & 80.54 & 83,56 & 85.30 & 85.63 \\
\hline lambda & 10 & 1 & 0.10 & 0.01 \\
\hline
\end{tabular}




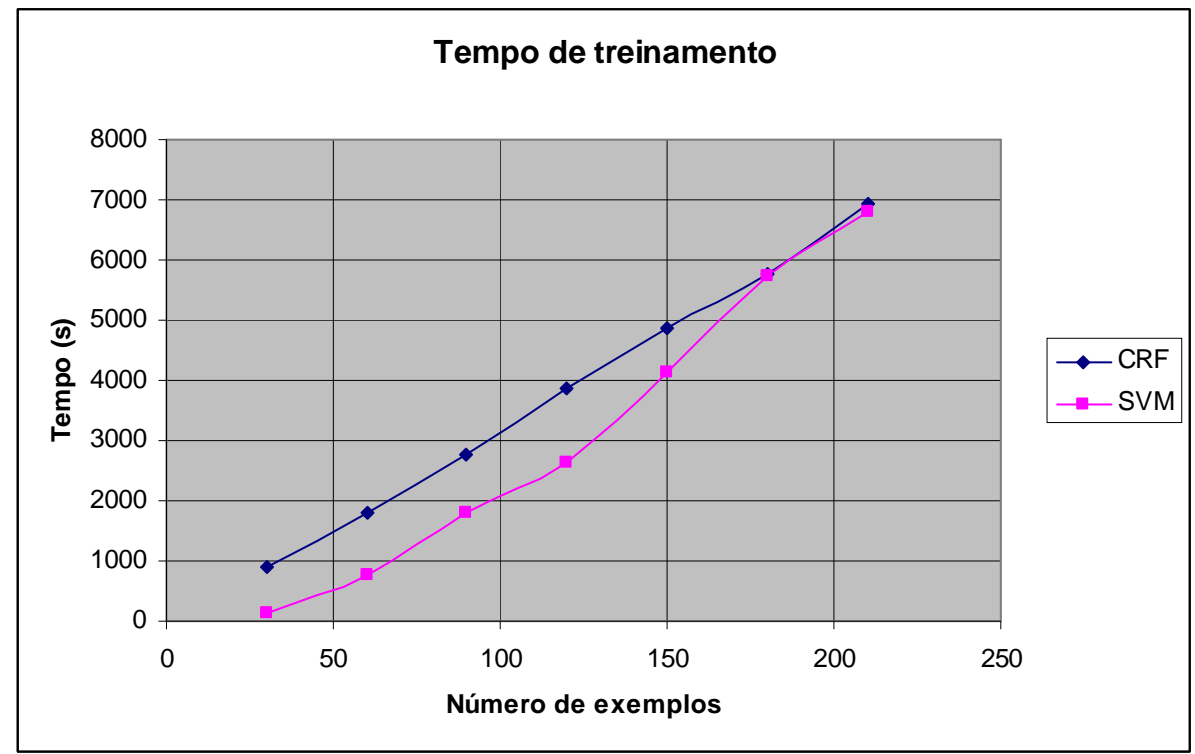

Figura 44. Gráfico da comparação entre o tempo de treinamento do CRF com o SVM.

Tabela 11. Comparação entre SVM e CRF.

\begin{tabular}{|c|c|c|}
\hline & SVM & CRF \\
\hline tempo de treinamento & $\sim 25 \mathrm{~min}$ & $\sim 1 \mathrm{~h} 3 \mathrm{~min}$ \\
\hline cobertura (\%) & 83,48 & 71,29 \\
\hline precisão (\%) & 89,05 & 91,30 \\
\hline exatidão (\%) & 87,59 & 83,56 \\
\hline
\end{tabular}

\subsubsection{Mapeamento semântico}

O mapeamento semântico foi realizado em duas etapas: uma de coleta dos dados sensoriais, onde o robô é tele-operado por uma trajetória qualquer no ambiente, e outra do processamento off-line dos dados para criação da representação semântica. Apesar de não ser uma das preocupações neste trabalho, o único impedimento para o processamento on-line são alguns algoritmos que estão implementados em MATLAB.

Os dados coletados a cada instante de tempo consistem de uma imagem omnidirecional colorida, de aproximadamente $768 \times 768$ pixels e de um conjunto de leituras do sensor laser (correspondendo no máximo a 180 
coordenadas $x_{\text {laser, }} y_{\text {laser }}$ referentes à distância), juntamente com a estimativa de postura $\left(x_{\text {robô, }} y_{\text {robô, }} \theta_{\text {robô }}\right)$ do robô.

O conjunto de leituras do laser obtido durante a navegação é usado para construir a grade de ocupação (Figura 45).

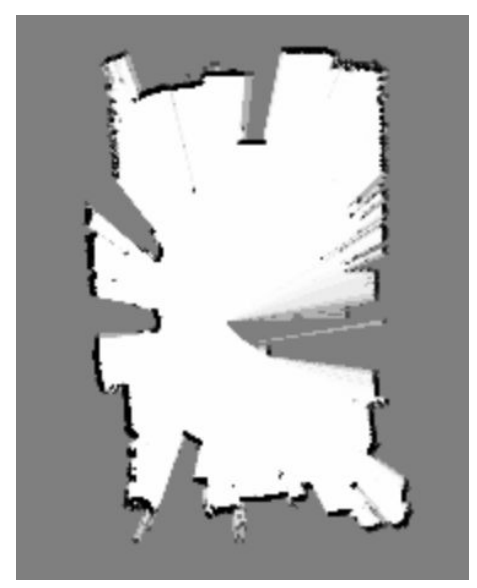

Figura 45. Grade de ocupação construída com os dados do laser e a estimação da posição do robô.

Depois de construída a grade de ocupação, é preciso agrupar as leituras do laser referentes a um mesmo obstáculo. Foram realizados vários testes com o algoritmo $K$-means para diferentes valores de $K$, ou seja, considerando diferentes quantidades de obstáculos no ambiente. As Tabela 12 e Tabela 13 exibem os resultados dos testes. Cada linha das tabelas apresenta os resultados do agrupamento para um valor de $K$ específico. As colunas contém as grade de ocupação indicando no máximo 6 obstáculos em cada, representados por cores diferentes atribuídas a algumas das células.

Como um obstáculo pode ser qualquer coisa desde uma caixa no meio do ambiente quanto uma mesa encostada na parede ou uma porta, é difícil determinar exatamente quantos objetos devem ser encontrados. Alguns dos agrupamentos correspondem a poucos pontos e podem ser desconsiderados como objetos. 
Os pontos marcados fora das células consideradas ocupadas também podem ser desprezados, mas correspondem muitas vezes a objetos como pés de cadeira e mesa identificados pelo laser.

Tabela 12. Comparação dos resultados do K-means para diferentes valores de $\mathrm{K}$.

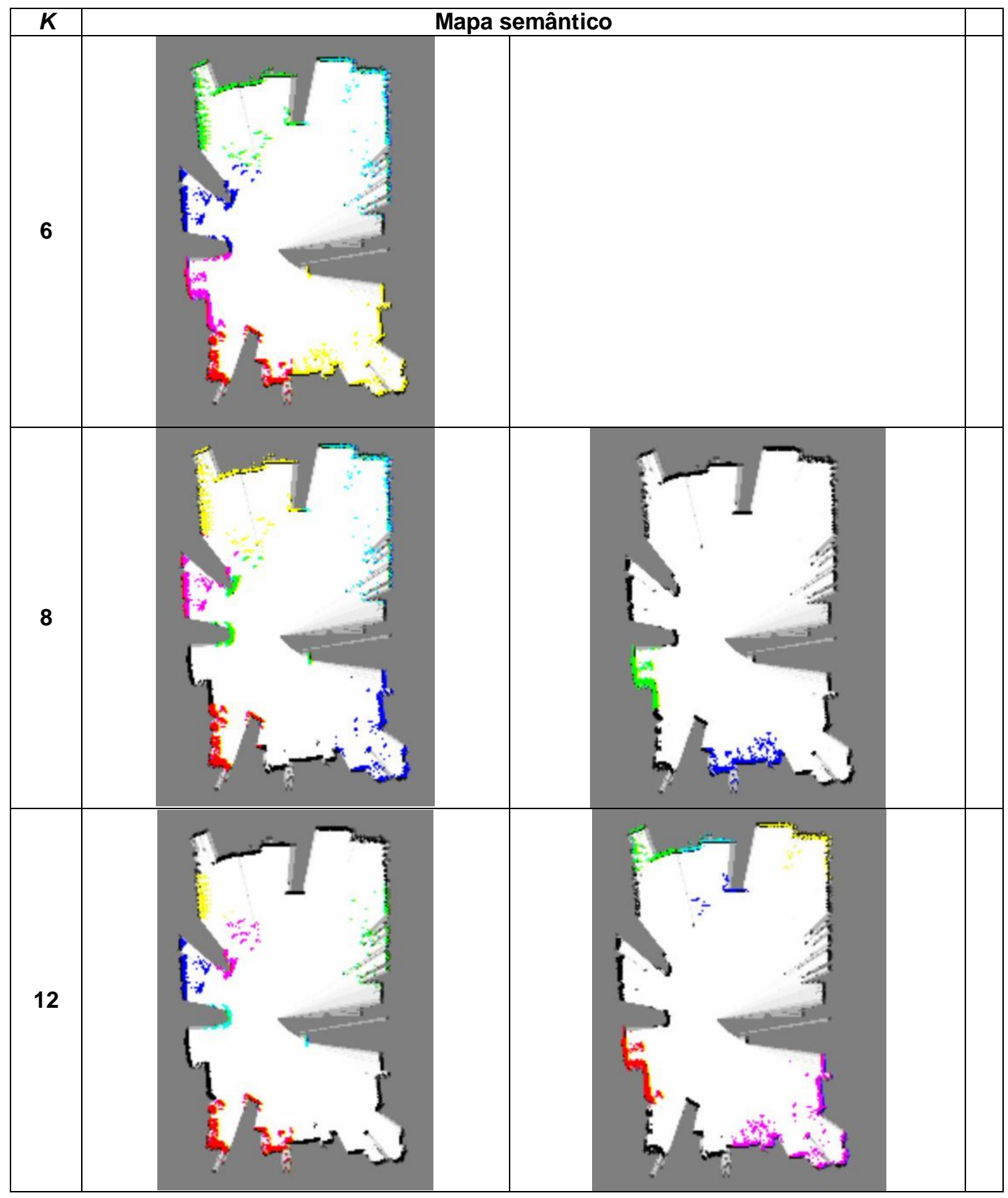


Tabela 13. Continuação dos resultados dos testes com o algoritmo Kmeans.

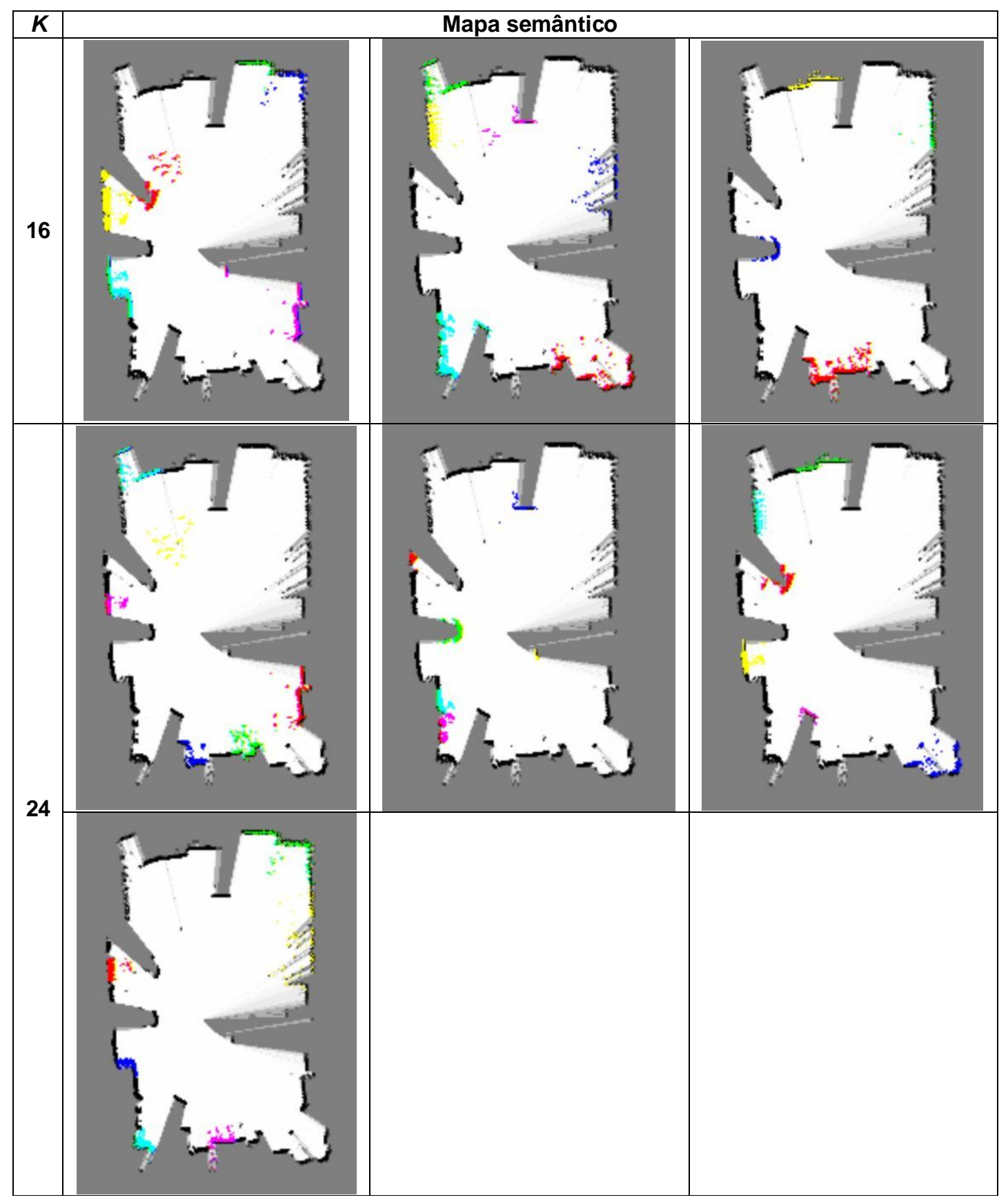

Conforme o valor de $K$ aumenta, cada agrupamento anterior tende a ser dividido em partes menores, até acabar por representar realmente um obstáculo na grade de ocupação. Analisando os resultados obtidos com a 
variação do valor de $K$, nota-se que a associação entre os agrupamentos formados pela aplicação do algoritmo e os obstáculos presentes no ambiente não coincidem completamente. Como será visto adiante, não é possível segmentar perfeitamente uma classe de obstáculos tão genérica quanto a proposta aqui. No entanto, os resultados obtidos são adequados para a obtenção de um mapa semântico que pode ser utilizado por um robô móvel para uma navegação segura pelo ambiente.

Uma outra forma de visualização estes agrupamentos, é pela projeção nas imagens perspectivas. A Figura 46 mostra a projeção de três agrupamentos correspondentes a uma mesma leitura do sensor laser, em perspectivas com ângulos diferentes. Cada grupo é identificado por uma seqüência de pontos de cores diferentes. A mesma cor em imagens diferentes não está relacionada a um mesmo obstáculo.
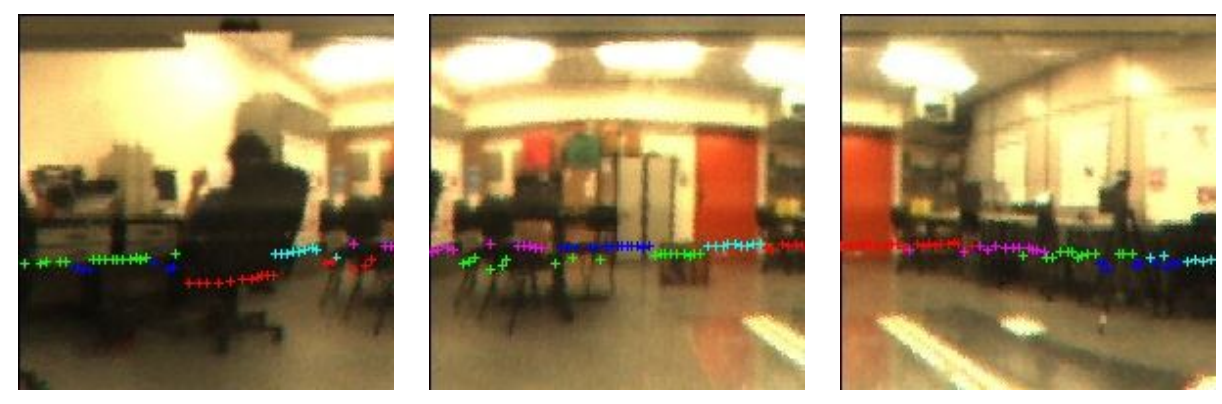

Figura 46. Agrupamento das leituras do laser.

Note que existem seqüências de mesma cor, mas espacialmente separadas. Isso é resultado do algoritmo $K$-means, quando o valor de $K$ é baixo.

Com as informações referentes a esta segmentação, é possível extrair regiões de interesse da imagem que correspondem às descrições visuais dos obstáculos. A Figura 47 mostra alguns exemplos de obstáculos extraídos. 


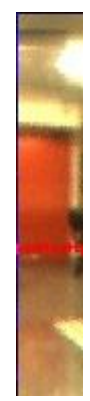

(a) porta

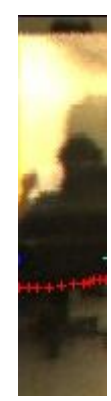

(b) cadeira

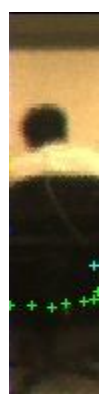

(c) cadeira

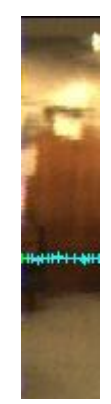

(d) armário

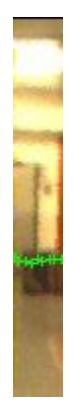

(e) caixa

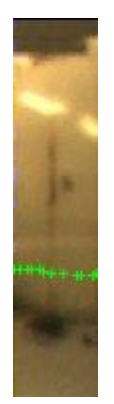

(f) armário

Figura 47. Região da imagem referentes a diversos tipos de obstáculos.

Com o agrupamento de todos os pontos do laser em obstáculos, concluí-se o mapeamento semântico com a atribuição das descrições visuais aos obstáculos. O mapa semântico final é apresentado em cinco figuras distintas para facilitar a visualização de todos os obstáculos encontrados. Para a obtenção deste resultado foi considerado um valor de $K$ igual a 30. 


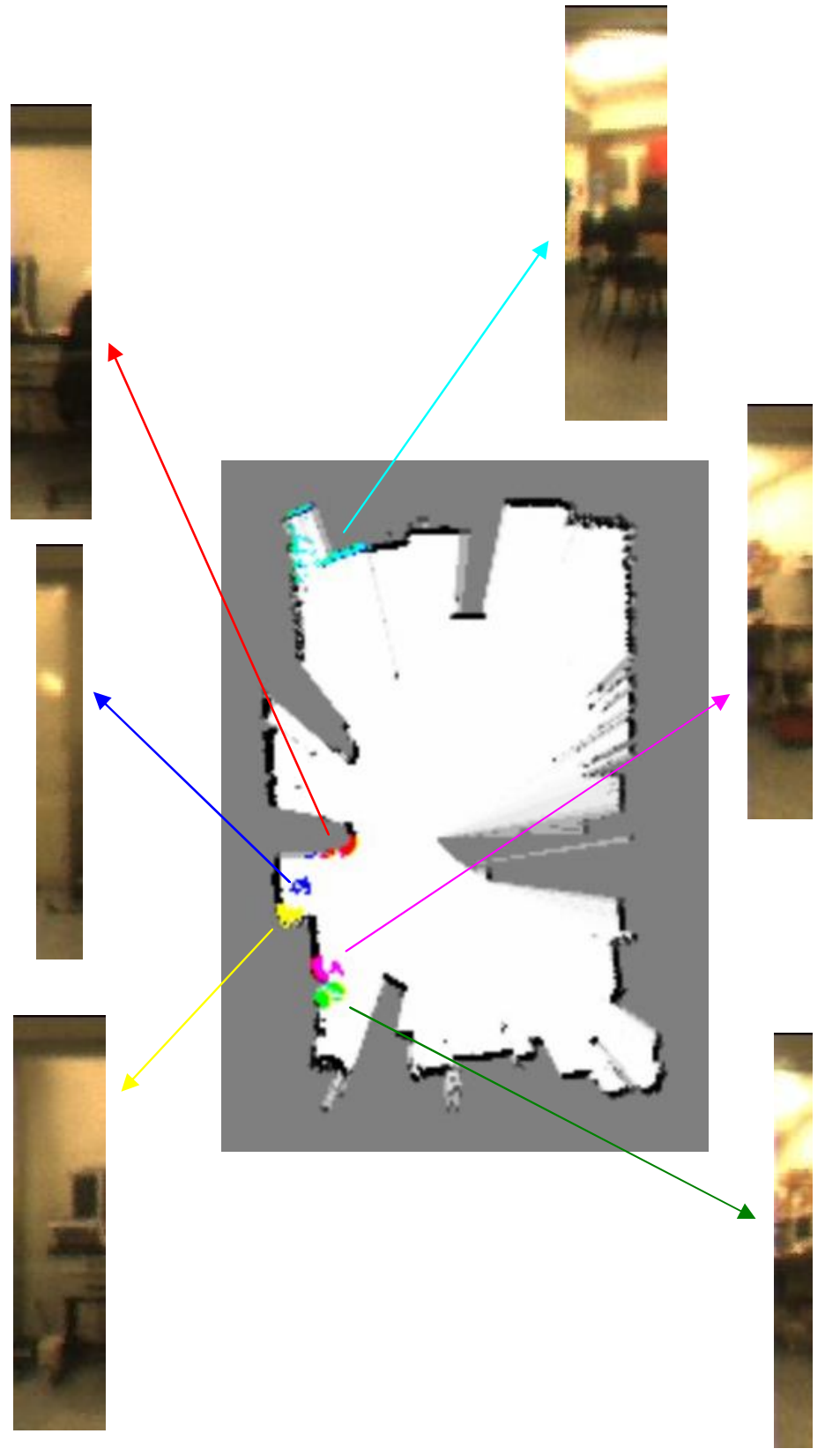

Figura 48. Mapa semântico (parte 1). 


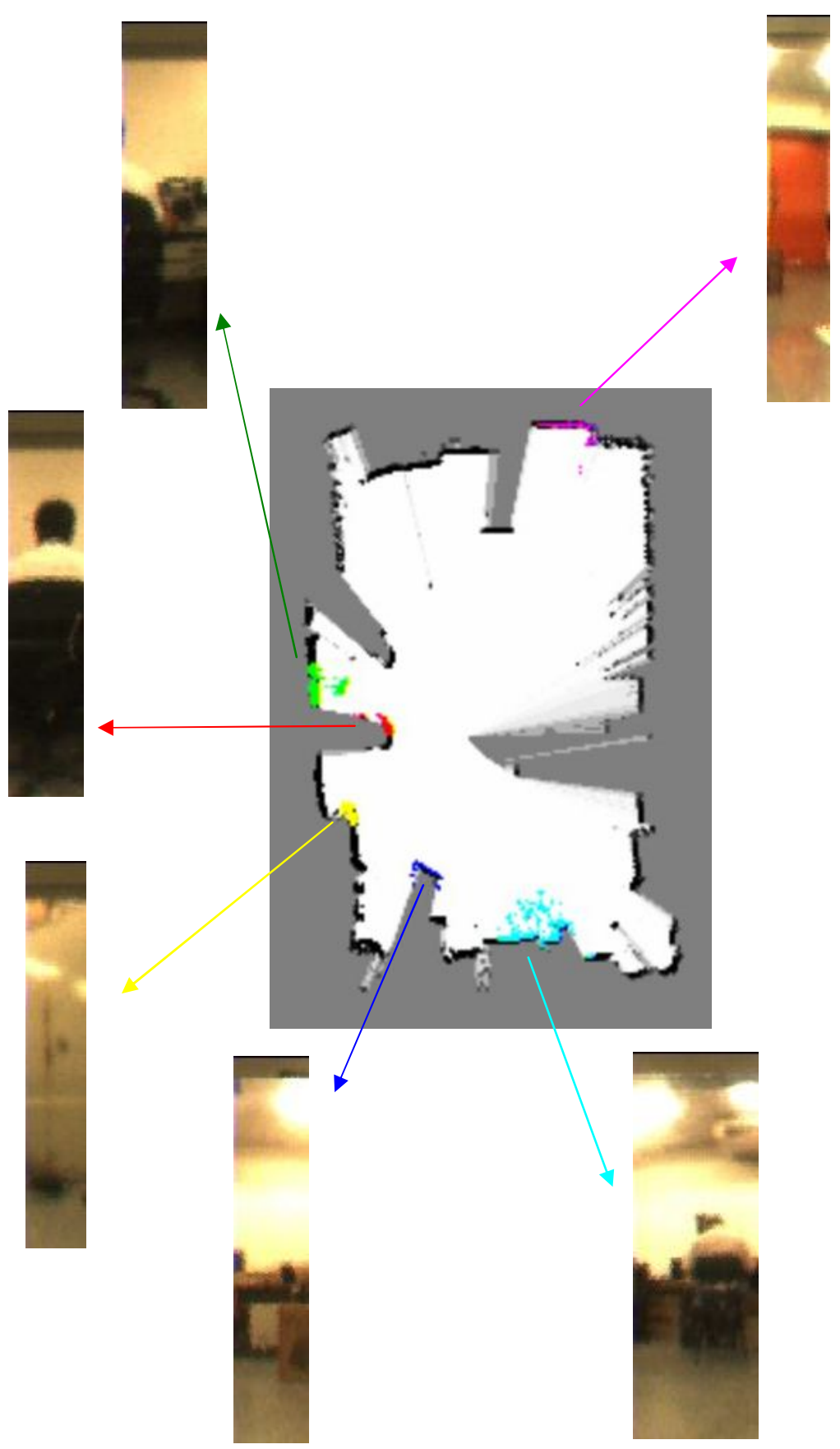

Figura 49. Mapa semântico (parte 2).

Cada figura representa seis obstáculos diferentes, identificados por cores distintas. Uma seta da mesma cor relaciona as células da grade com as descrições visuais extraídas. Optou-se por colocar apenas as regiões de 
interesse da imagem na descrição visual, sem a segmentação da imagem correspondente para que fosse possível identificar realmente o obstáculo.

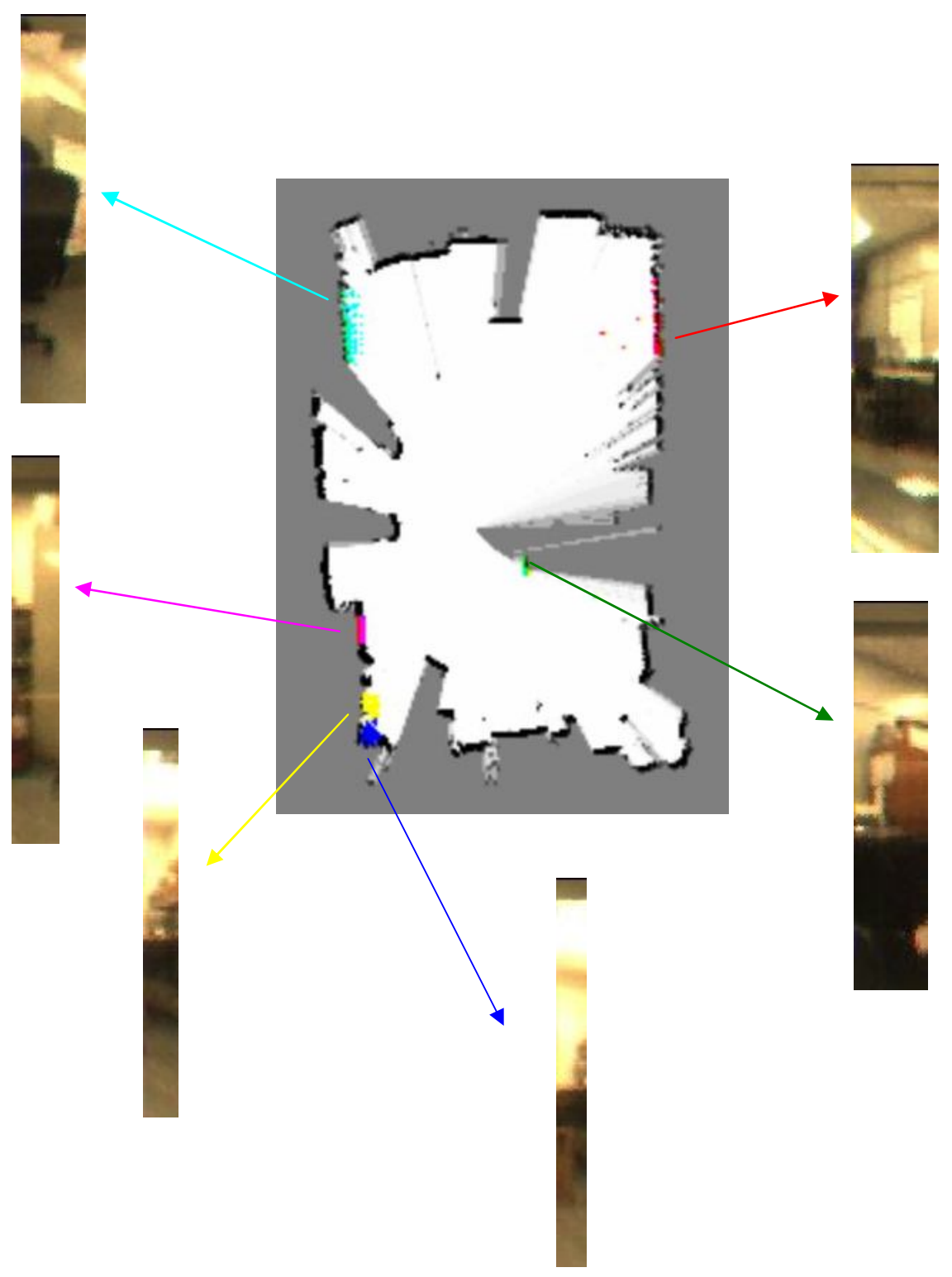

Figura 50. Mapa semântico (parte 3).

Existe uma dificuldade de identificação dos verdadeiros obstáculos associados devido à altura que o laser se encontra do robô. Em algumas ocasiões, como por exemplo na Figura 49, o obstáculo em verde se refere à parede mas na descrição visual facilmente interpreta-se que o obstáculo encontrado é uma cadeira. 


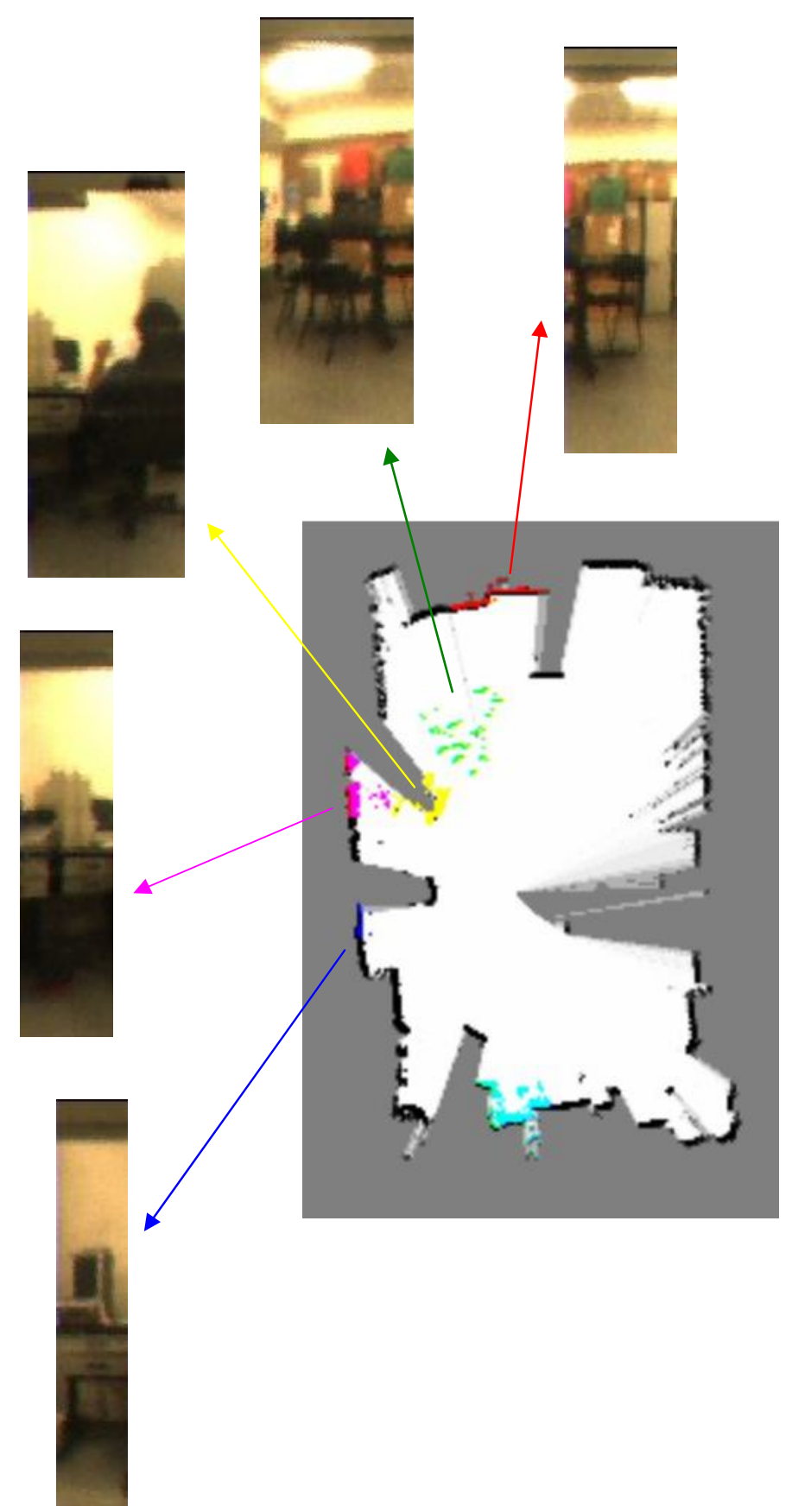

Figura 51. Mapa semântico (parte 4).

Nem todos os obstáculos encontrados pelo algoritmo são significativos. Mas este resultado é devido à formulação do problema, que não considerou nenhuma restrição quanto às medições do laser utilizadas na determinação dos agrupamentos (obstáculos). Um pré-processamento da grade de 
ocupação, e posterior identificação dos pontos do laser referentes, para selecionar apenas obstáculos que estão no meio do caminho do robô, como caixas ou cadeiras, proporcionaria um resultado melhor.

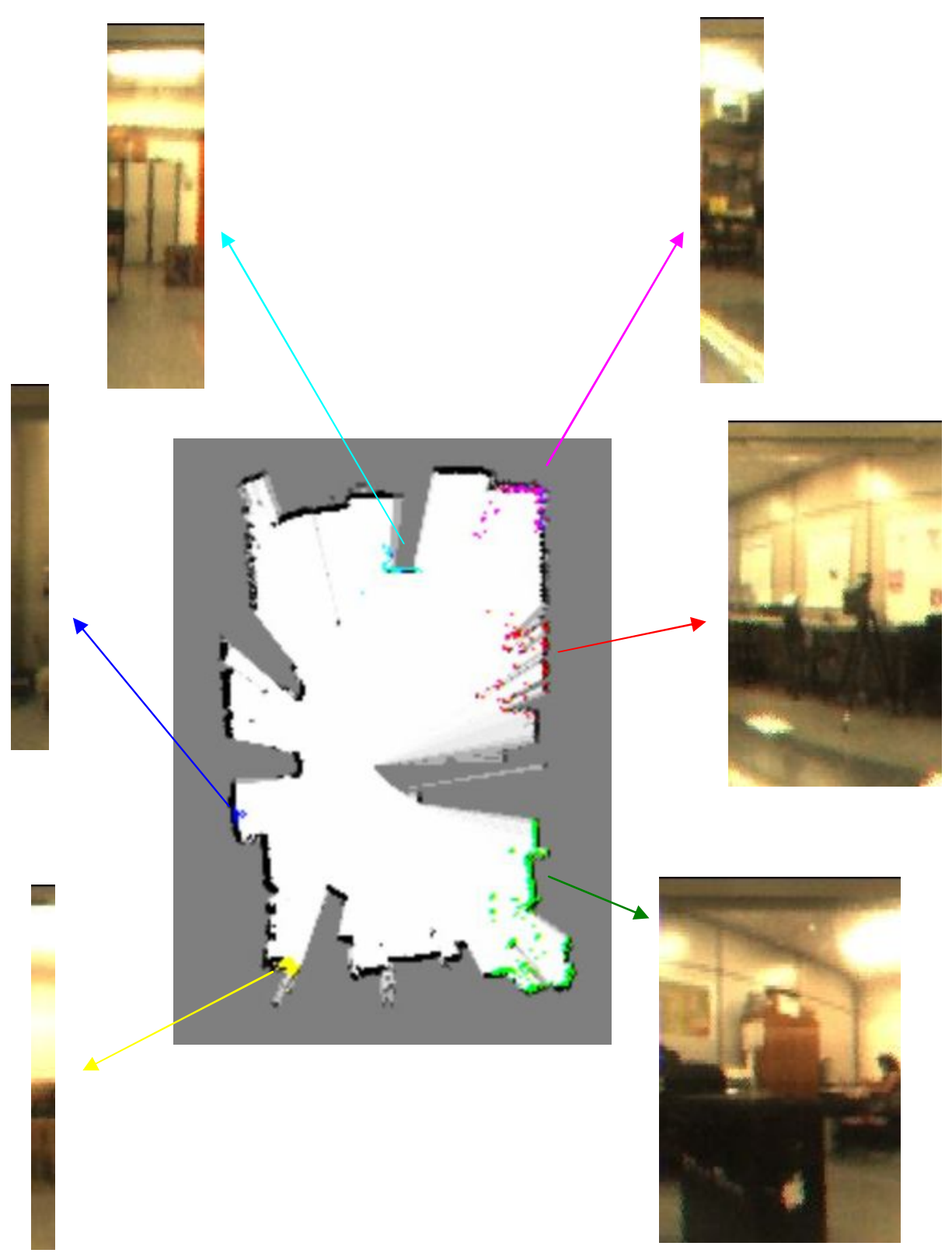

Figura 52. Mapa semântico (parte 5). 


\subsection{Análise dos resultados}

Com relação ao problema da segmentação de imagem, na qual foi utilizado o CRF, os resultados obtidos com este modelo não justificam por si só a opção por um modelo mais complexo, com descrição relacional. O que acontece é que a segmentação de obstáculos quaisquer, tanto um armário que tem a cor de uma parede quanto uma caixa de cor escura, e a quantidade destas duas classes de obstáculo no conjunto de treinamento, fez com que o modelo ignorasse obstáculos de cor clara. Outro fator está relacionado ao descritor local empregado. Analisando apenas a cor dos pixels é possível extrair os obstáculos desejados que são mais escuros, sem a utilização de um modelo de probabilidade.

Por isso o desempenho do SVM foi parecido com o do CRF. O CRF apresentou um valor ligeiramente superior na medida de precisão, mas em compensação ligeiramente inferior ao SVM nas medidas cobertura e exatidão. Seria necessário especificar um descritor mais apropriado que representasse melhor o problema em questão. Mesmo assim, os resultados de mais de $80 \%$ de acerto são satisfatórios e permitem a construção das descrições visuais para o mapa semântico.

O treinamento do CRF por verossimilhança condicionada não convergiu para nenhuma configuração de descritores. Mas os pesos encontrados produziram resultado semelhante ao obtido pelo treinamento por pseudoverossimilhança. Valores da ordem de 0,1 para a regulação do treinamento foram considerados suficientes.

O descritor de spin images, por conter além da distribuição de cores também uma representação das formas na imagem, mostrou-se mais adequado que somente a distribuição de cores.

Quanto ao mapeamento semântico, a metodologia para a construção das descrições visuais mostrou-se adequada. Foram localizados obstáculos que podem ser utilizados como informação para facilitar a realização de outras 
tarefas. Mas também foram encontrados obstáculos que pouco acrescentam ao sistema como um todo. O ideal seria usar algum algoritmo capaz de determinar os grupos realizando algum tipo de inferência. 
Capítulo 6

\section{CONCLUSÃO}

Esta tese tratou do problema do mapeamento semântico, assunto que tem atraído o interesse da comunidade de robótica móvel apesar de ainda permanecer pouco explorado. Foi proposta e validada uma síntese do estado da arte dos trabalhos relacionados ao mapeamento semântico, mostrando uma tendência na área de mapeamento para a inclusão de informações semânticas obtidas diretamente dos sensores dos robôs, como acontece com a informação espacial.

O mapa semântico do ambiente desenvolvido é tido como uma forma de representação de conhecimento para robôs móveis, com a qual podem ser abordados diversos problemas da robótica autônoma. Trata-se de uma representação hierárquica formada por um nível espacial e por um nível semântico. No primeiro nível está um mapa métrico detalhado do ambiente, construído com sensor laser por meio do algoritmo de grades de ocupação. No segundo nível estão as descrições visuais dos obstáculos presentes no mapa que consistem de regiões de imagens segmentadas.

A representação de mapa semântico consiste num conjunto de vínculos entre a parte sensorial do sistema (as imagens omnidirecionais do sistema de visão do robô) e a parte simbólica (objetos localizados na grade de ocupação). $\mathrm{Na}$ implementação, optou-se pelo emprego de modelos que combinassem probabilidade e lógica de primeira ordem.

Dessa maneira, os vínculos são representados pelos cliques e funções potenciais associados a um grafo não-direcionado (parte probabilística), permitindo a visualização das dependências entre as variáveis aleatórias do problema, bem como a representação das incertezas envolvidas e a aplicação de algoritmos para computações locais em grafos. O grafo em si é construído a partir da descrição relacional do domínio (parte da lógica de 
primeira ordem), que especifica as dependências entre as variáveis e constitui num modelo compacto e genérico, capaz de produzir diferentes grafos para combinações distintas de variáveis do problema. Nesse contexto, um modelo de CRF foi utilizado para a segmentação da imagem.

Tanto a combinação das leituras do laser, e da grade de ocupação produzida, com a imagem omnidirecional permitiram a obtenção de um mapa semântico apropriado sem a necessidade de realizar uma localização explícita do robô, embora as trajetórias percorridas pelo robô tenham sido restritas a um recinto fechado.

A metodologia e as ferramentas de software criadas nesse trabalho produziram bons resultados no mapeamento semântico. Mesmo assim, análises mais detalhadas de cada um dos algoritmos envolvidos poderão resultar em melhoras significativas do modelo.

A conclusão mais importante do trabalho refere-se ao emprego de técnicas de aprendizado estatístico relacional ao problema de mapeamento semântico proposto. A utilização de um modelo mais expressivo só dá melhores resultados quando a estrutura relacional do domínio contém dependências que englobam vizinhanças maiores que a de primeira ordem. No entanto, para realizar inferências neste tipo de grafo é necessário ferramentas de software ou a implementação de algoritmos mais eficazes.

Como trabalho futuro, o modelo proposto, na forma de uma descrição relacional do domínio que instancia um grafo não-direcionado ou CRF, pode ser desenvolvido para realizar inferências em conjunto dos rótulos dos pixels da imagem e do estado das células da grade de ocupação. Testes preliminares apontam a necessidade de empregar ferramentas de software mais eficientes para inferência em grafos gerais.

Possíveis aplicações para esta representação foram indicadas no texto e devem ser implementadas no futuro, como o SLAM, e o rastreamento e o reconhecimento visual de obstáculos na imagem. 


\section{REFERÊNCIAS BIBLIOGRÁFICAS}

ANDERSON, C. R., DOMINGOS, P., WELD, D. S. Relational Markov models and their application to adaptive web navigation. In: Proceedings of the Eighth International Conference on Knowledge Discovery and Data Mining (KDD), pg: 143-152, 2002.

ANGUELOV, D., BISWAS, R., KOLLER, D., LIMKETKAI, B., SANNER, S., THRUN, S. Learning hierarchical object maps of non-stationary environments with mobile robots. In: Proceedings of the 17th Annual Conference on Uncertainty in Al (UAI), pg: 10-17, 2002.

ANGUELOV, D., KOLLER, D., PARKER, E., THRUN, S. Detecting and modeling doors with mobile robots. In: Proceedings of the IEEE International Conference on Robotics \& Automation (ICRA), pg: 37773784, 2004.

ANGUELOV, D., TASKAR, B., CHATALBASHEV, V., KOLLER, D., GUPTA, D., HEITZ, G., NG, A. Discriminative learning of Markov random fields for segmentation of 3D scan data. In: Proceedings of the 2005 IEEE Computer Society Conference on Computer Vision and Pattern Recognition (CVPR), volume 2, pg: 169-176, 2005.

BESAG, J. Efficiency of pseudolikelihood estimation for simple gaussian fields. In: Biometrika, 64(3), pg: 616-618, 1977.

BISHOP, C.M. Pattern recognition and machine learning. Springer, 2007.

BOUMAN, C. A., SHAPIRO, M. A multiscale random field model for bayesian image segmentation. In: IEEE Transactions on Image Processing, volume 3, no. 2, pg: 162-177, 1994. 
CHATILA, R., LAUMOND, J. P. Position referencing and consistent world modeling for mobile robots. In: Proceedings of the IEEE International Conference on Robotics \& Automation (ICRA), pg: 138-145, 1985.

CORADESCHI, S. e SAFFIOTTI, A. Anchoring symbols to sensor data: preliminary report. In: Proceedings of the 17th National Conference on Artificial Intelligence (AAAl), pg: 129-135, 2000.

CORADESCHI, S. e SAFFIOTTI, A. An introduction to the anchoring problem. In: Robotics and Autonomous Systems 43 (2-3), pg: 85-96, 2003.

CORREA, F. R., OKAMOTO JR, J. Omnidirectional stereovision system for occupancy grid. In: Proceedings of the 12th International Conference on Advanced Robotics (ICAR), Seattle, WA, pg: 628-634, 2005.

CRISTIANINI, N., SHAWE-TAYLOR, J. An Introduction to Support Vector Machines and Other Kernel-based Learning Methods. Cambridge University Press, 2000.

ELFES, A. Occupancy Grids: a probabilistic framework for robot perception and navigation. Ph.D. Thesis - Carnegie-Mellon University. Pittsburgh, 1989.

FABRIZI, E., SAFFIOTTI, A. Extracting topology-based maps from gridmaps. In: Proceedings of IEEE International Conference on Robotics and Automation (ICRA), pg: 2972-2978, 2000.

FRIEDMAN, N., GETOOR, L., KOLLER, D., PFEFFER, A. Learning probabilistic relational models. In: Proceedings of the Sixteenth International Joint Conference on Artificial Intelligence (IJCAI), pg: 13001309, 1999.

FRIEDMAN, N., KOLLER, D., PFEFFER, A. Structured representation of complex stochastic systems. In: Proceedings of the 15th National Conference on Artificial Intelligence (AAAI), pg: 157-164, 1998. 
GALINDO, C., SAFFIOTTO, A., CORADESCHI, S., BUSCHKA, P., FERNÁNDEZ-MADRIGAL, J. A., GONZÁLEZ, J. Multi-hierarchical semantic maps for mobile robotics. In: IEEE/RSJ International Conference on Intelligent Robots and Systems, pg: 3492-3497, 2005.

GEMAN, S., GEMAN, D. Stochastic relaxation, Gibbs distributions, and the Bayesian restoration of images. In: IEEE Transactions on Pattern Analysis and Machine Intelligence, volume 6, pg: 721-741, 1984.

GETOOR, L., TASKAR, B. Introduction to Statistical Relational Learning. MIT Press, 2007.

GILKS, W.R., RICHARDSON, S., SPIEGELHALTER, D.J. Markov Chain Monte Carlo in Practice. Chapman and Hall/CRC, 1996.

GRASSI JR, V. Sistema de visão omnidirecional aplicado no controle de robôs móveis. Dissertação de mestrado, Escola Politécnica da USP, 2002.

GROVE, A. J., HALPERN, J. Y., KOLLER, D. Asymptotic conditional probabilities for first-order logic. In: Proceedings of the 24th ACM Symposium on Theory of Computing, pg: 294-305, 1992.

GUESTRIN, C., KOLLER, D., GEARHART, C., KANODIA, N. Generalizing plans to new environments in relational MDPs. In: International Joint Conference on Artificial Intelligence (IJCAI), pg: 1003-1010, 2003.

HE, X., ZEMEL, R. S., CARREIRA-PERPINAN, M. A. Multiscale conditional random fields for image labeling. In: Proceedings of the Conference on Computer Vision and Pattern Recognition (CVPR), volume 2, pg: 695702, 2004.

JAEGER, M. Relational Bayesian networks. In: Proceedings of the Thirteenth Annual Conference on Uncertainty in Artificial Intelligence (UAl), pg: 266273, 1997. 
JOACHIMS, T. Making large-scale SVM learning practical. In: Advances in Kernel Methods - Support Vector Learning, MIT-Press, 1999.

JONES, K. S. Collective intelligence: it's all in the numbers. In: IEEE Intelligent Systems, The Future of Al, pg: 64-65, 2006.

KOLLER, D., PFEFFER, A. Probabilistic frame-based systems. In: Proceedings of the Fifteenth National Conference on Artificial Intelligence (AAAI), pg: 580-587, 1998.

KORTENKAMP, D., WEYMOUTH, T. Topological mapping for mobile robots using a combination of sonar and vision sensing. In: Proceedings of the Twelfth National Conference on Artificial Intelligence (AAAI), pg: 979-984, 1994.

KORČ, F., FÖRSTNER, W. Approximate parameter learning in conditional random fields: an empirical investigation. In: Annual Symposium of the German Association for Pattern Recognition (DAGM), Lecture Notes on Computer Science (LNCS) 5096, pg: 11-20, Springer-Verlag, 2008.

KOUZOUBOV, K, AUSTIN, D. Hybrid topological/metric approach to SLAM. In: Proceedings of IEEE Conference on Robotics \& Automation (ICRA), 2004, volume 1, pg: 872-877.

KUIPERS, B., BYUN, Y.-T. A robot exploration and mapping strategy based on a semantic hierarchy of spatial representations. In: Journal of Robotics and Autonomous Systems, no. 8, pg: 47-63, 1991.

KUMAR, S., HEBERT, M. Discriminative random fields: A discriminative framework for contextual interaction in classification. In: Proceedings of the International Conference on Computer Vision (ICCV), pg: 1150-1157, 2003.

KWOK, C., FOX, D., MEILA, M. Real-time particle filters. In: Proceedings of the IEEE, Volume 92, no 3, Special Issue on Sequential State Estimation, pg: 469-484, 2004. 
LAFFERTY, J., MCCALlUM, A., PEREIRA, F. Conditional random fields: probabilistic models for segmenting and labeling sequence data. In: Proceedings of the International Conference on Machine Learning (ICML), pg: 282-289, 2001.

LAZEBNIK, S., SCHMID, C., PONCE, J. Sparde texture representation using affine-invariant neighborhoods. In: Proceedings of the Conference on Computer Vision and Pattern Recognition (CVPR), pg: 319-324, 2003.

LI, S.Z. Markov Random Field Modeling in Computer Vision. SpringerVerlag, 1995.

LIANG, P., JORDAN, M. I. An asymptotic analysis of generative, discriminative, and pseudolikelihood estimators. In: Proceedings of the International Conference on Machine Learning (ICML), pg: 584-591, 2008.

LIMKETKAI, B., LIAO, L., FOX, D. Relational object maps for mobile robots. In: Proceedings of the International Joint Conference on Artificial Intelligence (IJCAI), pg: 1471-1476, 2005.

LOOKINGBILL, A., LIEB, D., STAVENS, D., THRUN, S. Learning activitybased ground models from a moving helicopter platform. In: IEEE International Conference on Robotics \& Automation (ICRA), pg: 39483953, 2005.

LOU, J., LIU, Q., HU, W. M., TAN, T. N. Semantic interpretation of object activities in a surveillance system. In: International Conference on Pattern Recognition (ICPR), volume 3, pg: 777-780, 2002.

LOWE, D. G. Object recognition from local scale-invariant features. In: Proceedings of the International Conference on Computer Vision (ICCV), volume 2, pg: 1150-1157, 1999. 
MAKRIS, D., ELLIS, T. Automatic learning of an activity-based semantic scene model. In: IEEE Conference on Advanced Video and Signal Based Surveillance, pg: 183-190, 2003.

MAUSAM, WELD, D. Solving relational MDPs with first order machine learning. In: Proceedings of the ICAPS Workshop on Planning under Uncertainty and Incomplete Information, 2003.

MARTIN, C., THRUN, S. Real-time acquisition of compact volumetric maps with mobile robots. In: Proceedings of the International Conference on Robotics and Automation (ICRA), volume 1, pg: 311-316, Washington, 2002.

McCULLAGH, P., NELDER, J.A. Generalized Linear Models. Chapman and Hall, 1989.

MIKOLAJCZYK, K., SCHMID, C. A performance evaluation of local descriptors. In: IEEE Transactions on Pattern Analysis and Machine Intelligence, volume 27, no. 10, pg: 1615-1630, 2005.

MITCHELL, T. Machine Learning. WCB/McGraw-Hill, 1997.

MORAVEC, H.; ELFES, A. High resolution maps from wide angle sonar. In: IEEE Proceedings of the International Conference on Robotics \& Automation (ICRA), pg: 116-121, St. Louis, 1985.

MOZOS, O. M., TRIEBEL, R., JENSFELT, P., ROTTMANN, A., BURGARD, W. Supervised semantic labeling of places using information extracted from sensor data. In: Robotics and Autonomous Systems, volume 55, no. 5, From Sensors to Human Spatial Concepts, pg: 391-402, 2007.

MURPHY, K. P., WEISS, Y., JORDAN, M. I. Loopy belief propagation for approximate inference: an empirical study. In: Proceedings of the Conference on Uncertainty in Artificial Intelligence (UAI), pg: 467-475, 1999. 
MURPHY, R.R. Introduction to Al Robotics. Massachusetts: MIT Press, 2000.

NEVILLE, J., JENSEN, D. Relational dependency networks. In: Journal of Machine Learning Research, volume 8, pg: 653-692, 2007.

NILSSON, N. J. Probabilistic logic. In: Artificial Intelligence volume 28, pg: $71-87,1986$.

NUCHTER, A., WULF, O., LINGEMANN, K., HERTZBERG, J., WAGNER, B., SURMANN, H. 3d mapping with semantic knowledge. In: RoboCup International Symposium, 2005.

PEARL, J. Probabilistic Reasoning in Intelligent Systems. Morgan Kaufmann, 1988.

PFEFFER, A. Probabilistic reasoning for complex systems. PhD Thesis, Stanford University, 1999.

POSNER, I, SCHROETER, D., NEWMAN, P. Using scene similarity for place labeling. In: $10^{\text {th }}$ International Symposium on Experimental Robotics (ISER), 2006.

RABINER, L. A tutorial on hidden Markov models and selected applications in speech recognition. In: Proceedings of the IEEE, volume 77, no. 2, pg: 257-286, 1989.

RAMOS, F., NIETO, J., DURRANT-WHYTE, H. Combining object recognition and SLAM for extended map representations. In: $10^{\text {th }}$ International Symposium on Experimental Robotics (ISER), 2006.

RICHARDSON, M., DOMINGOS, P. Markov logic networks. In: Machine Learning, volume 62, pg: 107-136, 2006.

SMITH, R., SELF, M., CHEESEMAN, P. Estimating uncertain spatial relationships in robotics. In: Autonomous robot vehicles, pg: 167-193, Springer-Verlag, 1990. 
STAUFFER, C., GRIMSON, W. E. L. Learning patterns of activity using realtime tracking. In: IEEE Transactions on Pattern Analysis and Machine Intelligence, volume 22, pg: 747-757, 2000.

SUTTON, C., ROHANIMANESH, K., McCALLUM, A. Dynamic conditional random fields: factorized probabilistic models for labeling and segmenting sequence data. In: Journal of Machine Learning Research, volume 8, pg: 693-723, 2007.

SUTTON, C., McCALLUM, A. An introduction to conditional random fields for relational learning. In: Introduction to Statistical Relational Learning, MIT Press, pg: 93-127, 2007.

SVOBODA, T.; PAJDLA, T.; HLAVÁC, V. Epipolar geometry for panoramic cameras. In: Proceedings of the 5th European Conference on Computer Vision, pg: 218-232, 1998.

TAPUS, A., SIEGWART, R. A cognitive modeling of space using fingerprints of places for mobile robot navigation. In: Proceedings of the IEEE International Conference on Robotics and Automation (ICRA), pg: 11881193, 2006.

TASKAR, B., ABBEEL, P., KOLLER, D. Discriminative probabilistic models for relational data. In: Proceedings of the Conference on Uncertainty in Artificial Intelligence (UAl), pg: 485-492, 2002.

TASKAR, B, CHATALBASHEV, V., KOLLER, D. Learning associative markov networks. In: Proceedings of the $21^{\text {st }}$ International Conference on Machine Learning (ICML), pg: 102, 2004.

TASKAR, B, ABEEL, P., WONG, M-F., KOLLER, D. Relational Markov Networks. In: Introduction to Statistical Relational Networks, MIT Press, pg: 175-199, 2007. 
THORPE, C., DURRANT-WHYTE, H. Field robots. In: Proceedings of the International Symposium of Robotics Research (ISRR), pg: 329-340, 2001.

THRUN, S. Learning metric-topological maps for indoor mobile robot navigation. In: Artificial Intelligence, volume 99, pg: 21-71, 1998.

THRUN, S. Robotic mapping: a survey. (Technical Report CMU-CS-02-111) Pittsburgh: School of Computer Science, Carnegie Mellon University, 2002.

THRUN, S., BURGARD, W., FOX, D. Probabilistic Robotics, MIT Press. 2005.

THRUN, S., MONTEMERLO, M., DAHLKAMP, H., STAVENS, D., ARON, A., DIEBEL, J., FONG, P., GALE, J., HALPENNY, M., HOFFMANN, G., LAU, K., OAKLEY, C., PALATUCCI, M., PRATT, V., STANG, P. et al. Stanley: the robot that won the DARPA grand challenge. In: Journal of Field Robotics, volume 23, no. 9, pg: 661-692, 2006.

TRIEBEL, R., SCHMIDT, R., MOZOS, O.M., BURGARD, W. Instance-based AMN classification for improved object recognition in 2D and 3D laser range data. In: Proceedings of the Twentieth International Joint Conference on Artificial Intelligence (IJCAI), pg: 2225-2230, 2007.

VANMARCKE, E. Random Fields: Analysis and Synthesis. The MIT PRESS, 1983.

VAPNIK, V. N. The Nature of Statistical Learning Theory. Springer-Verlag, Nova lorque, 1995.

VASUDEVAN, S., GÄCHTER, S., NGUYEN, V., SIEGWART, R. Cognitive maps for mobile robots - an object based approach. In: Robotics and Autonomous Systems, no. 55, pg: 359-371, 2007. 
WOLF, D. F., SUKHATME, G. S. Mobile robot simultaneous localization and mapping in dynamic environments, In: Autonomous Robots, volume 19, no. 1, pg: 53-65, 2005.

WOLF, D. F., SUKHATME, G. S. Activity-based semantic mapping of an urban environment. In: $10^{\text {th }}$ International Symposium on Experimental Robotics (ISER), 2006.

WON, C. S., GRAY, R. M. Stochastic Image Processing, Kluwer Academic, 2004.

ZIVKOVIC, Z., BOOIJ, O., KRÖSE, B. From images to rooms. In: Robotics and Autonomous Systems, no. 55, pg: 411-418, 2007. 